Westinghouse Nuclear Energy Systems

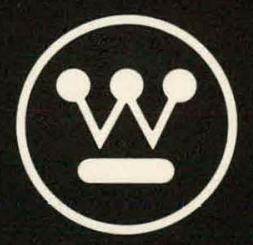




\section{DISCLAIMER}

This report was prepared as an account of work sponsored by an agency of the United States Government. Neither the United States Government nor any agency Thereof, nor any of their employees, makes any warranty, express or implied, or assumes any legal liability or responsibility for the accuracy, completeness, or usefulness of any information, apparatus, product, or process disclosed, or represents that its use would not infringe privately owned rights. Reference herein to any specific commercial product, process, or service by trade name, trademark, manufacturer, or otherwise does not necessarily constitute or imply its endorsement, recommendation, or favoring by the United States Government or any agency thereof. The views and opinions of authors expressed herein do not necessarily state or reflect those of the United States Government or any agency thereof. 


\section{DISCLAIMER}

Portions of this document may be illegible in electronic image products. Images are produced from the best available original document. 
This report was prepared as an account of work sponsored by the United States Government. Neither the United States nor the United States Atomic Energy Commission, nor any of their employees, nor any of their contractors, subcontractors, or their employees, makes any warranty, express or implied, or assumes any legal liability or responsibility for the accuracy, completeness or usefulness of any information, apparatus, pleteness or usefulness of any information, apparatus, would not infringe privately owned rights.

\title{
SAXTON CORE II NUCLEAR OPERATIONS SUMMARY
}

by

R. L. Thompson

A. J. Impink

R. W. Colombo

\section{Nuclear Operations Group \\ Systems Englneering Section}

December 1970

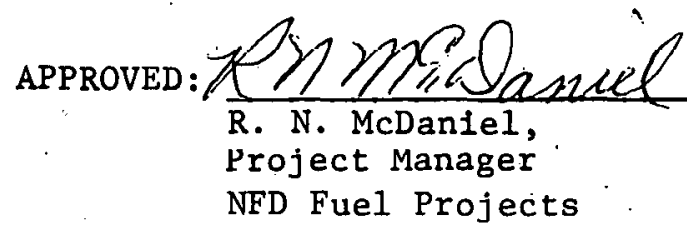

APPROVED :

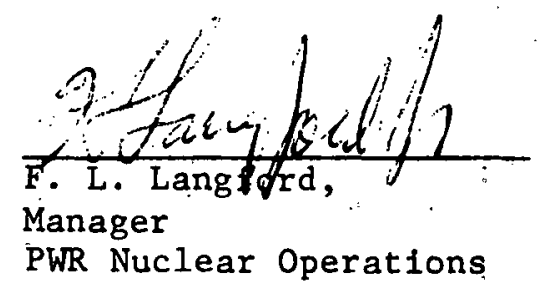

\author{
WESTINGHOUSE ELECTRIC CORPORATION \\ Nuclear Fuel division \\ P. 0. Box 355 \\ Pittsburgh, Pennsylvania 15230
}




\section{THIS PAGE \\ WAS INTENTIONALLY \\ LEFT BLANK}


Printed in the United States of America Available from

National Technical Information Service Springfield, Virginia 22151

Price: Printed Copy $\$ 3.00$, Microfiche $\$ 0.65$ 
THIS PAGE

WAS INTENTIONALLY

LEFT BLANK 


\section{NOT ICE}

This report was prepared as an account of work sponsored by the United States Government. Neither the United States nor the United States Atomic Energy Commission, nor any of their employees, nor any of their contractors, subcontractors, or their employees, makes any warranty, express or implied, or assumps any 1e.gal liability or responsibility for the accuracy, completeness or usefulness of any information, apparatus, product or process disclosed, or represents that its use would not infringe privately-owned rights. 


\section{THIS PAGE \\ WAS INTENTIONALLY \\ LEFT BLANK}


EXTERNAL DISTRIBUTION

U. S. Atomic Energy Commission (45) Brussels Office 23 Avenue des Arts Brussels, Belgium

Attention: Senior AEC Representative

U. S. Atomic Energy Commission New York Operations Office

376 Hudson Street

New York, New York 10014

Attention: Industrial Contracts Branch I (2)

Attention: Reports Library (1)

U. S. Atomic Energy Commission (1) Office of Foreign Activities, GM Washington, D. C. 20545

U. S. Atomic Energy Commission (1) Assistant General Counsel for Patents Washington; D. C. 20545

U. S. Atomic Energy Commission (1)

R. D. T. Site Representative

P. O. Box 154

Madison, Pa., 15663

Attention: T. Iltis
U. S. Atomic Energy Commission (224) Division of Technical Information Extension P. 0. Box 62 Oak Ridge, Tennessee 37830

U. S. Atomlc Energy Commission (1) Brookhaven Office

Upton, L. I., New York 11973

Attention: Chief, Patent Group

U. S. Atomic Energy Commission (8) Division of Reactor Development \& Technology

Washington, D. C. 20545

Attention: Chief, Water Reactors Branch

Battelle Northwest (1)

P. O. Box 999

Richland, Washington 99352

Attention: Mr. M. D. Freshley 
THIS PAGE

\section{WAS INTENTIONALLY LEFT BLANK}

$:$

i 
TABLE OF . CONTENTS

1.5 Comparison Between Measured and Calculated Values of Key Nuclear Parameters

\subsection{Initial Criticality 2.1}

3.1 Zero Power Beginning-of-Life Measurements at Ambient Temperature

3.2 Control Rod Worth Measurements

3.3 Moderator Temperature Coefficient Measurements

3.1

3.4 Cold-to-Hot Reactivity Defects

3.5 Zero Power Reactivity Measurements at Operating Temperature

3.5.3 Moderator Temperature Coefficient $\quad 3.22$

3.5.4 Pressure Coefficient Measurements $\quad 3.22$

3.5.5 Xenon Reactivity Worth 3.27

3.5.6 Minimum Shutdown Reactivity Measurements 3.32

$\begin{array}{lll}3.6 \text { Reactivity Measurements at Power } & 3.37\end{array}$

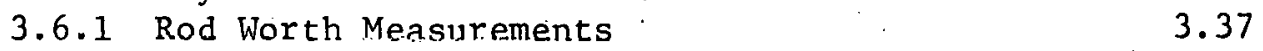

3.6.2 Differential Boron Worth Measurements 3.41

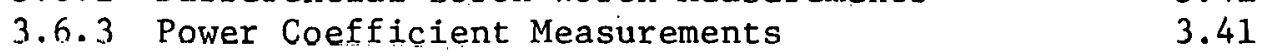

3.6.4 Moderator Temperature Coefficient Measurements

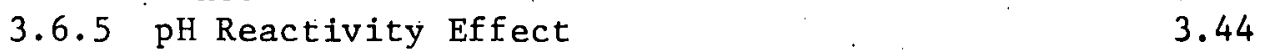


TABLE OF CONTENTS (Cont.)

Section

4.0
Title

CORE DEPLETION ANALYSIS

4.1 Experimental Core Burnup Follow 4.2 Analytic Corc Burnup Follow

POWER DISTRIBUTION MEASUREMENTS
Page

4-1

4-1

$4-1$

$5-1$ 


\section{THIS PAGE}

\section{WAS INTENTIONALLY \\ LEFT BLANK}




\section{LIST OF ILLUSTRATIONS}

Figure

2.1

2.2

2.3

2.4

\section{1}

3.2

3.3

3.4

3.5

3.6

3.7 : Saxton Core II Differential Moderator Heatup Coefficient and Heatup Reactivity Defect, 5475 MWD/MTM, 798 PPM Boron

3.8 Saxton Core II Control Rod 2 Differential and. Integral Worths. Beginning of Life Hot, Zero Power

3.9 Saxton Core II Control Rod 5 Differential and Integral Worths Beginning of Life

Hot, Zero Power
Page

$2-2$

$2-3$ 
LIST OF ILLUS. (CONT.)

Figure

Title

Page

3.10 Saxton Core II Rod \#2 Differential Worth at 5715 MWD/MTM Burnup

Saxton Core II Contral Rod 非 Integral Worth at 5715 MWD/MTM Burnup

Saxton core II DIffeiertial and Intogral worths of Rod 非 2 at 10590 MWD/MTM Burnup

3.13 Saxton Core II Muderator Temperature Coefficient at beginning of $\mathrm{Life}$

Saxton Core II Moderator Temperature Coefficients versus Boron Concentration at 3716,5715 and $10490 \mathrm{MWD} / \mathrm{MTTM}$ Burnup

Saxton Core II Moderatore Temperature Coefficient versus Temperature

Correlation of Differential Pressure and Temperature Coefficients at Startup of Saxton Cores $I$ and II

Recommended Differential pressure Coeffleient For Saxton Core II Beginning of Life

Saxton Core II Transient Xenon Defect After Shutdown From 21.5 MWT (Beginning of Life)

Saxton Core II Semi-Log Plot of Transient Xenon Defect Atter Shutdown From 21.5 MWT (Beginning of. Lifc)

Saxton lore II Wedsuled Differential Worths of Control Rod 5 During Xenon Follow

Saxton Coré II 5715 MW/MTM Xèün Buildin Curve at 23.2 MWT

Saxton Cure II Control Rod 2- Differential and Integral Worths- (Hot, at Power) 
LIST OF ILLUS. (CONT.)

Figure

Title

- Page

3.24 Saxton Core II Differential Boron Worth versus Boron Concentration

3.25 Saxton Core II Power Coefficient

3.26 Moderator Temperature Coefficient versus Boron

(Rod 2 Moving 30-18 Inches)

Saxton Core pH Coefficient

4.1 Comparison of the Calculated and Measured Critical

Rnrnn Concentration as a Function of Burnup

$4-2$

4.2 Cömparison of the Callculated and Measured Critical Boron Concentration as a Function of Hours Operation for Saxton Core II

4.3 Comparison of $5.7 \%$ Enriched UO Resonance Fission Product

Cross Section from CINDER with ${ }^{2}$ Fit from LEOPARD

4.4 Comparison of $5.7 \%$ Enriched UO Thermal Fission Product

Cross Section from CINDER with ${ }^{2}$ Fit from LEOPARD

4.5 Comparison of $\mathrm{PuO}_{2}$ Resonance Fission Product Cross Section from CINDER with FIT from LEOPARD

4.6 Comparison of $\mathrm{PuO}_{2}$ Thermal Fission Product Cross. Section from CINDER with fit from LEOPARD

4.7 Reactivity Difference Between Uniform and Non-..Uniform

$$
\text { Depletion - } 6.6 \mathrm{w} / \mathrm{O} \mathrm{PuO}_{2} \text { and } 5.7 \mathrm{w} / 0 \mathrm{UO}_{2} \text { Fuel }
$$

5.1 Saxton Core II Hot Channel Locations

$5-4$

\section{2}

Saxton Axial Peaking Factor

Saxton Nuclear Enthalpy Rise Peaklng Faclus

5.4 Saxton Nuclear Heat Flux Peaking Power 5-7

5.5 Saxton Axial Peaking Factors 5-10

5.6 Saxton Nuclear Heat Flux Peaking Factor 5- 11 


\section{THIS PAGE \\ WAS INTENTIONALLY \\ LEFT BLANK}




\section{LIST OF TABLES}

Table

Title

Page

1.1 Calculated Versus Measured Moderator l'emperature Coefficient As A Function of Burnup

$1-5$

1.2 Calculated Versus Measured Rod 2 Integral Worth As A Function of Burnup

$1-6$

1.3 Calculated Versus Measured Plutonium Average and Peak Pellet Burnups at EOL

Saxton Core 2 Fuel Loading

Summary of Endpoint Measurements

Calculated Effective Delayed Neutron Fractions

Summary of Endpoint Measurements at Hot Zero Power Conditions

Differential Boron Worths

Calculated $\mathrm{B}_{\mathrm{EFF}^{\prime} \mathrm{S}}$ (at $3716 \mathrm{MWD} / \mathrm{MTM}$ )

Results of the Xenon Build-in Measurement at 23.2 MWT After 5715 MWD/MTM Burnup in Saxton Core. II

Minimum Shutdown Reactivity Measurements 
LIST OF TABLES. (Cont.)

Tahle

4.3

4.4

5.1
Titie.

PDQ-7 Analysis Sequence and Core Changes Used in

Saxton Core II Depletion Study

4-13

Comparison of Calculated and Measured Critical Boron Concentrations as A Function of Saxton Core II

Operation

Hot Channel Factors (Rod 2 Inserted)
Page.

$5-2$ 
SECTION 1

\section{INTRODUCT ION}

\subsection{Description of The Saxton Plutonium Program}

\subsection{Purpose}

The purpose of the Saxton Plutonium Program was to develop information concerning the use of plutonium-enriched fuel in pressurized water reactor systems through the design, fabrication, and operation of a partial core of $\mathrm{PuO}_{2}-\mathrm{UO}_{2}$ fuel in the Saxton reactor. The in-pile performance of the fuel will be evaluated and a post-irradiation examination of fuel samples will be made. The basic program objective was to achieve as high a burnup in the plutonium fuel as possible during the available period of operation.

\subsection{Program Sequence}

The nuclear program sequence can be divided into four phases. During phase one, the nuclear design phase, the requirement was to develop the specifications for the partial loading of the mixed-oxide $\left(\mathrm{PuO}_{2}-\mathrm{UO}_{2}\right)$ fuel assemblies.to be used in Saxton Core II. It was necessary to determine a plutonium loading that would provide the desired lifetime within the power limitations set by the plant, thermal, and hydraulic design. At the start of the nuclear design work, goals of $10,000 \mathrm{MWD} / \mathrm{MTM}$ average burnup in the plutonium fuel with a peak burnup of 20,000 MWD/MTM were established. The second phase consisted of a series of design-oriented, critical experiments conducted at the Westinghouse Reactor Evaluation Center (WREC) utilizing the same fuel rods as those used later in the irradiation test. The purpose of these experiments was to verify the nuclear design of the unirradiated fuel before power operation. 
The third phase concerned the operation of the partial plutonium core in the Saxton reactor. During this phase, periodic measurements were made to determine the system reactivity, control rod and boron worth, flux and power distributions, and temperature, pressure, and power coefficients. In addition, a supporting analytic program was carried out to establish the adequacy of available methods in duplicating the observed performance of the core. The fourth phase consisted of a post-irradiation examination of fuel samples and comparison with analytic predictions.

\section{$1: 3$ Seope of the Report}

This report describes the work carried out in the third phase, the nuclear operations summary of Saxton Core II. A similar nuclear follow program of $\mathrm{PuO}_{2}-\mathrm{UO}_{2}$ fuel is continuing during Core III operation, which began in December, 1969, and will continue until early 1972. WCAP 3385-51, "Nuclear Design of the Saxton Partial P1utonium Core," describes the nuclear design work performed under phases 1 and 2 .

\section{4 . Description of Saxton Core II}

The Saxton Core II fuel loading consisted of nine central mixed-oxide $\left(\mathrm{PuO}_{2}-\mathrm{UO}_{2}\right)$ fuel assemblies and twelve outer $\mathrm{UO}_{2}$ fuel assemblies. The mixed-oxide contained $6.6 \mathrm{w} / \mathrm{O} \mathrm{PuO}_{2}$ in natural $\mathrm{UO}_{2} \cdot$ The $\mathrm{UO}_{2}$ assemblies were enriched to $5.7 \mathrm{w} / 0 \mathrm{U}-235$. Of the nine plutonium assemblies, two contained vibratory compacted fuel and were installed on the flats in positions $\mathrm{D}-2$ and $\mathrm{D}-4$. The remaining seven assemblies contained pelletized fuel. The plutonium fuel rods were clad with zircaloy-4 with the exception of some thirty fuel rods which were clad with 304 stainless steel. These special stainless steel rods were distributed in the central plutonlum region to meet specific irradiation objectives. All of the plutonium assemblies contained Inconel 718 grids.

The twelve $\mathrm{UO}_{2}$ assemblies consisted of five assemblies with the original Core I design ( 304 SS grids). Of these, one assembly (E-1) was a special 51-rod hollow $\mathrm{UO}_{2}$ assembly designed to accomodate a supercritical test loop. 
This assembly accumulated $\sim 2100 \mathrm{MWD} /$ tonne burnup during Saxton Core I operation. At the start of the plutonium program, it contained a stainless steel filler. The seven remaining $\mathrm{UO}_{2}$ assemblies were of a new design (Inconel grids). These assemblies were located at the corners of the core to reduce the reactivity loss associated with the higher neutron cross section and the increased material volume of the new grid structure.

The special L-shaped assemblies ( $\mathrm{UO}_{2}$ fueled), used in Saxton Core $I$, and the original fuel bearing control rod followers ( $\mathrm{UO}_{2}$ ) were utilized in Saxton Core II.

The design of Saxton Core II is described in greater detail in References 1,2 , and 3 (below):

1. W. L. Orr, et. al., "Nuclear Design of the Saxton Partial Plutonium Core," EURAEC-1490, WCAP-3385-51, December 1965.

2. E. A. Bassler, et. a1., "Mechanical, Thermal and Hydraulic Design of Saxton Partial Plutonium Core," EURAEC-1491, WCAP-3385-52, December 1965.

3. A. Biancheria, et. a1., "Materials Design and Fabrication of the Saxton Partial Plutonium Core," EURAEC-1492, WCAP-3385-53, December 1965.

1.5 Comparison Between Measured and Calculated Values of Key Nuclear Parameters

A comparison between measured and calculated values of the moderator temperature coefficient, Rod 2 integral worth, the average burnup of the plutonium-bearing fuel, as well as the peak plutonium pellet burnup, is presented in Tables $1-1,1-2$, and 1-3. There is excellent agreement between the measured and predicted values for ail of the above parameters, except for peak pellet burnup. The lack of agreement in the peak peliet burnup, however, is to be expected, since the analytical predictions were based on steady full power operation, with all rods out, for the initial core loading. 
In practice, Core II was operated with Rod 2 in during the initial 800 hours of full power operation (23.5 MWt). This resulted in a lower than predicted peak pellet burnup, since the peak rod was in Assembly D-3, adjacent to control $\operatorname{Rod} 2$.

It is important to note that Core II operated for 9,390 effective full power hours (EFPH) before shutdown. At shutdown, however, the moderator still contained an equivalent boron concentration of $150 \mathrm{ppm}$ (normalized to a power level of $23.5 \mathrm{MWt}$ and a moderator temperature of $530^{\circ} \mathrm{F}$ ), which is equivalent to 860 EFPH. Thus, a total of $10250 \mathrm{EFPH}$ of operation was available, compared to the predicted value of $9500 \mathrm{EFPH}$. 
TABLE 1.1

CALCULATED VERSUS MEASURED MODERATOR TEMPERATURE COEFFICIENT

AS A FUNCTION OF BURNUP

\begin{tabular}{|c|c|c|c|c|}
\hline $\begin{array}{l}\text { Core Average } \\
\text { Burnup } \\
\text { (MWD/MTM) }\end{array}$ & $\begin{array}{l}\text { Moderator } \\
\text { Temperature } \\
\quad\left({ }^{\circ} \mathrm{F}\right) \\
\end{array}$ & $\begin{array}{l}\text { Boron } \\
\text { Concentration } \\
\quad(\mathrm{ppm}) \\
\end{array}$ & $\left(\frac{\delta \rho}{\delta \mathrm{T}}\right)_{\text {Calculation }}$ & $\left(\frac{\delta \rho}{\delta T}\right)$ Measurements \\
\hline 0 & 530 & 2260 & $-2.22 \times 10^{-4}$ & $-2.36 \times 10^{-4}$ \\
\hline 5715 & 515 & 1240 & $-2.56 \times 10^{-4}$ & $-2.61 \times 10^{-4}$ \\
\hline 10196 & 530 & 620 & $-3.34 \times 10^{-4}$ & $-3.30 \times 10^{-4}$ \\
\hline
\end{tabular}


TABLE 1.2

CALCULATED VERSUS MEASURED ROD 2 INTEGRAL WORTH AS A FUNCTION OF BURNUP

Core Average
Kurnun (MWI)/MTM)

0

3716

5716

10490
Calculated

Worth

$(\% \Delta \mathrm{k} / \mathrm{k})$
Mcasured

Worth

$(\% \Delta \mathrm{k} / \mathrm{k})$
3.55

3.38

3.40

3.25
3.66

3.40

3.26

3.30 
TABLE 1.3

CALCULATED VERSUS MEASURED PLUTONIUM AVERAGE AND PEAK PELLET BURNUPS AT EOL

Calculated

Measured

Burnup (MWD/MTM)

Burnup (MWD/MTM)

$\begin{array}{lll}\mathrm{PuO}_{2} \text { Region Average } & 15,925 & 15,440 \\ \mathrm{PuO}_{2} \text { Peak Pellet } & 32,700 & 29,520\end{array}$




\section{SECTION 2}

CORE LOADING

During the core loading, twenty burned fuel assemblies in Core I were exchanged for twenty tresh-fuel assemblies. The fresh-fuel consisted of nine $\mathrm{PuO}_{2}-\mathrm{UO}_{2}$ assemblies and eleven $\mathrm{UO}_{2}$ assemblies. One burned assembly (E-1) from Core I, containing the superheat loop, was not exchanged. Of the nine $\mathrm{PuO}_{2}-\mathrm{UO}_{2}$ assemblies, two contained vibratory compacted zirc-clad fuel, and the remaining seven assemblies contained pelletized zirc-clad fuel. Three of the nine $\mathrm{PuO}_{2}-\mathrm{UO}_{2}$ assemblies contained some stainless steel clad rods dispersed among the Zircaloy-4 clad rods. Table 2.1 ists the exchanged assemblies, and date of loading. Figure 2.1 is a plan view of the fuel loading showing the positions of the different fuel types.

After each step in the loading sequence, the neutron multiplication was obtained by measuring count rates in the two source range channels and two special channels monitoring the startup sources. A plot of inverse multiplication $(1 / M)$ as a function of exchanged fuel for the "all rods in" configurations is shown in Figure 2-2. Detailed records were kept of 1/M for different rod configurations, step-by-step loading procedures, and count rate data at each step

\subsection{Initial Criticality}

Core II startup testing was begun with the approach to, and establishment of, initial criticality of the reactor on December 6, 1965. Criticality was achieved by boron dilution with all control rods fully withdrawn from the core. Inverse multiplication was monitored as a function of time during boron dilution. Operational interruption of the boron dilution and the 
TABLE 2.1

SAXTON CORE 2 FUEL LOADING

\begin{tabular}{|c|c|c|c|c|}
\hline $\begin{array}{l}\text { Plutonium } \\
\text { Assembly - Serial 非 }\end{array}$ & Dace Loaded & Fixed FueI Rods & Removable Fuel Rods & Total Fuel Rods \\
\hline D3 $-503-13-1$ & $10-05-65$ & $\begin{array}{l}57 \text { zirc* - pellets } \\
2 \text { SS - pellets } \\
2 \text { SS - vipac }\end{array}$ & & 61 \\
\hline$. C 4-503-12-7$ & $15-05-65$ & i0 zirc - pellets & 1 zirc - pellets & 71 \\
\hline$C 2-503-12-2$ & $15-07-65$ & 70 zirc - pellets & 2 zirc - peilets & 72 \\
\hline E2-503-12-4 & $15-08-65$ & .0 zirc - pellets & 1 zirc - pellets & 71 \\
\hline$E 4-503-12-8$ & $10-11-65$ & ?0 zirc - pellets & 2 zirc - pellets & 72 \\
\hline C3-503-12-3 & $10-11-65$ & $\begin{array}{r}52 \text { zirc - pellets } \\
18 \mathrm{sS} \text { - pellets }\end{array}$ & & 70 \\
\hline D2-503-12-5 & $10-11-65$ & ?0 zirc - vipac & 2 zirc - vipac & 72 \\
\hline$E 3-503-12-6$ & $10-12-65$ & 70 zirc - pellets & $\begin{array}{l}1 \text { zirc - pellets } \\
1 \text { source tube }\end{array}$ & 71 \\
\hline$D 4-503-12-1$ & $10-12-65$ & $\begin{array}{l}\text { Б2 zirc - vipac } \\
8 \text { SS - vipac }\end{array}$ & & 70 \\
\hline
\end{tabular}

*All zirc cladding is Zircaloy-4. 
TABLE 2.1 (Cont)

SAXTON CORE 2 FUEL LOADING

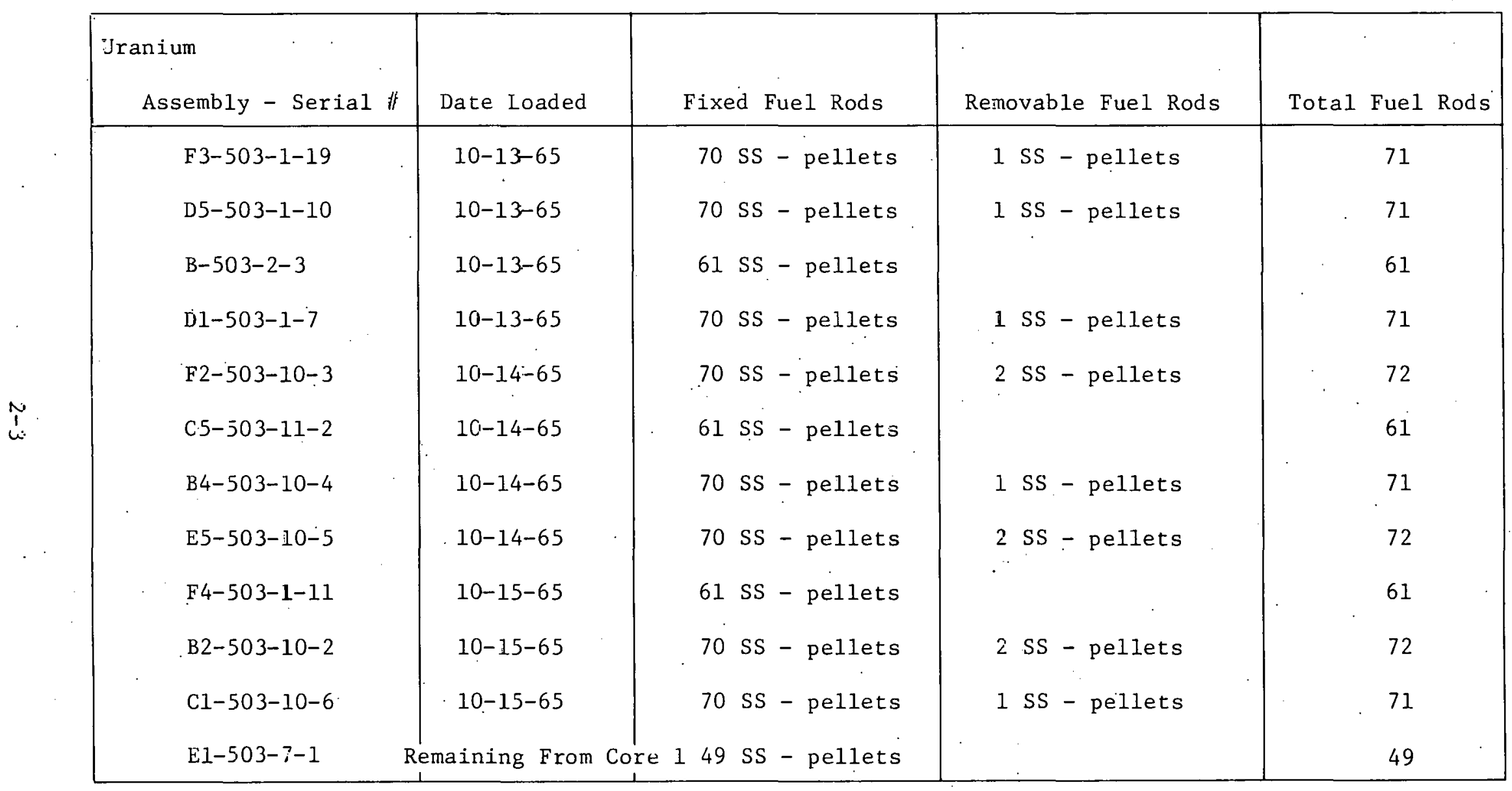


TAB:E 2.1 (COnt)

SAXTON CORE 2 FUEL LOADING

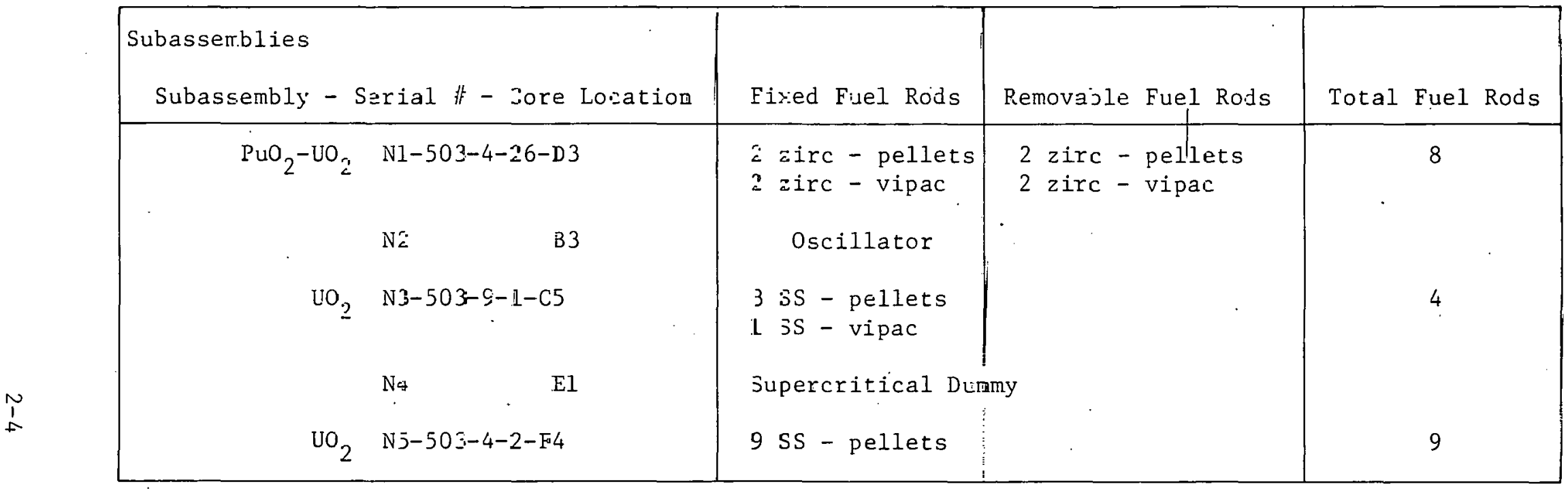




\section{TABLE 2.1 (Cont)}

SAXTON CORE 2 FUEL LOADING

Totals (Assemblies and Subassemblies)

$$
\begin{aligned}
& \text { Pelletized }(\mathrm{Zr})=461(\text { fixed })+9(\text { removable }) \quad=470 \\
& \text { Pelletized }(\mathrm{SS})=20 \text { (fixed) }=20 \\
& \text { Vibratory compacted }(\mathrm{Zr})=134(\text { fixed })+4(\text { removable })=138 \\
& \text { Vibratory compacted }(\mathrm{SS})=10 \text { (fixed) }=\frac{10}{638} \\
& \text { Pelletized }(\mathrm{SS})=804(\text { fixed })+11 \text { (removable) }=815 \\
& \mathrm{UO}_{2} \text { Vibratory compacted }(\mathrm{SS})=1 \text { (fixed) }=\frac{1}{816}
\end{aligned}
$$

$\underline{\text { (Followers and "L" Sections) }^{\Delta}}$

Six followers - pelletized (SS)

$\mathrm{UO}_{2}$ Nine "L" Sections - pelletized (SS)

$\begin{array}{ll} & =108 \\ & =\frac{81}{189} \\ \text { Grand Total } & =1643 \text { Fuel Rods }\end{array}$

$=108$

$=1643$ Fuel Rods

\footnotetext{
${ }^{\triangle}$ Fuel from Core 1
} 


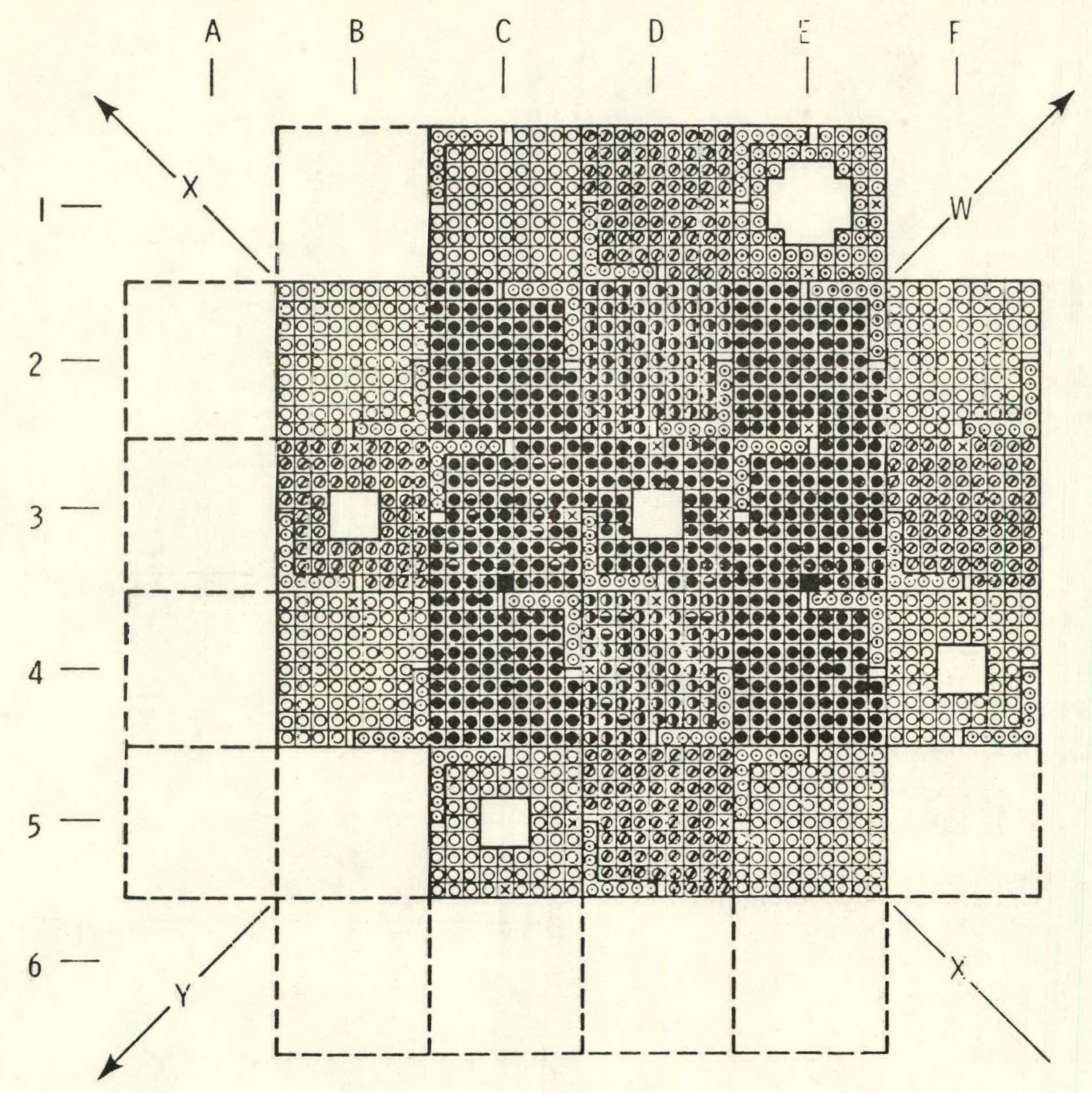
G $\mathrm{PUO}_{2} / \mathrm{UO}_{2}-\mathrm{ZIRC}$-PELLETS
G $\mathrm{PuO}_{2} / \mathrm{UO}_{2}-\mathrm{STEEL}$
(1) $\mathrm{PuO}_{2} / \mathrm{UO}_{2}-\mathrm{ZIRC}-\mathrm{VIPAK}$

@ UO-STEEL-INCONEL GRIDS

U $\mathrm{OO}_{2}$-STEEL-SS GRIDS

U $0_{2}$-STEEL-SS GRIDS (BURNED)

๑ $\mathrm{UO}_{2}$-STEEL-L SECTION \& FOLLOWERS

$\times$ FLUX MAPPING THIMBLE

- ANTIMONY-BERYLLIUMII SOURCE

Figure 2.1. Saxton Core II Fuel Configuration 


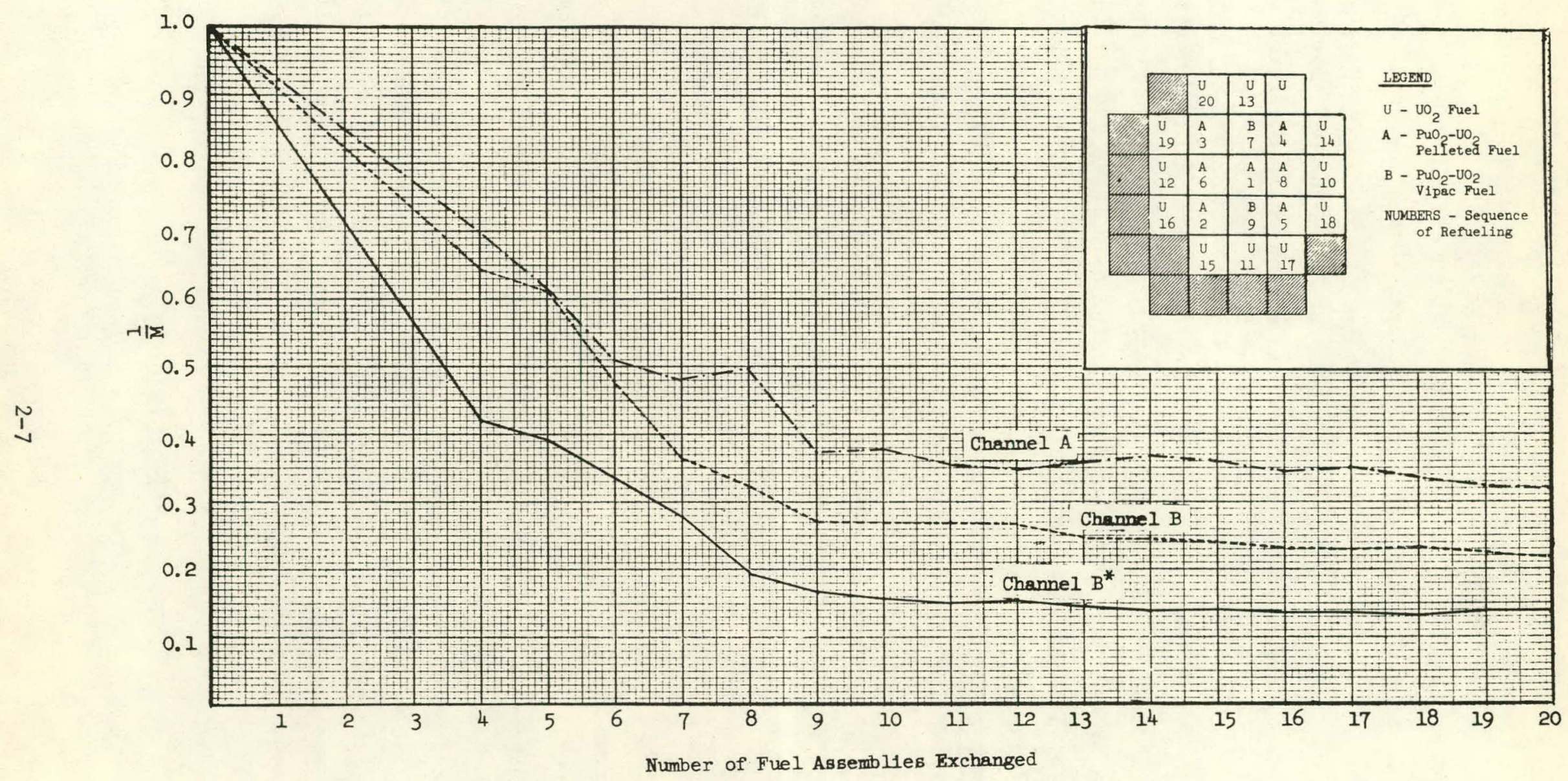

Figure 2.2. Saxton Core II: Inverse Multiplication $\left(\frac{1}{M}\right)$ versus Number of Fuel Assemblies Exchange 
relatively large time constant associated with fluid circulation and mixing in the low pressure surge tank and reactor coolant system obscured, in part, the relation of inverse multiplication with estimated boron concentration in the core. The inverse multiplication data obtained, however, was entirely adequate for regulating demineralized water injection and for determining the point of criticality.

During the dilution, flow rates and tank levels were periodically monitored. These data were used,subsequenlly, in constructing a time-dependent horon balance in the fluid system and in generating the calculated reactor coolant boron concentration history (shown in Figure 2.3). The calculated history shows good agreement with the measured borun cumcentrations taken from periodic reactor coolant samples. Part of the discrepancy between the boron concentrations obtained by sampling and those calculated is attributed to the transit time in the sampling time from the pressure vessel to the sample collection point. The time corresponding to each sample is the time of collection, not the time of departure from the reactor. Another part of the discrepancy may well be the result of incorporating a low pressurizer spray flow rate in generating the boron balance. The absolute value of the spray flow rate is now well known.

Correlation of the time-dependent change in inverse multiplication with the time-dependent change in (calculated) boron concentration in the core yields the plot of inverse multiplication as a function of boron concentration (shown in Figure 2.4). The near linearity of the dependence of inverse multiplication on boron concentration is indicative of the close control which can be maintained over an approach to criticality by boron dilution, provided a reliable indication of change in reactur cuolant boron concentration is available. The perturbations in the $1 / \mathrm{M}$ plot near criticality are due, primarily, to small errors in the calculated boron concentration resulting trom interruptions in dilution ratc. 


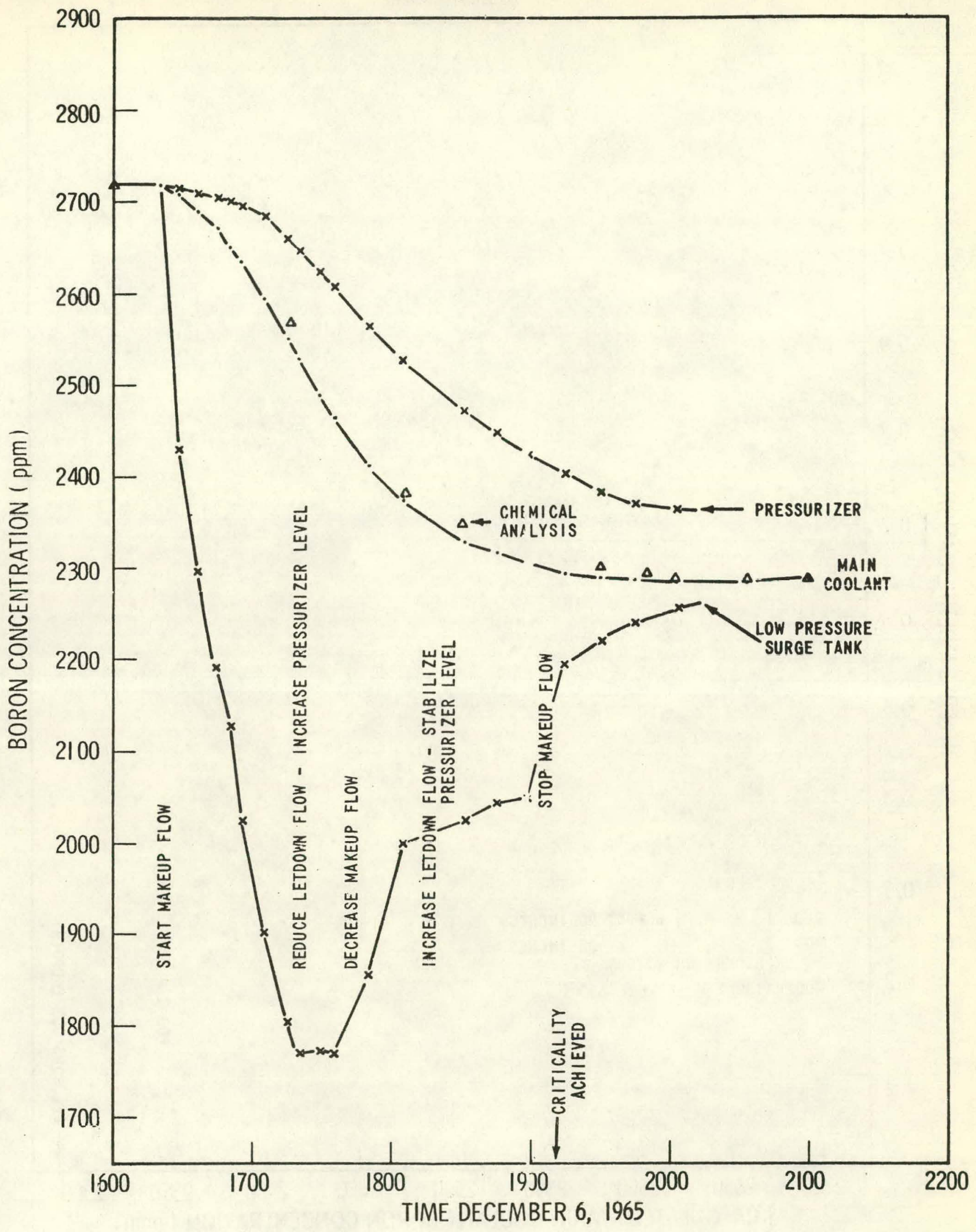

Figure 2.3. Saxton Core II Calculated Boron Concentration History Approach to Initial Criticality 


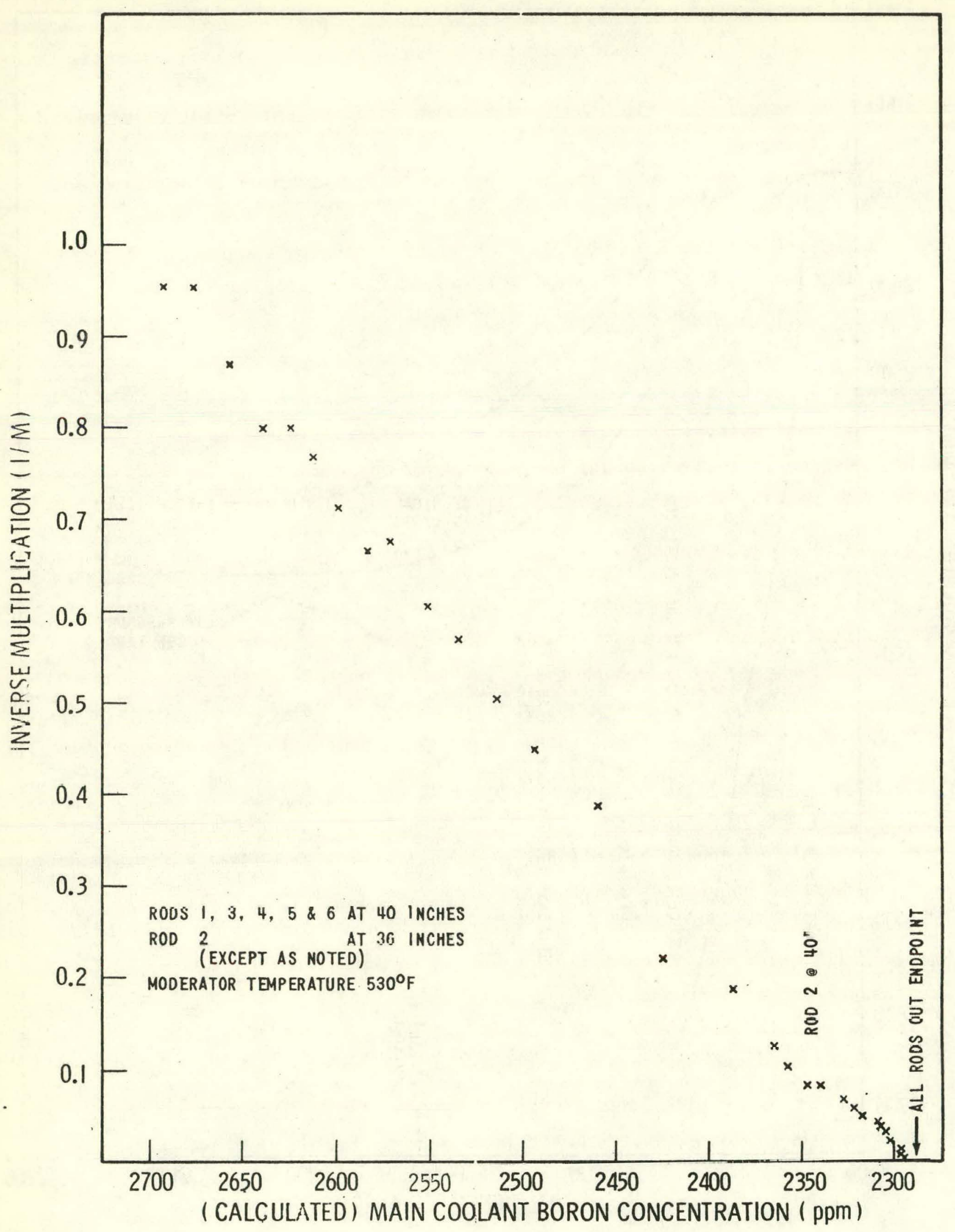

Figure 2.4. Saxton Core II Inverse Multiplication Plot Approach to Initial Criticality 


\section{SECTION 3}

REACTIVITY KINETICS, COEFFICIENTS AND ROD WORTHS

At the beginning of core life and periodically throughout core life, measurements were made to determine control rod worths, boron worths, and moderator temperature coefficients. These measurements were made to determine the adequacy of design calculations and to obtain data which could be used to improve calculational techniques as well as to provide the ruactoroperator with the nuclear data necessary for the safe operation of the plant.

\subsection{Zero Power Beginning-of-Life Measurements at Ambient Temperature} Immediately following initial criticality (hot) on December 6, 1965, zero power testing began. Boron endpoint measurements for all rods out, rod 2 in, rods 2 and $5 \mathrm{in}$, and rods 2 and $5 \mathrm{in}$, with rods 1 and 6 partially inserted, were made with the reactor at cold conditions. Table 3.1 shows the measured boron endpoints along with some pre-startup analytical predictions of endpoint borons. Experimental and analytical boron worths calculated from these endpoints and the integral rod worths are also included in the table.

\subsection{Control Rod Worth Measurements}

Differential control rod worths were obtained during a continuous boron dilution by recording the amount of rod travel and reactivity change associated with the rod travel. Reactivity was measured by means of an on-line analog computer. Effective delayed neutron fractions required by the computer for each rod configuration are given in Table 3.2 
TABLE 3.1

SUMMARY OF ENDPOINT MEASUREMENTS

Established During Cold Conditions (ppm)

\begin{tabular}{|c|c|c|c|}
\hline Configuration & $\begin{array}{l}\text { Core Average } \\
\text { Temperature }\left(\mathrm{F}^{\circ}\right)\end{array}$ & $\begin{array}{c}\text { Calculated } \\
\text { Boron Concentraticn } \\
(\mathrm{ppm})\end{array}$ & $\begin{array}{c}\text { Measured } \\
\text { Endpoint Boron } \\
\text { Concentration (ppm) }\end{array}$ \\
\hline A11 Rods out & 135 & 2715 & 2718 \\
\hline $\begin{array}{l}\text { Rods } 1,3,4,5 \& 6 \text { out } \\
\operatorname{Rod} 2\end{array}$ & 155 & 2245 & 2263 \\
\hline $\begin{array}{ll}\text { Rods } 1,3,4 \& 6 & \text { out } \\
\text { Rods } 2 \& 5 & \text { in }\end{array}$ & 155 & 1690 & $17 \angle 2$ \\
\hline 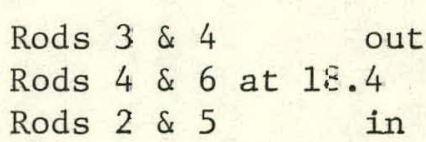 & 150 & - & 1516 \\
\hline
\end{tabular}


TABLE 3.1 (Cont)

DIFFERENTIAL BORON WORTHS

\begin{tabular}{|c|c|c|c|c|c|}
\hline $\begin{array}{l}\text { Control Rod } \\
\text { Configuration }\end{array}$ & $\begin{array}{l}\text { Calculated } \\
\text { Boron } \\
\text { Equivalent } \\
\text { (ppm) }\end{array}$ & $\begin{array}{l}\text { Boron } \\
\text { Equivalent } \\
\text { (ppm) }\end{array}$ & $\begin{array}{l}\text { Measured } \\
\text { Integrated Control } \\
\text { Rod Worth } \\
(\% \Delta \rho)\end{array}$ & $\begin{array}{l}\text { Calculated } \\
\text { Inverse } \\
\text { Boron Worth } \\
(\mathrm{ppm} / \%)\end{array}$ & $\begin{array}{l}\text { Measured } \\
\text { Inverse } \\
\text { Boron Worth } \\
(\mathrm{ppm} / \%)\end{array}$ \\
\hline & & & \multicolumn{2}{|c|}{ Cold $\left(150^{\circ} \mathrm{F}\right)$ Measurements } & \\
\hline $\begin{array}{l}\text { Al1 rods out } \\
\text { Rod } 2 \text { in }\end{array}$ & 470 & 450 & 2.866 & 148 & 158 \\
\hline $\operatorname{Rod} 2 \& 5$ in & 555 & 526 & 3.153 & 132 & 166 \\
\hline $\begin{array}{l}\text { Rods } 2 \& 5 \text { ir } \\
1 \& 6 \text { at } 18.4\end{array}$ & & 225 & 1.453 & - & 155 \\
\hline
\end{tabular}


TABLE 3.2

\section{CALCULATED EFFECTIVE DELAYED \\ NEUTRON FRACTIONS}

Control Rod Configuration

All Rods Out

Rod 2 Worth Experiment

Rod 2 in

Rod 5 Worth Experiment

Rod 2 and 5 in

Rod 1 and 6 Worth Experiment
$\underline{\text { eff }}$
0.0040730
0.0041950
0.0043171
0.0044391
0.0045611
0.0045611

Differential and integral worth curves for rodo 1 and $h$ nver Llie upper portion of their travel (with rods 2 and 5 in), rod 5 (with rod 2 in), and rod 2 (with all other rods out) for the cold condition are given in Figures $3.1,3.2$ and 3.3 , respectively. Each rod worth measurement was made by withrrawing and inserting the rod. No significant differences in worth were noted between withdrawal and insertion.

\subsection{Moderator Temperature Coefficient Measuremeuts}

In addition to the above measurements, experimental determination of differential temperature coefficients at each of the end point boron concentrations in the cold $\left(150^{\circ} \mathrm{F}\right)$ conditions are shown in Figure 3.4. Each plotted data polnt represents a single temperature of a few degrees about the reference tempcrature. In general, the data points show the expected degree of consistency. It should be noted that to obtain boron concentrations the rods had to be inserted so that the trend of differential temperature coefficient with boron shown is really a trend of temperature cuefficient with boron and rod insertion.

\subsection{Cold-to-Hot Reactivity Defects}

As part of the initial testing program, the reactivity defect associated with heatup/cooldown was measured at two boron concentrations. The results of analysis of data secured during cooldown at $2130 \mathrm{ppm}$ and subsequent heatup 


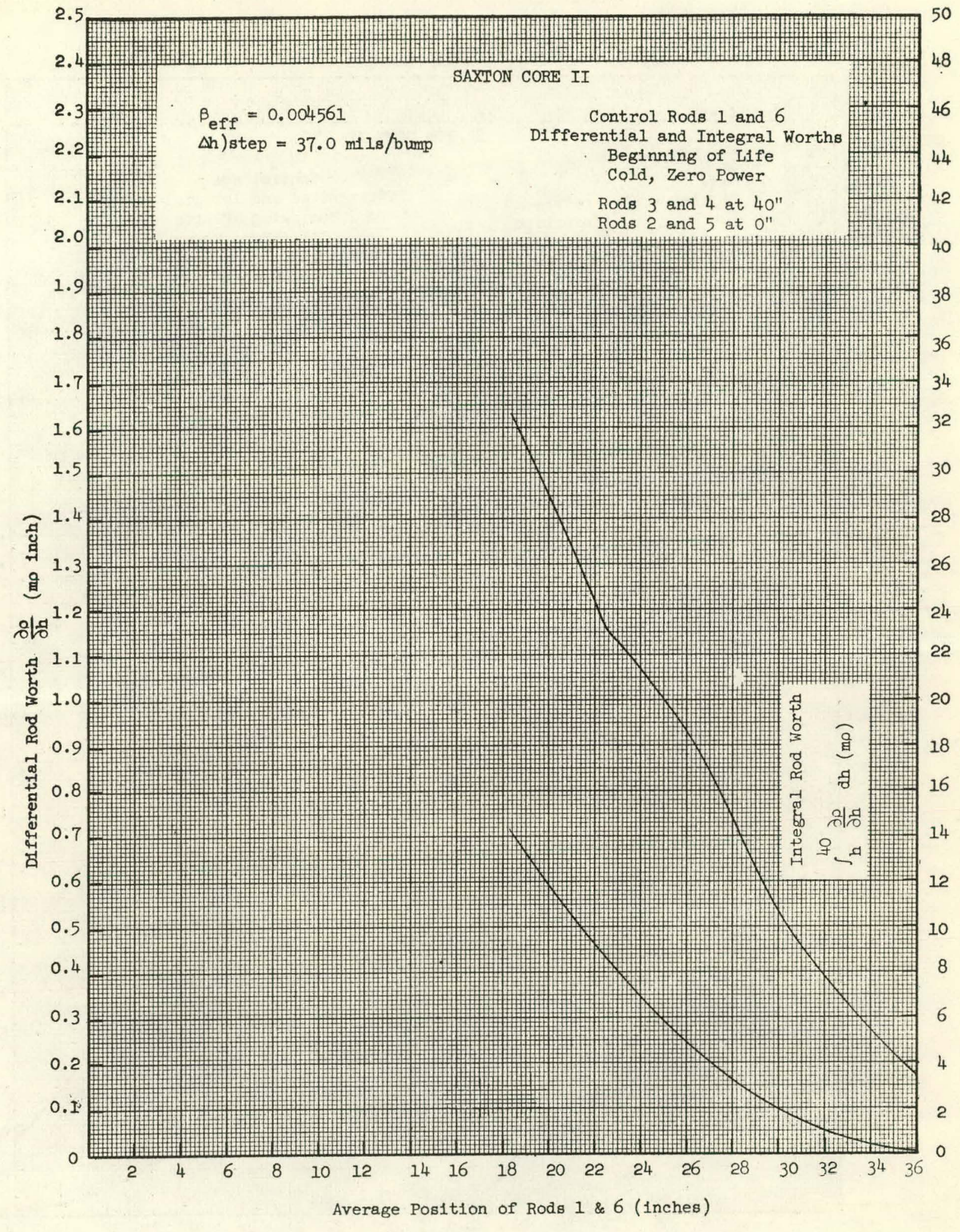

Figure 3.1. Saxton Core II Control Rods 1 and 6 Differential and Integral Worths (Beginning of Life, Cold, Zero Power) 


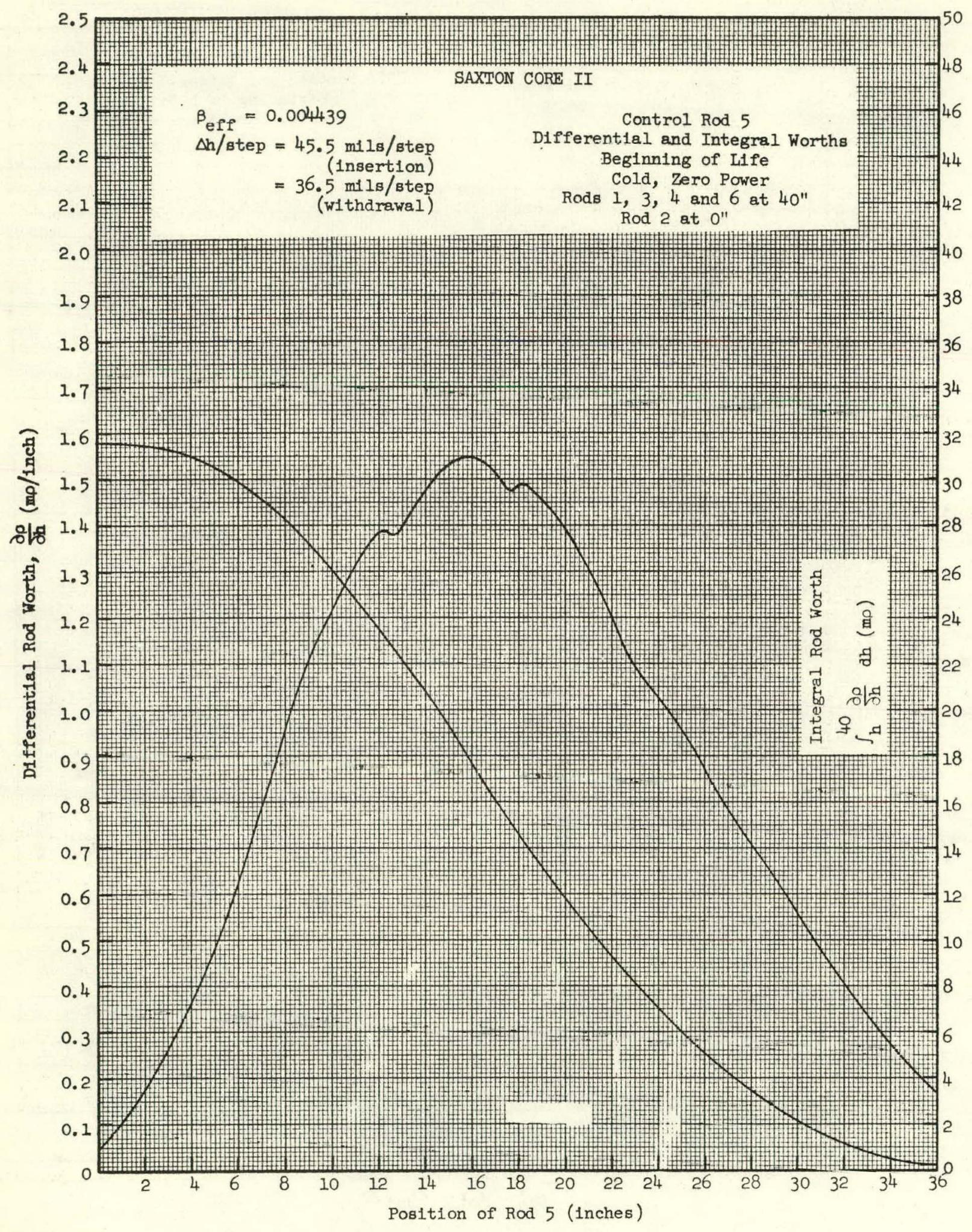

Figure 3.2. Saxton Core II Control Rod 5 Differential and Integral Worths (Beginning of Life, Cold, Zcro Power) 


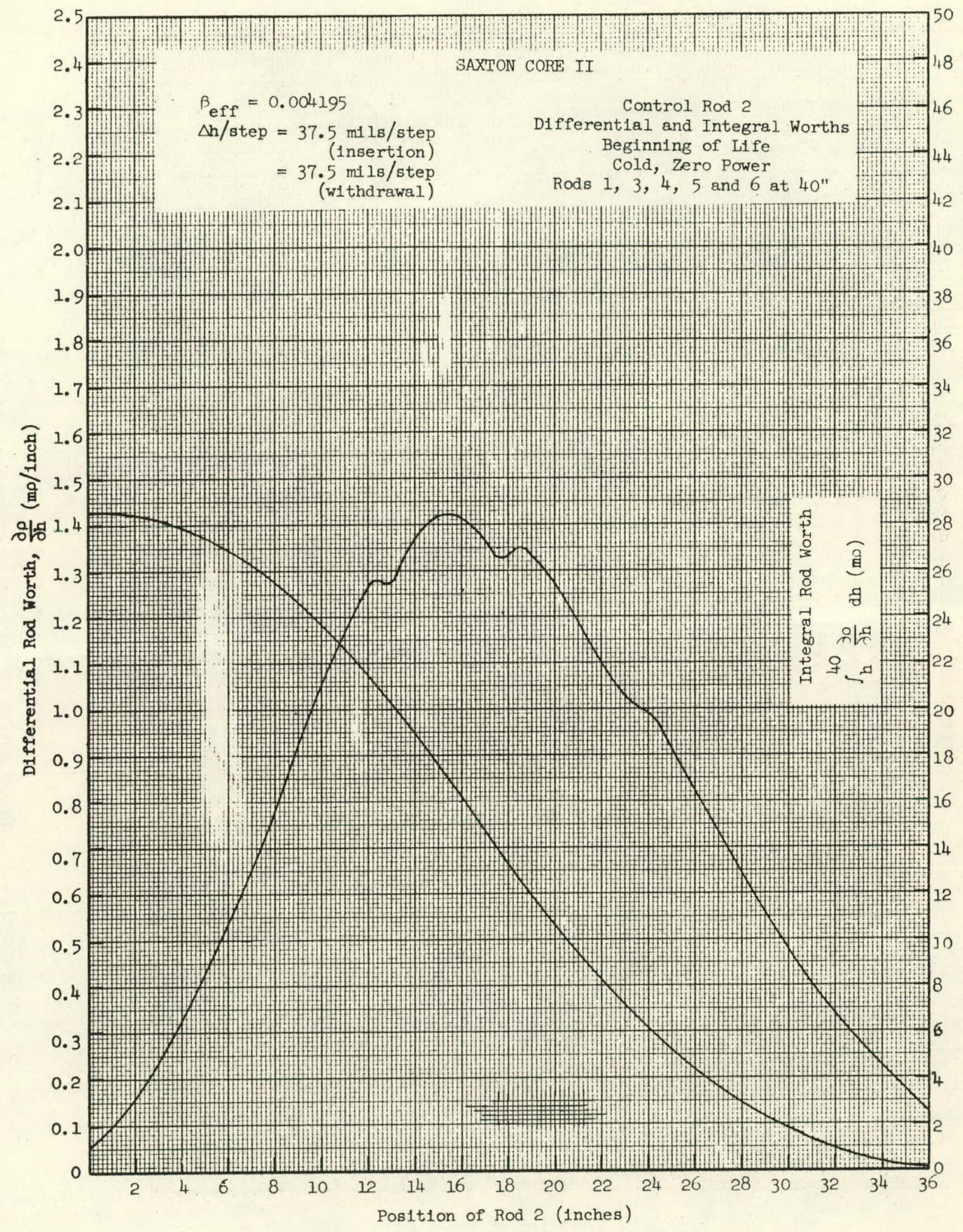

Figure 3.3. Saxton Core IT Control Rod 2 Differenlial and Integral Worths (Beginning of Life, Cold, Zero Power) 


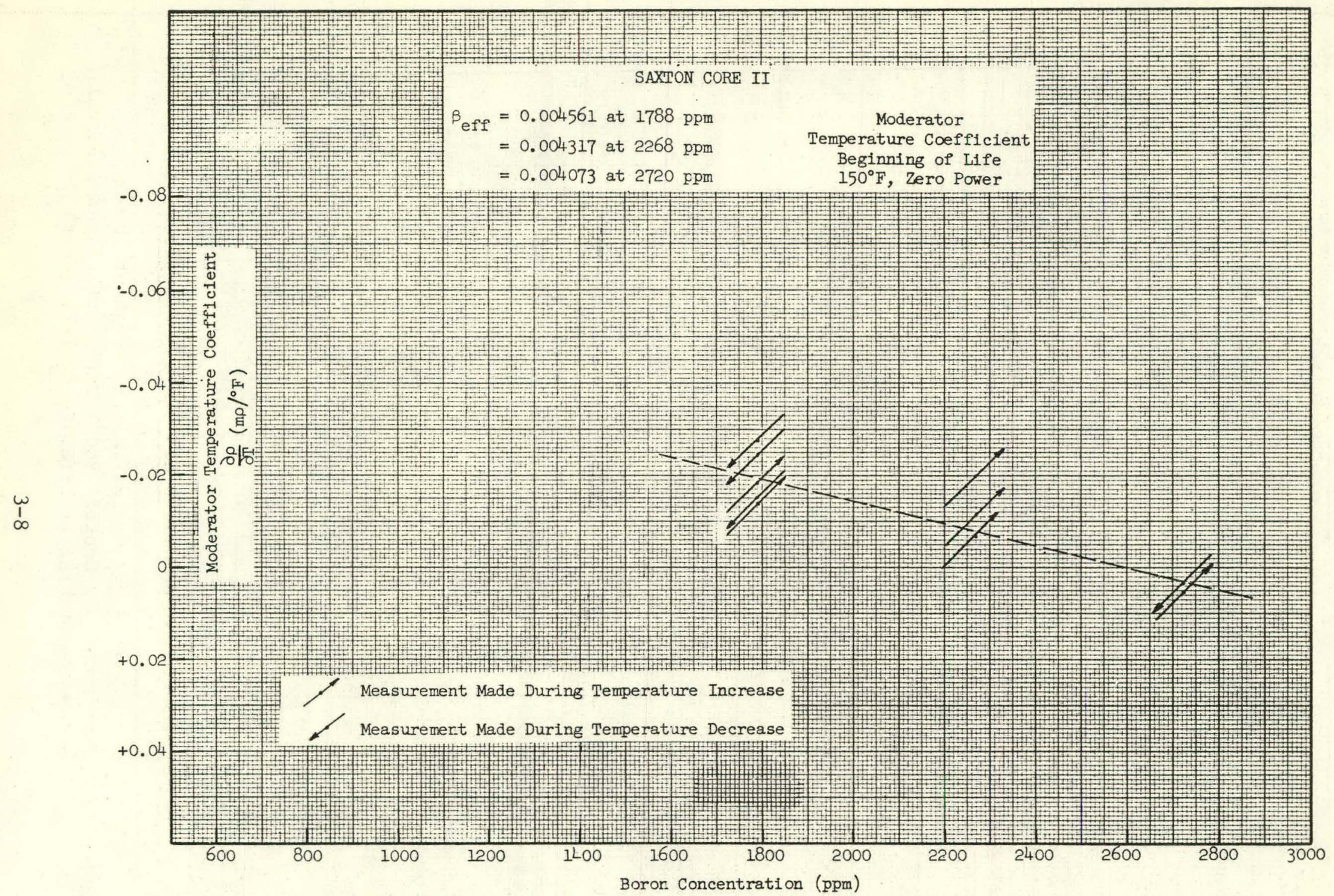

Figure 3.4. Saxtcn Core II Moderator Temperature Coefficient (Beginning of Life, $150^{\circ} \mathrm{F}$, Zero Power) 
at $1700 \mathrm{ppm}$ are shown in Figure 3.5 and Figure 3.6, respectively. In both cases, the experimental data was erratic. The cooldown data was reasonably consistent down to a temperature of about $300^{\circ} \mathrm{F}$, at which point, makeup water was injected into the primary system and that supplied as makeup disrupted reactivity. The correlation of temperature with reactivity and subsequent data were lost. During the heatup, the reactivity values generated by the reactivity computer proved to be singularly poor; differential control rod worths derived from the data have little relationship to corresponding rod worths obtained at hot or cold conditions. Consequently, the reactivity data was discarded and the change in reactivity corresponding to change in temperature during heatup was deduced from observed changes in control rod position and interpolation between hot and cold differential control rod worth values secured at constant temperature.

A close examination of the statepoint measurements in the hot and cold condition shows that the integrated reactivity defect in Figure 3.5 and Figure 3.6 is significantly larger than that obtained from statepoint differences and boron worths. This seeming inconsistency is a result of the method of making the measurement and not of any inherent error in either set. The measurements during the heatup and cooldown are made by moving control rods to maintain the reactor critical. This insertion of control rods during the cooldown would make the temperature coefficient more negative and the integrated defect larger. To attain a critical state with rod 2 inserted in the hot condition, the heatup must have been started with more rod inserted, and this would cause the differential coefficient to be more negative and the integrated defect larger.

After the core had accumulated 8475 MWD/MTM burnup, the reactivity defect on heatup again was measured using the same method as before. This measurement was made only between $280^{\circ} \mathrm{F}$ and $500^{\circ} \mathrm{F}$ and at $798 \mathrm{ppm}$ boron. The results are shown in Figure 3.7.

\subsection{Zero Power Reactivity Measurements at Operating Temperature}

At the beginning of core life and periodically throughout the cycle, 


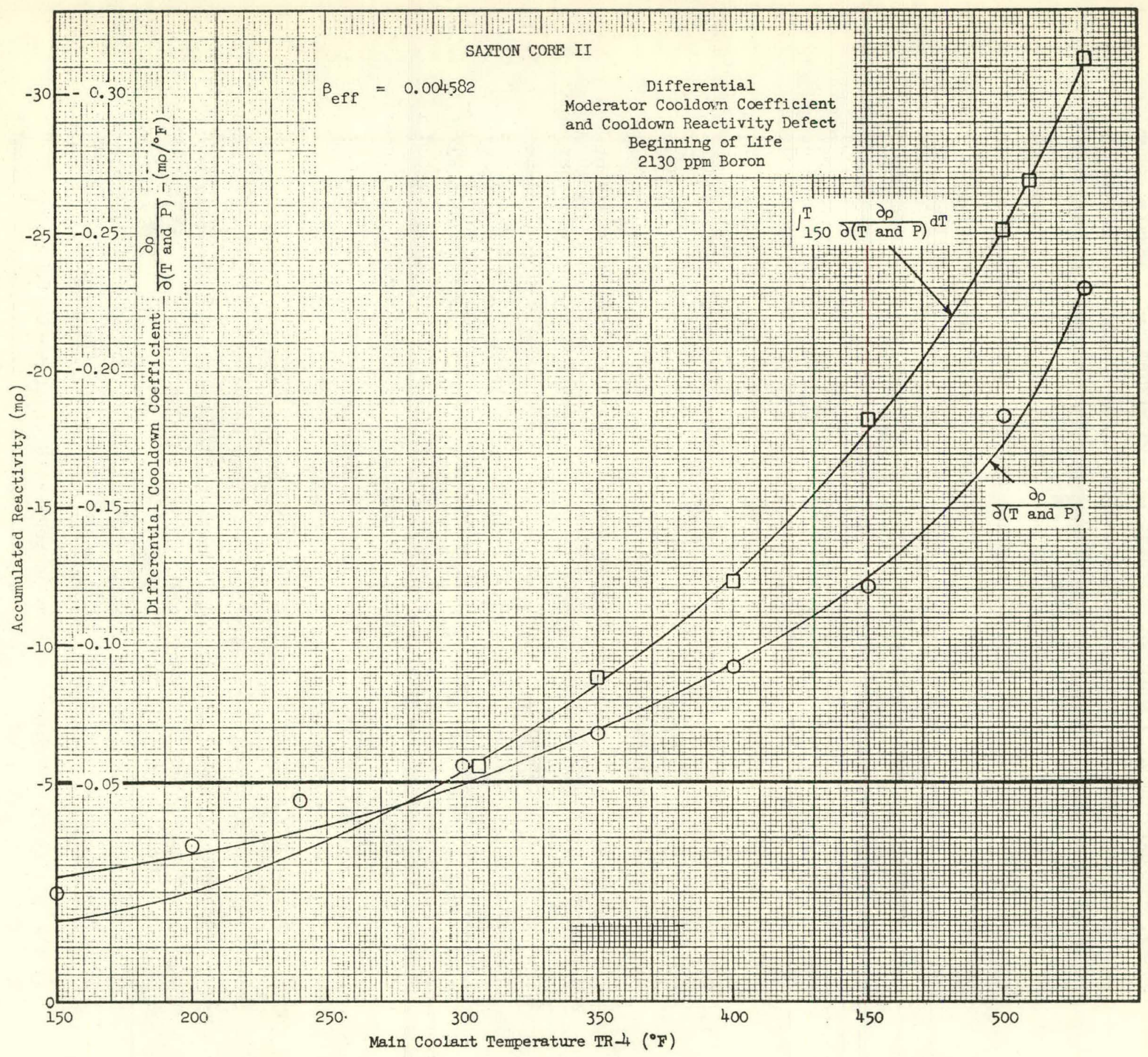

Figure 3.5. Saxton Core II Differential Moderator Cooldown Coefficient and Cooldown Reactivity Defect (Beginning of Life, 2130 ppm Boron) 


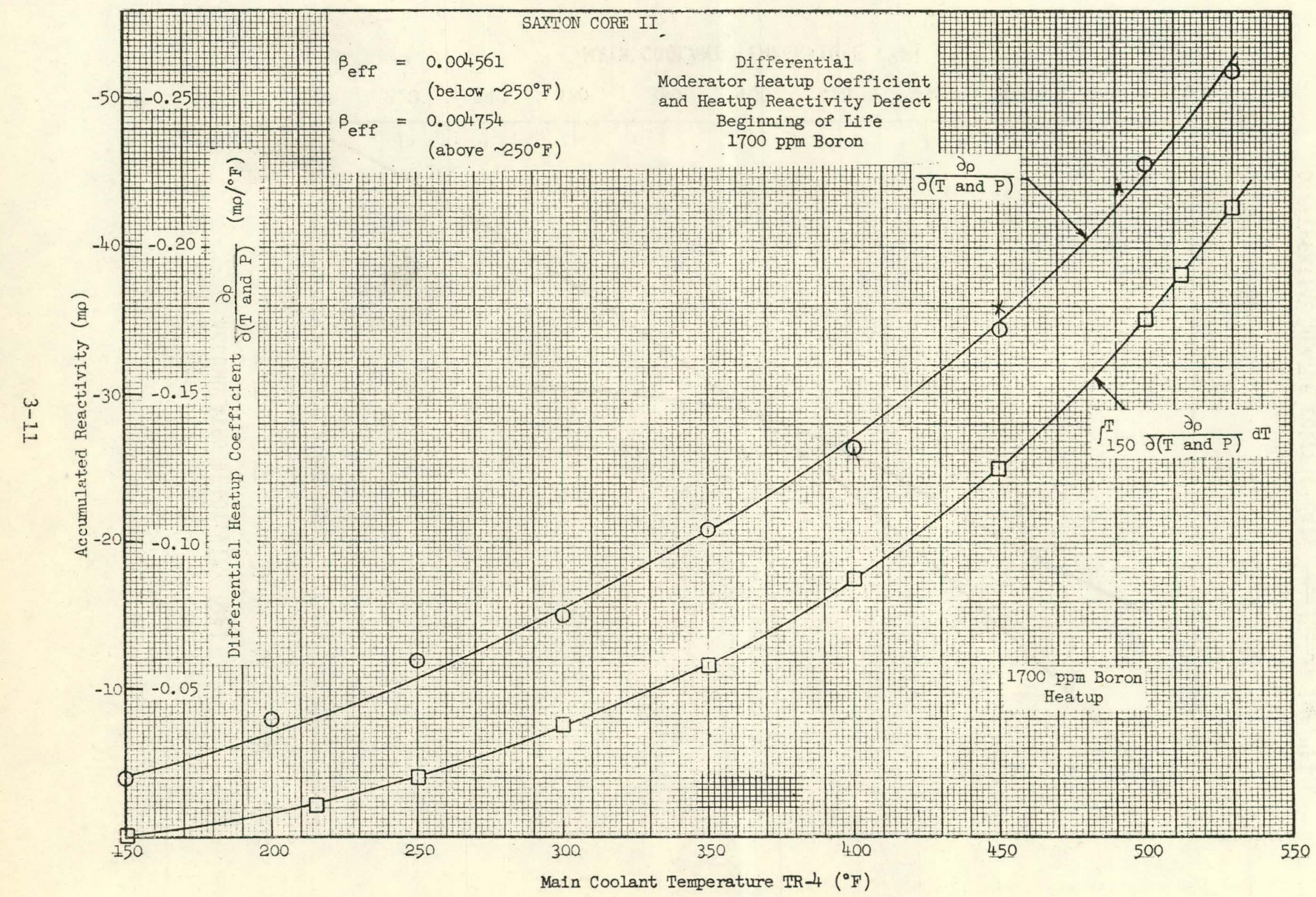

Figure 3.6. Saxton Core II Differential Moderator Heatup Coefficient and Heatup Reactivity Defect Beginning of Life 1700 ppm Boron 


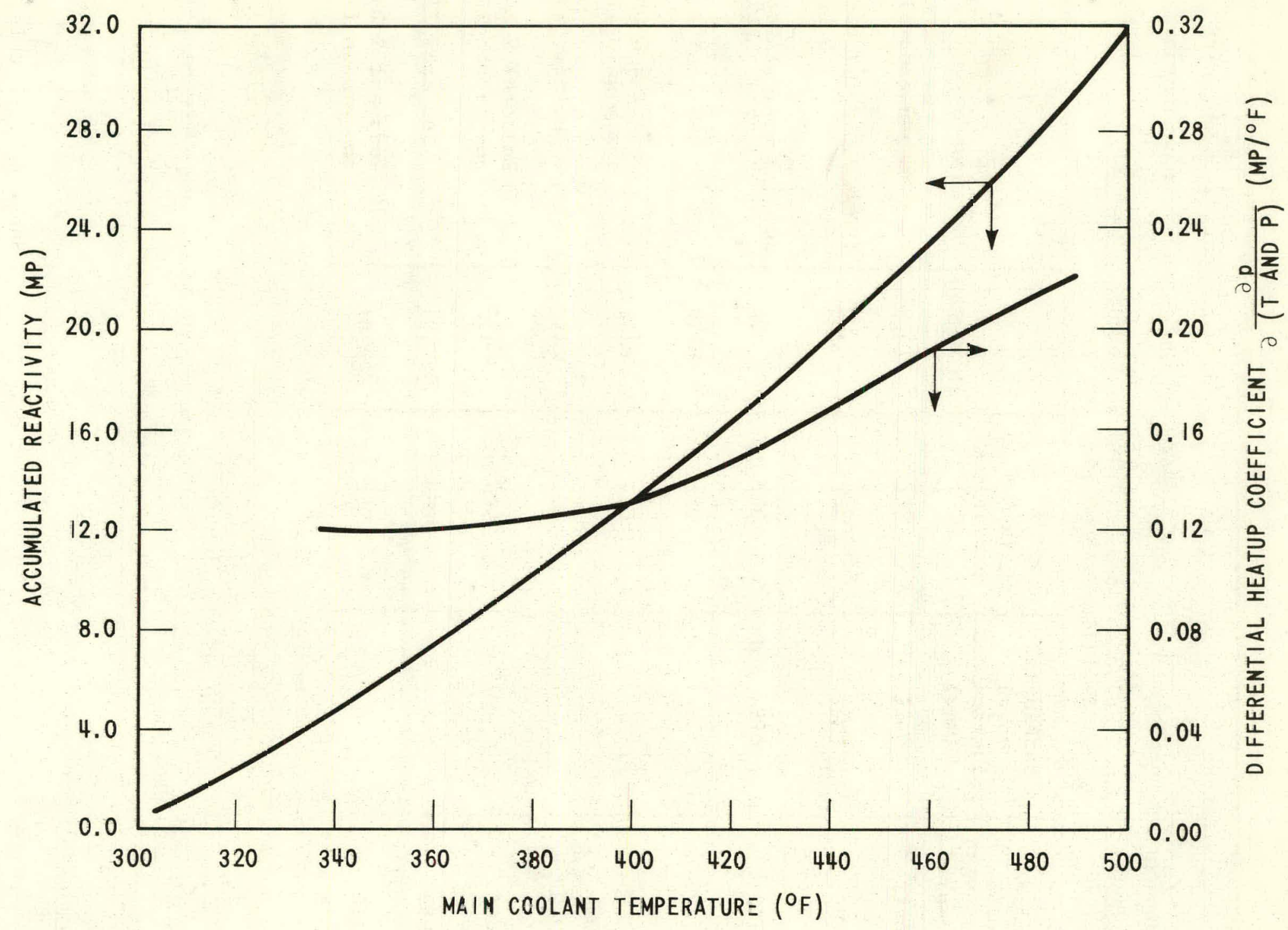

Figure 3.7. Saxton Core II Differential Moderator Heatu Coefficient and Heatup Reactivity Defect 5475 MWD MTM 798 PPNi Boron 
measurements were made of the al1-rods-out and rod 2 inserted boron concentrations, the worth of control rod 2, the differential boron worth, the differential moderator temperature coefficient, and the xenon worth.

\subsubsection{Boron Endpoints and Boron Worths}

The just-critical boron concentration was determined in the all-rods-out configuration and the rod 2 inserted configuration at beginning-of-1ife (BOL), 3716 MWD/MTM, 5715 MWD/MTM and 10,490 MWD/MTM.

The data is given in Table 3.3. At beginning-of-life (BOL), measurements of the rod 2 and rod 5 in endpoint boron concentration, and the analytical prediction of the endpoint borons, were available for the BOL condition. They are presented in Table 3.3 for comparison. In general, the agreement between the calculated and the measured values is good. Differential boron worths calculated from the boron endpoints and the integral control rod worths given in the following section are presented in Table 3.4. Again at BOL, calculated values are presented for comparison. Though the BOL measurements failed to show the expected trend of boron worth with boron concentration, subsequent measurements do show a trend. This trend to higher boron worth is due to lower boron concentration and a shift in core power to the uranium with higher burnup. The end-of-life differential boron worth seems to be singularly high, but no convincing reason has been found to" invalidate the measurement.

\subsubsection{Control Rod Worth Measurements}

The direct differential worth of a control rod was measured during continuous boron dilution or insertion by moving the rod to be measured in a series of steps and recording the amount of travel and change in reactivity associated with each step. The analog computer again was used for measuring reactivity. The different delayed neutron fractions used by the computer are listed in l'able 3.5. Calculations made at $3716 \mathrm{MWD} / \mathrm{M}$ 'lM to determine the change in $B_{\text {eff }}$ with burnup show only a 0.34 percent difference. Subsequent to this, no additional calculations of $B_{\text {eff }}$ were made. 
TABLE 3.3

SUMMARY OF ENDPOINT MEASUREMENTS

AT HOT ZERO POWER CONDITIONS

\begin{tabular}{|c|c|c|c|c|}
\hline $\begin{array}{l}\text { Control Rod } \\
\text { Configuration }\end{array}$ & $\begin{array}{l}\text { Burnup } \\
\text { (MWD/MTM) }\end{array}$ & $\begin{array}{c}\text { Core Average } \\
\text { Temperature } \\
\left({ }^{\circ} \mathrm{F}\right)\end{array}$ & $\begin{array}{c}\text { Calculated } \\
\text { Boron } \\
\text { Concentration } \\
(\text { ppm) }\end{array}$ & $\begin{array}{l}\text { Endpoint } \\
\text { Boron } \\
\text { Concentration } \\
(\mathrm{ppm})\end{array}$ \\
\hline All rods out & BOL & 530 & 2240 & 2296 \\
\hline $\begin{array}{ll}\text { Rods } 1,3,4,5 \& 6 & \text { out } \\
\operatorname{Rod} 2 & \text { in }\end{array}$ & BOL & 530 & 1600 & 1702 \\
\hline $\begin{array}{l}\text { Rods } 1,3,4 \& 6 \\
\text { Rods } 2 \& 5\end{array}$ & BOL & 530 & 925 & 1047 \\
\hline All rods out & 3716 & 530 & - & 1565 \\
\hline $\begin{array}{l}\text { Rod } 2 \text { inserted } \\
\text { All others out }\end{array}$ & 3716 & 530 & - & 1037 \\
\hline All rods out & 5715 & 530 & - & 1266 \\
\hline $\begin{array}{l}\text { Rod } 2 \text { inserted } \\
\text { Al1 utliers out }\end{array}$ & 5715 & 530 & - & 79.5 \\
\hline Al1 rods out & 10,490 & 530 & - & 683 \\
\hline $\begin{array}{l}\text { Rod } 2 \text { inserted } \\
\text { All others out }\end{array}$ & 10,490 & 530 & - & 312 \\
\hline
\end{tabular}


TABLE 3.4

DIFFERENTIAL BORON WORTHS

\begin{tabular}{|c|c|c|c|c|c|c|}
\hline Rad. 2 worth & BOL & 3.69 & 594 & 640 & 161 & 178 \\
\hline $\begin{array}{l}\text { Fod } 5 \text { worth } \\
\left(\begin{array}{l}2 \\
2\end{array}\right)\end{array}$ & $\mathrm{BOL}$ & 4.03 & .655 & 675 & 162 & 152 \\
\hline Rod 2 wcrth & 3716 & .3 .30 & 528 & - & 160 & - \\
\hline Rod 2 warth & 5715 & 3.26 & 491 & - & 151 & - \\
\hline Rod 2 worti & $10, \dot{490}$ & 3.20 & 371 & & & \\
\hline
\end{tabular}


TABLE 3.5

CALCULATED B eff's (AT 3716 MWD/MTM)

Control Rod Configuration

All. Rods Out

$\frac{B_{\text {eff }}}{.0 .0044957}$

Rod 2 Moving

0.0045817

Rod 2 in

0.0046677

Rod 5 Moving

0.0047536

Rod 2 and 5 in

0.0048395

Differential and integral worth curves for rod 2 (all others out) and rod 5 (with 2 inserted) are shown in figure 3.8 and Figure 3.9. l'he differential worth of rod 2 after 5715 MWD/MTM is shown in Figure 3.10. After the initial flattening from BOL there is very little change in the worth of $\operatorname{rod} 2$.

The integral worths for $5715 \mathrm{MWD} / \mathrm{MTM}$ are given in Figure 3.11. The end-oflife $(10,490$ MWD/MTM) differential and integral worth of control rod 2 are shown. in Figure 3.12. Again there is no change in the differential or integral WULLli.

The following tabulation shows the boron equivalent worth, the reactivity worth, and the calculated reàctivitey worth of control ród 2 as a function of burnup.

TABLE 3.6

ROD 2 EQUIVALENT REACTIVITY WORTHS

\begin{tabular}{llll}
$\begin{array}{l}\text { Burnup } \\
\text { (MWD/MM) }\end{array}$ & $\begin{array}{l}\text { Roron } \\
\text { Equivalent (ppm) }\end{array}$ & $\begin{array}{l}\text { Reactivity } \\
\text { Worth }(\% \Delta \rho)\end{array}$ & \multicolumn{2}{l}{$\begin{array}{l}\text { Caliculated } \\
\text { Worth }(\% \Delta \rho)\end{array}$} \\
\hline 0 & 594 & 3.66 & 3.55 \\
3716 & 528 & 3.40 & 3.38 \\
5716 & 491 & 3.26 & 3.40 \\
10,490 & 371 & 3.30 & 3.25
\end{tabular}




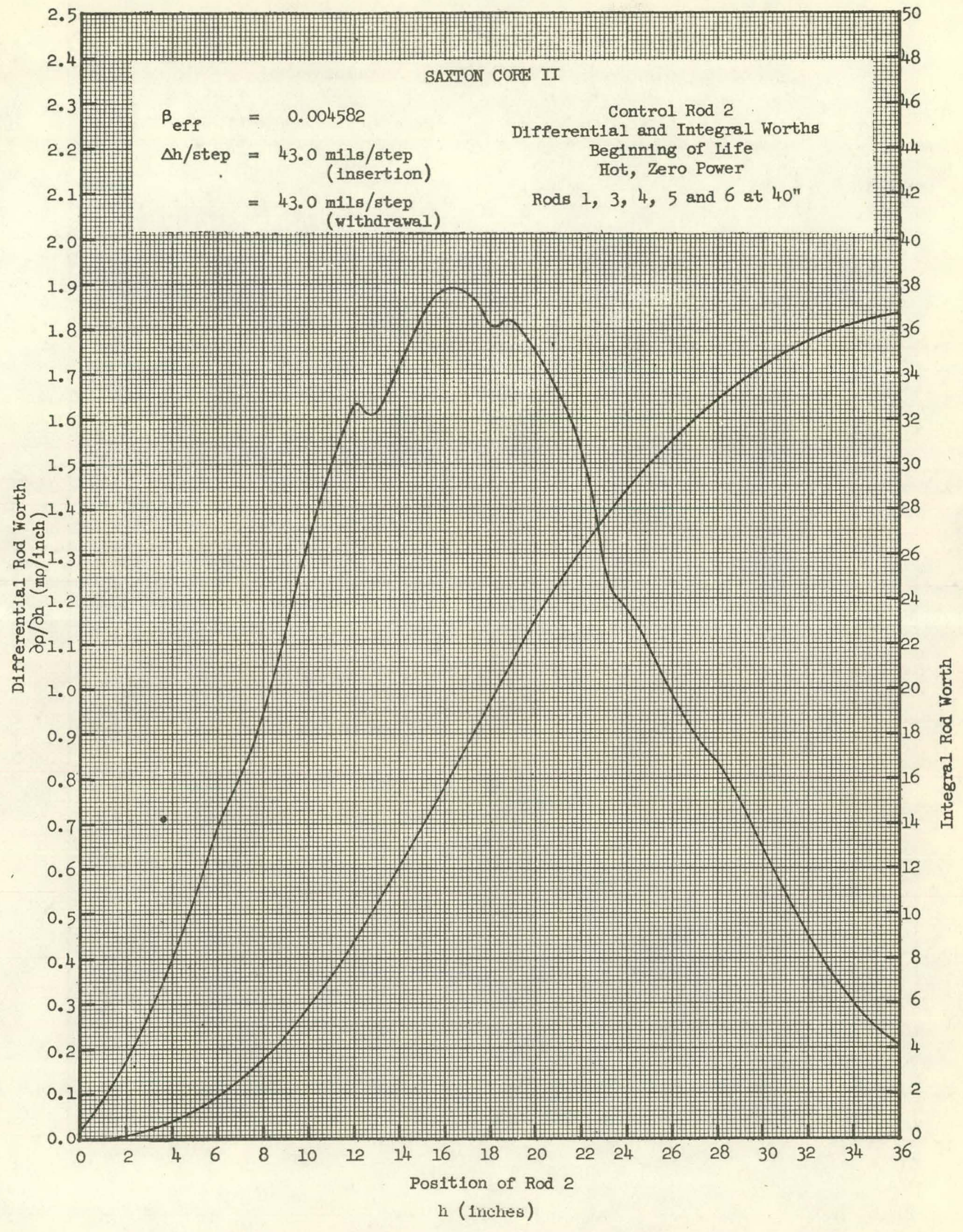

Figure 3.8. Saxton Core II Control Rod 2 Differential and Integral Worths (Beginning of Life, Hot, Zero Power) 


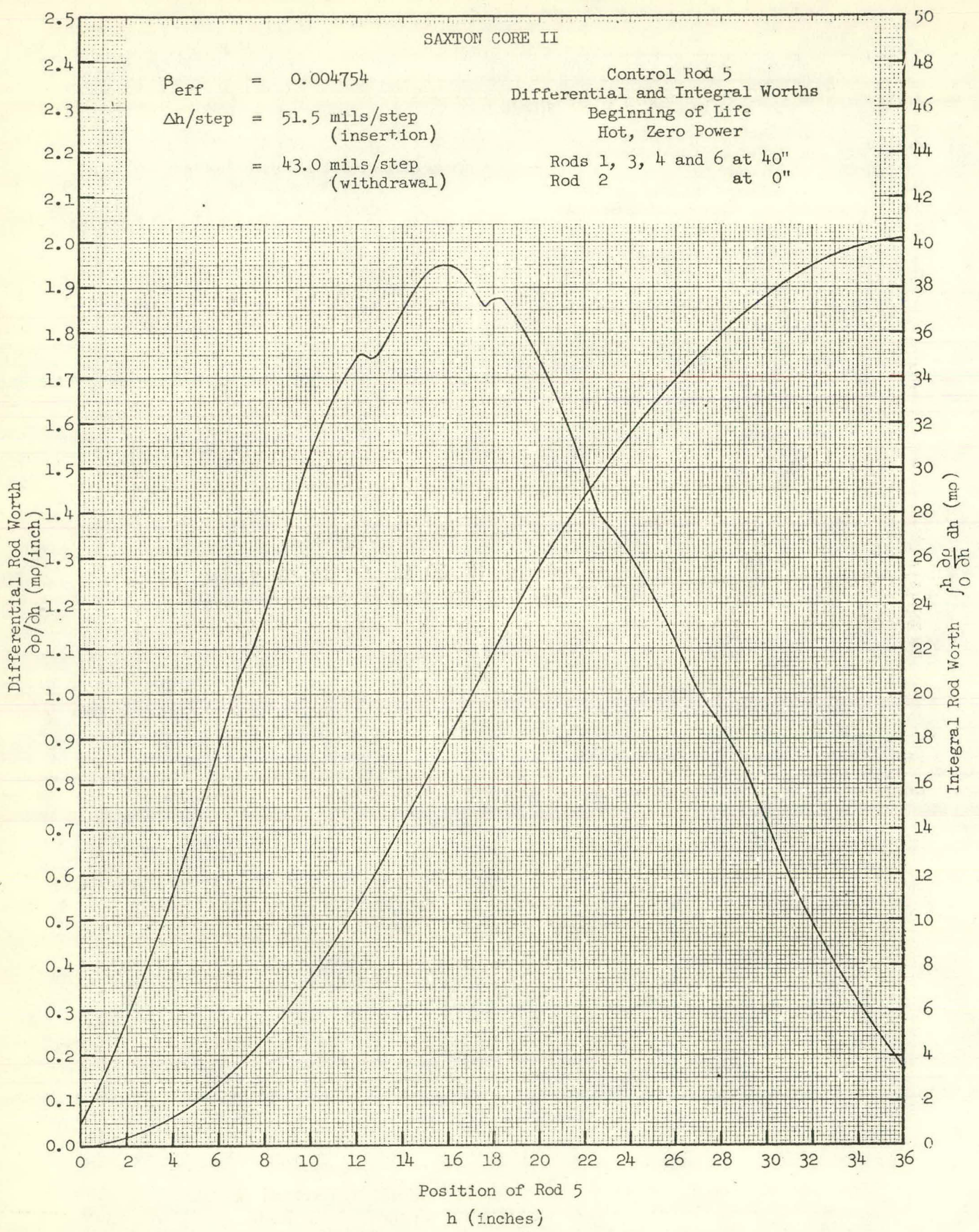

Figure 3.9 Saxton Core II Control Rod 5 Differential and Integral Worths (Beginning of Life, Hot, Zero Power) 


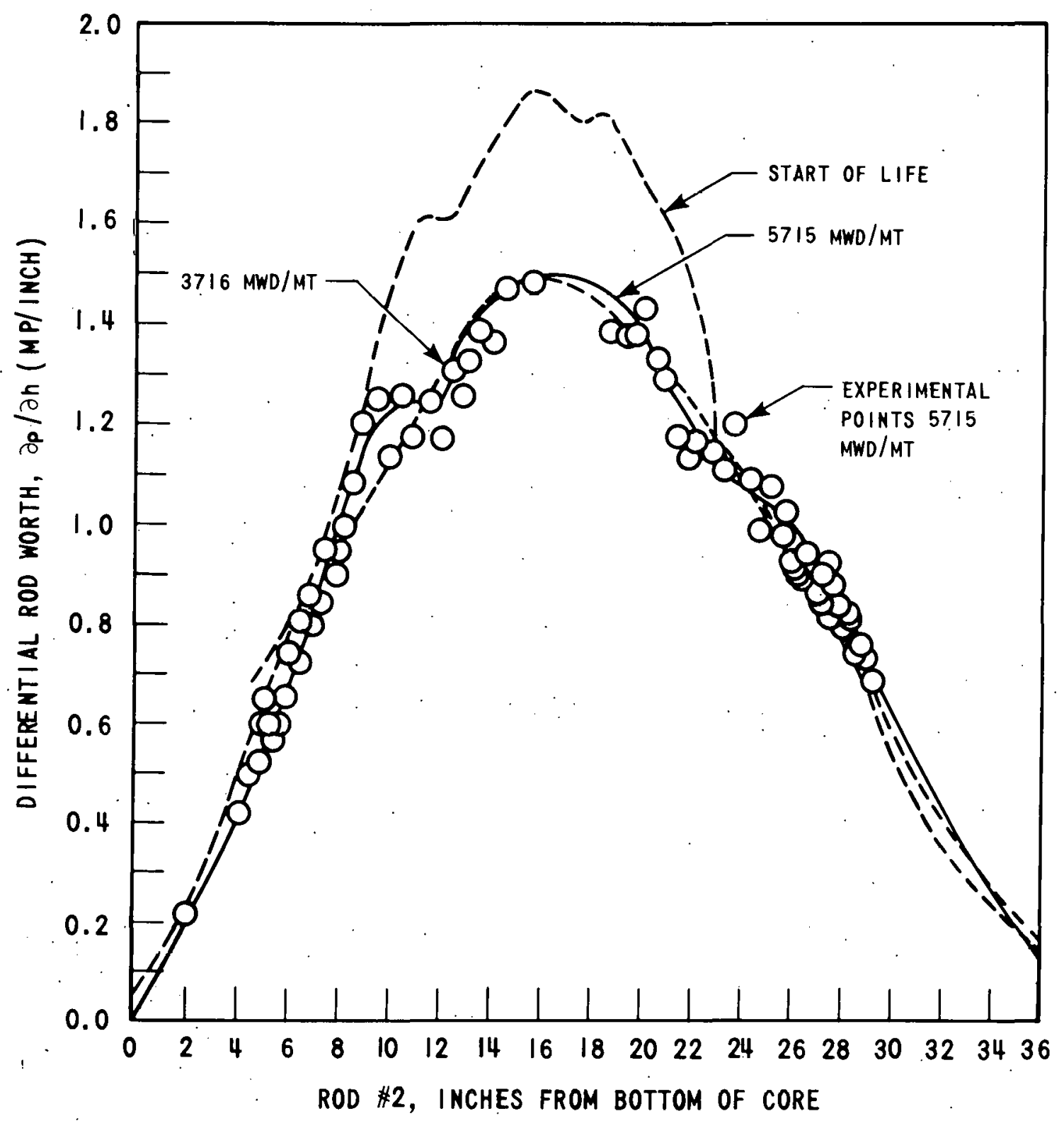

Figure 3. 10: Saxton Core II. Control Rod \#2 Differential Worth (57.15 MWD/MIM Rarnup, Hnt, Zero Power, Rods 1, 3, 4,5 and 6 at $40^{.}$) 


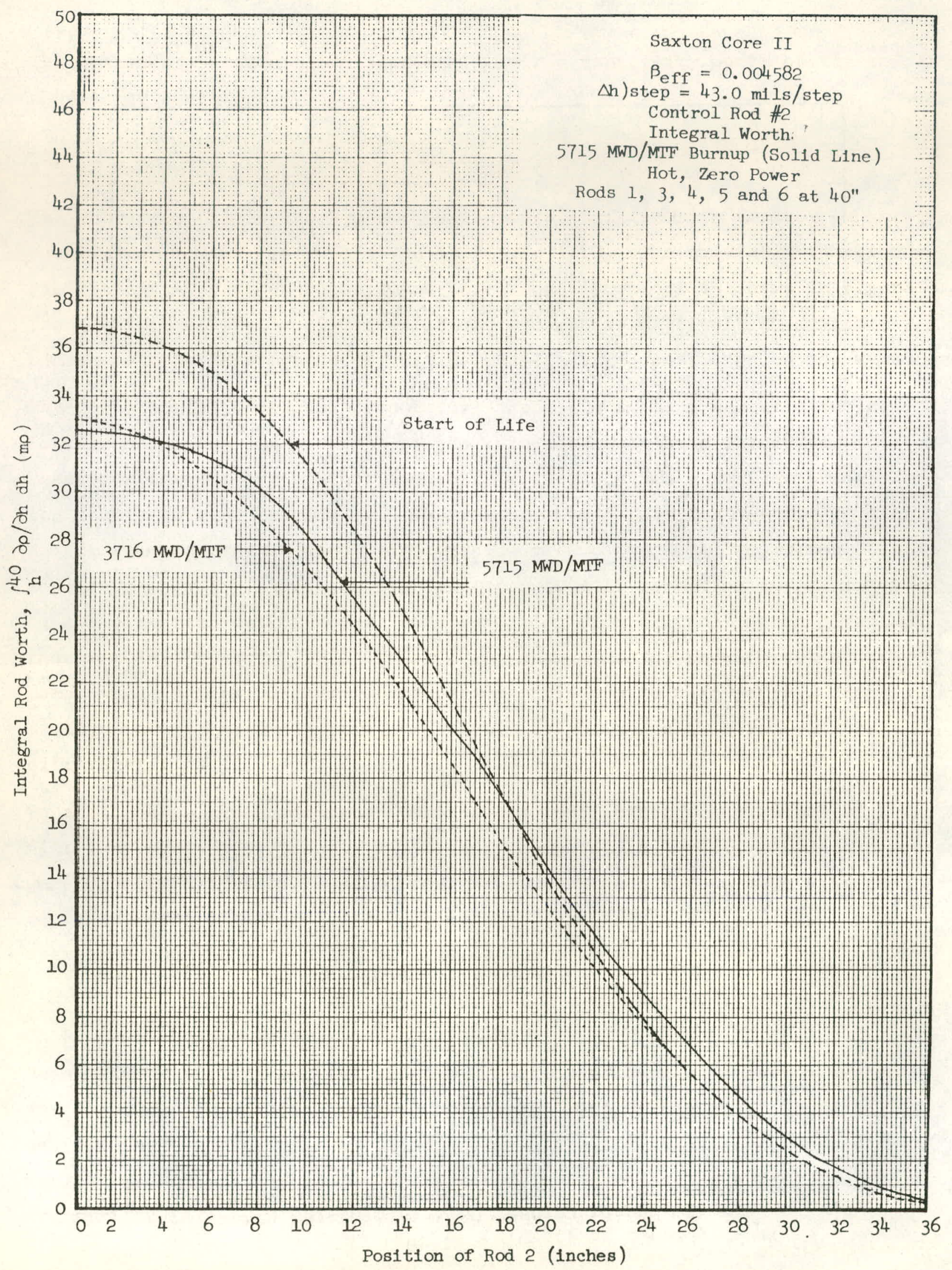

Figure 3.11. Saxton Core II Control Rod 非 Integral Worth 


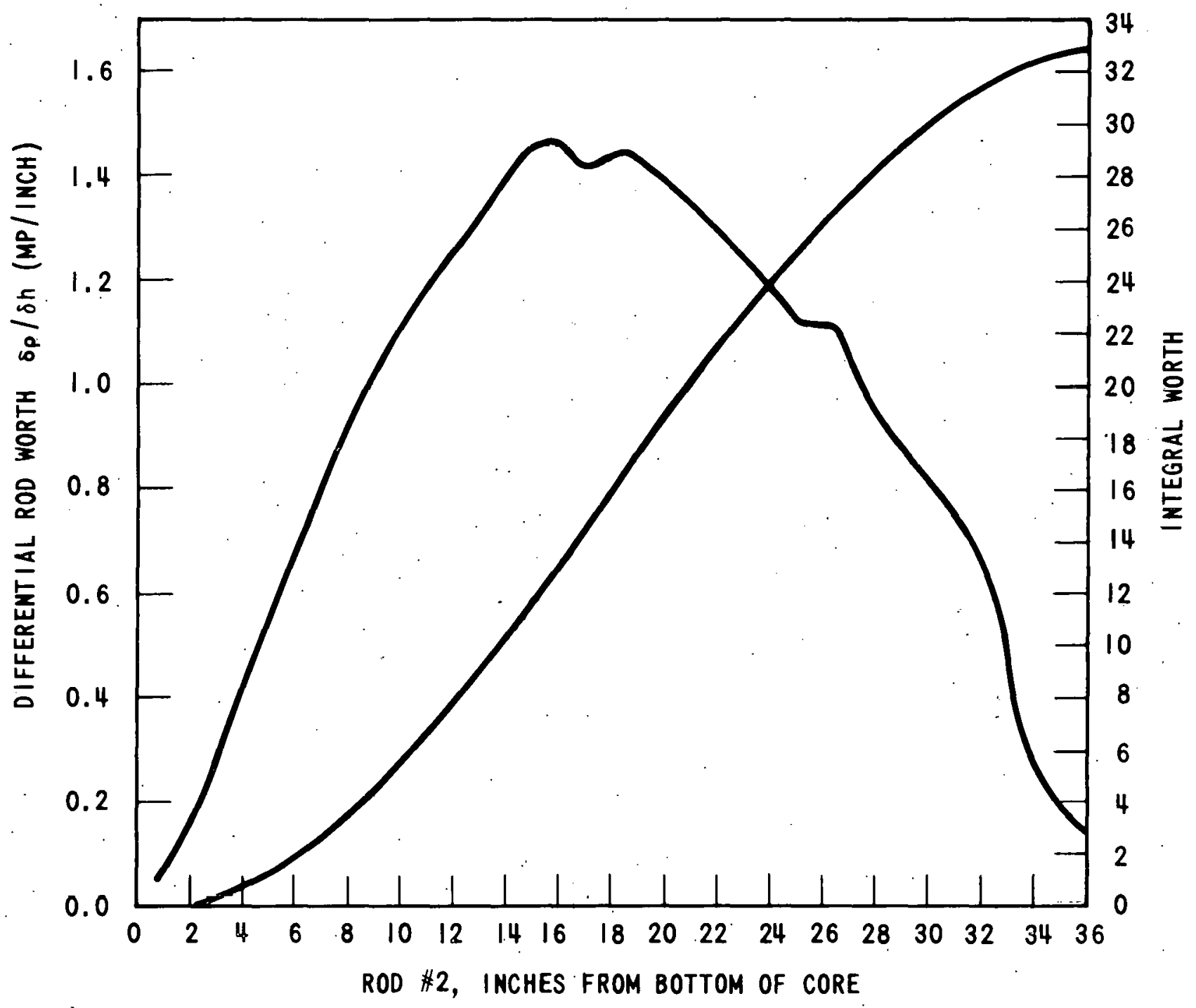

Figure 3.12. Saxton Core II Differential and Integral Worths of Rinl 2 ( 10590 MWD/MIM Burnup, Hot, Zero Power, Rods $1,3,4,5$ and 6 , at $\left.40^{\prime \prime}\right)$ 
The agreement between calculated and measured reactivity worth of the rod is considered excellent.

\subsubsection{Moderator Temperature Coefficient}

The data from the hot zero power beginning-of-life (BOL) moderator temperature coefficient measurements is given in Figure 3.13. The moderator temperature coefficient at various burnups and boron concentrations is shown in Figure 3.14. The exact trend of the differential coefficient is difficult to decipher because of the interaction of controi rods, burnup, and boron on the measurements. 'l'he ditterential moderator temperature coetticients were measured during continuous heatup and cooldown by observing at one minute intervals moderator average temperature (measured with RTD's and a Mueller bridge) and change in core reactivity. The reactor was maintained nearly critical during temperature change by compensating with control rod movement. Change in core reactivity due to change in temperature at each time point was given ty the algebraic sum of actual core deviation from criticality as given by the computer at that time point plus the accumulated change in reactivity compensated for by periodic steps of rod motion up to that point. Correlation of temperature change in time and reactivity change in time yielded the differential coefficient.

In addition to those moderator temperature coefficient measurements at different boron and burnups, a series of temperature coefficient measurements were made at different temperatures. The measurements were made with the following core conditions: zero power, $800 \mathrm{ppm}$ boron, all rods out, core average burnup of 8470 MWD/MTM. The data are shown in Figure 3.15.

\subsubsection{Pressure Coefficient Measurements}

Measurements of differential pressure coefficient were made during heatup and again at $530^{\circ} \mathrm{F}$, both times in connection with differential temperature coefficient measurements made under closely similar conditions. Since the nuclear mechanisms underlying the pressure and temperature coefficients are similar, a scheme developed during Core I startup was used to evaluate 


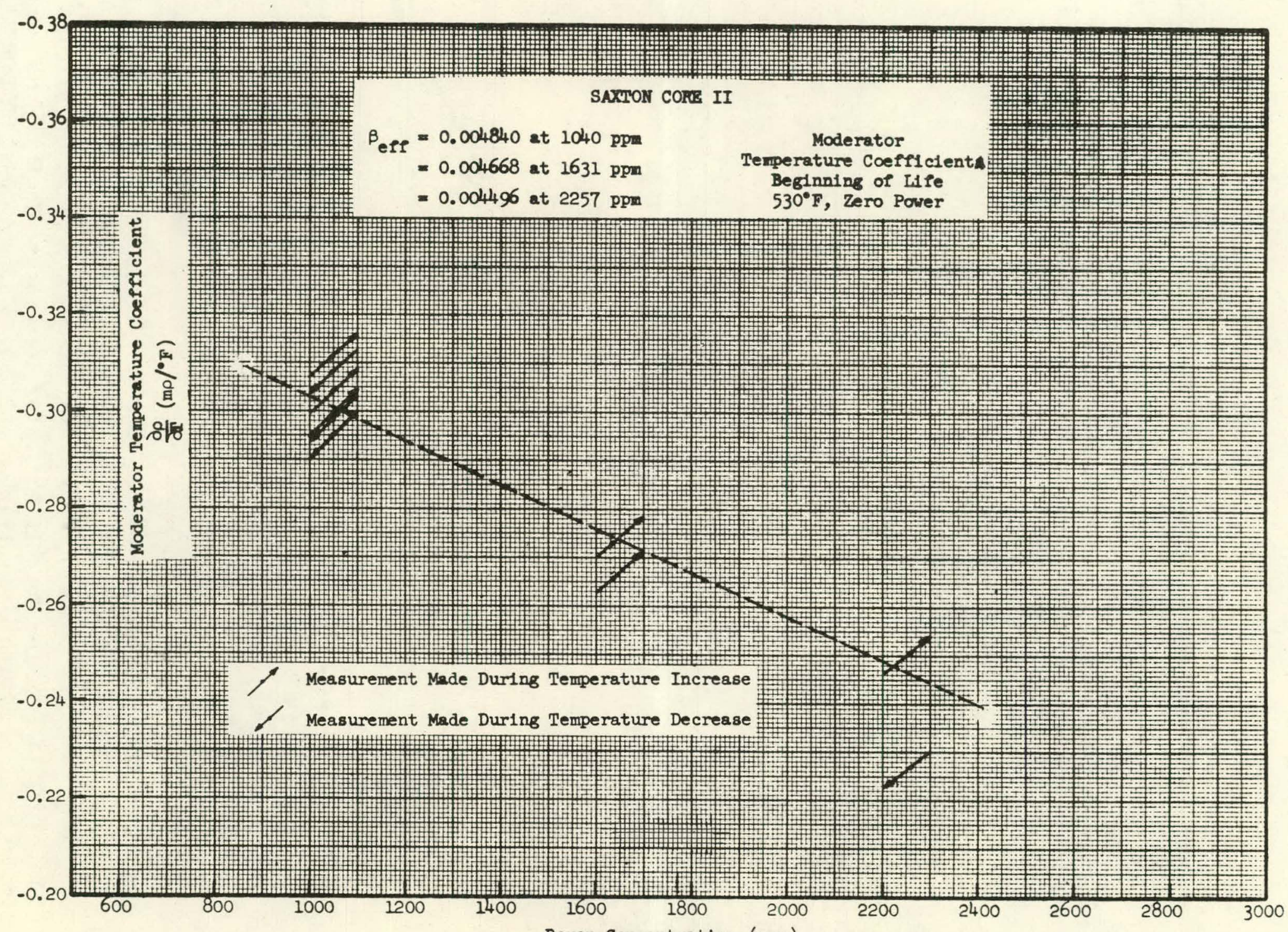

Figure 3.13. Saxton Core 11 Moderator lemperature Coefficient (Beginning of Life, $530^{\circ} \mathrm{F}$, Zero Power) 


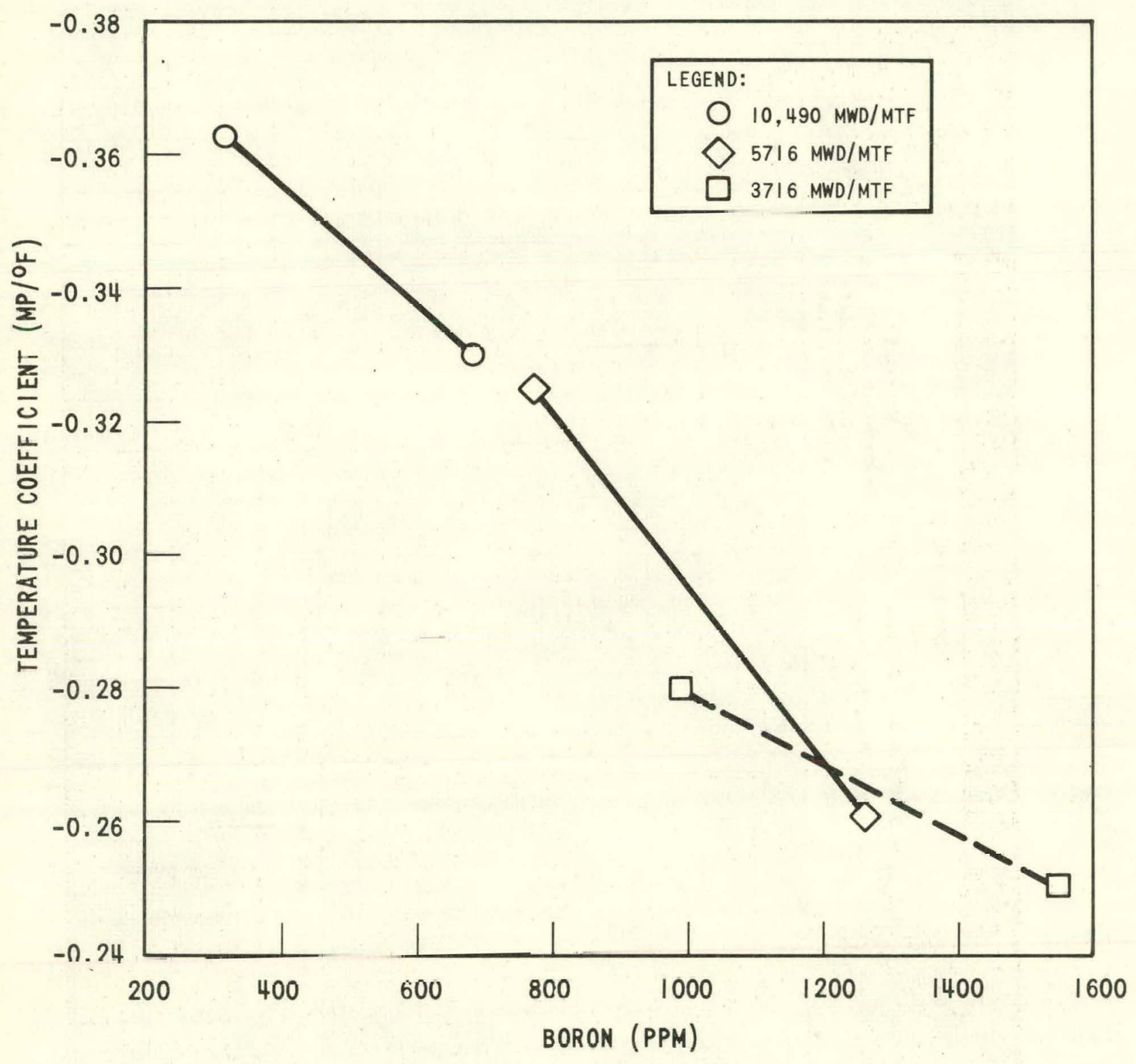

Figure 3.14. Saxton Core II Moderator Temperature Coefficients versus Boron Concentration at 3716,5715 and 10490 MWD/MTM Burnup; Hot, Zero Power 


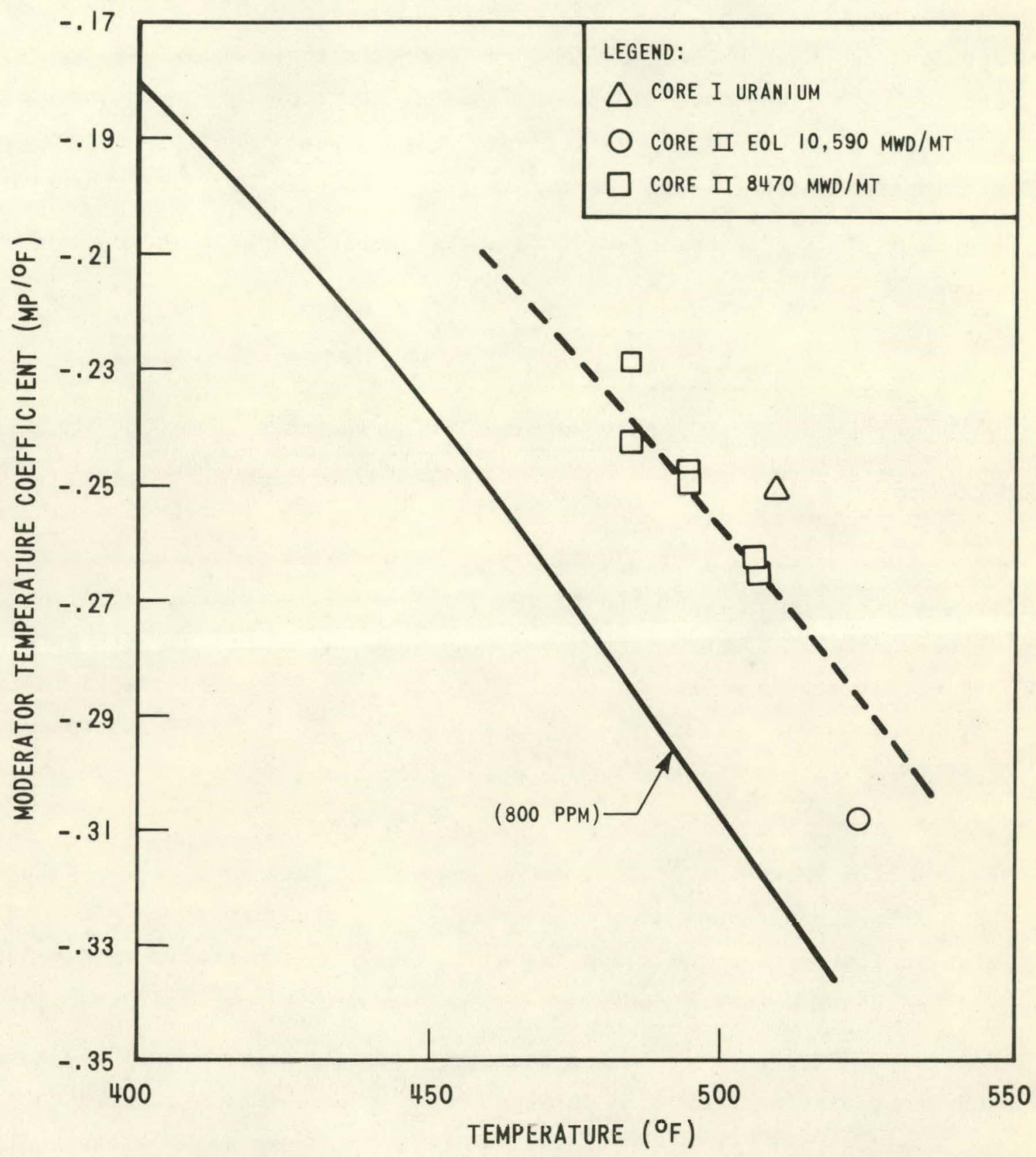

Figure 3.15. Saxton Core II Moderator Temperature Coefficient veisus Temperature 
the Core II results. Figure 3.16 is a plot of differential pressure coefficient versus differential temperature coefficient, showing the Core II data points superimposed on the Core I correlation. The close agreement between Core I and Core II results is indicative of the fact that both temperature and pressure coefficients rely on water density changes and that the interrelation between the two is little affected by fuel characteristics. Figure 3.17 is a recommended differential pressure versus boron concentration curve.

\subsubsection{Xenon Reactivity Worth}

A 72-hour xenon decay measurement following shut down from equilibrium 21.5 MWt ronditions was carried out as part of the Elevated Power Test Program at BOL. However, since the conditions of measurement were those of zero power, the results are reported here. Figure 3.18 shows the time dependent reactivity defect attributed to xenon as a function of time after power decrease from 21.5 MWt. The xenon transient shows consistently lower worth and relatively less peaklng diter shutdown than did rnrresponding data taken during the life of the all-uranium Core I. The differences are attributed th the increased core absorption cross section and to the lower average flux level prevelant in Core II as compared to Core I.

Figure 3.19 shows the gradual establishment of pure xenun decay with a half 1 ife of 9.1 hours at the later stages of the transient. The semi-log plot indicates that the xenon transient can be successfully extrapolated and the xenon defect closely estimated by about 50 hours after shutdown. Values of differential control rod worth deduced from control rod motion and reactivily data secured during the xenon follow are compared to the recommended operational curve in Figure 3.20. There is no clear indication within the relatively broad band of experimental uncertainty of dependence of control rod differential worth on xenon concentration. 


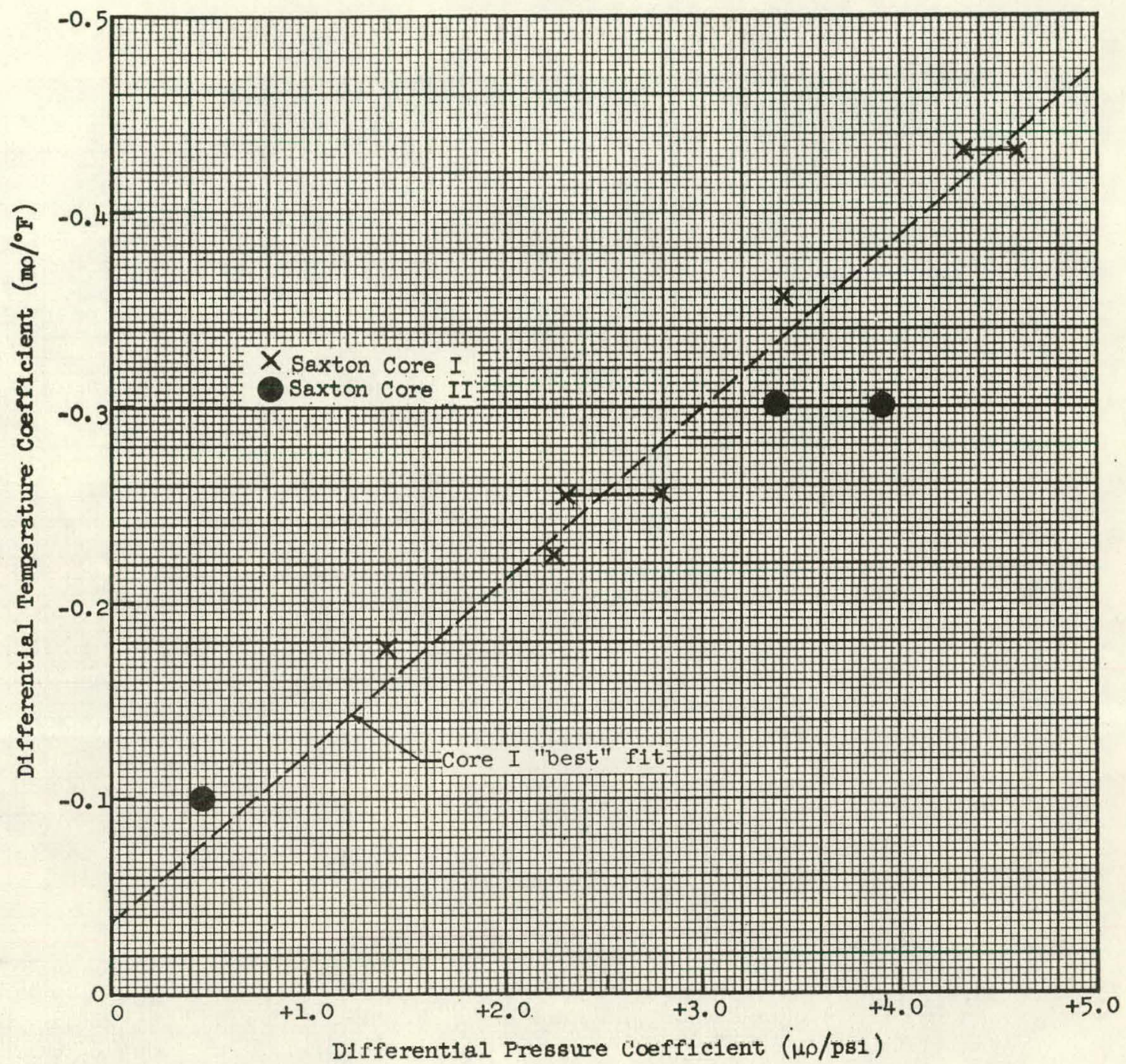

Figure 3.16. Correlation of Differential Pressure and Temperature Co:cfficients at Startup of Saxton Cores I and II 


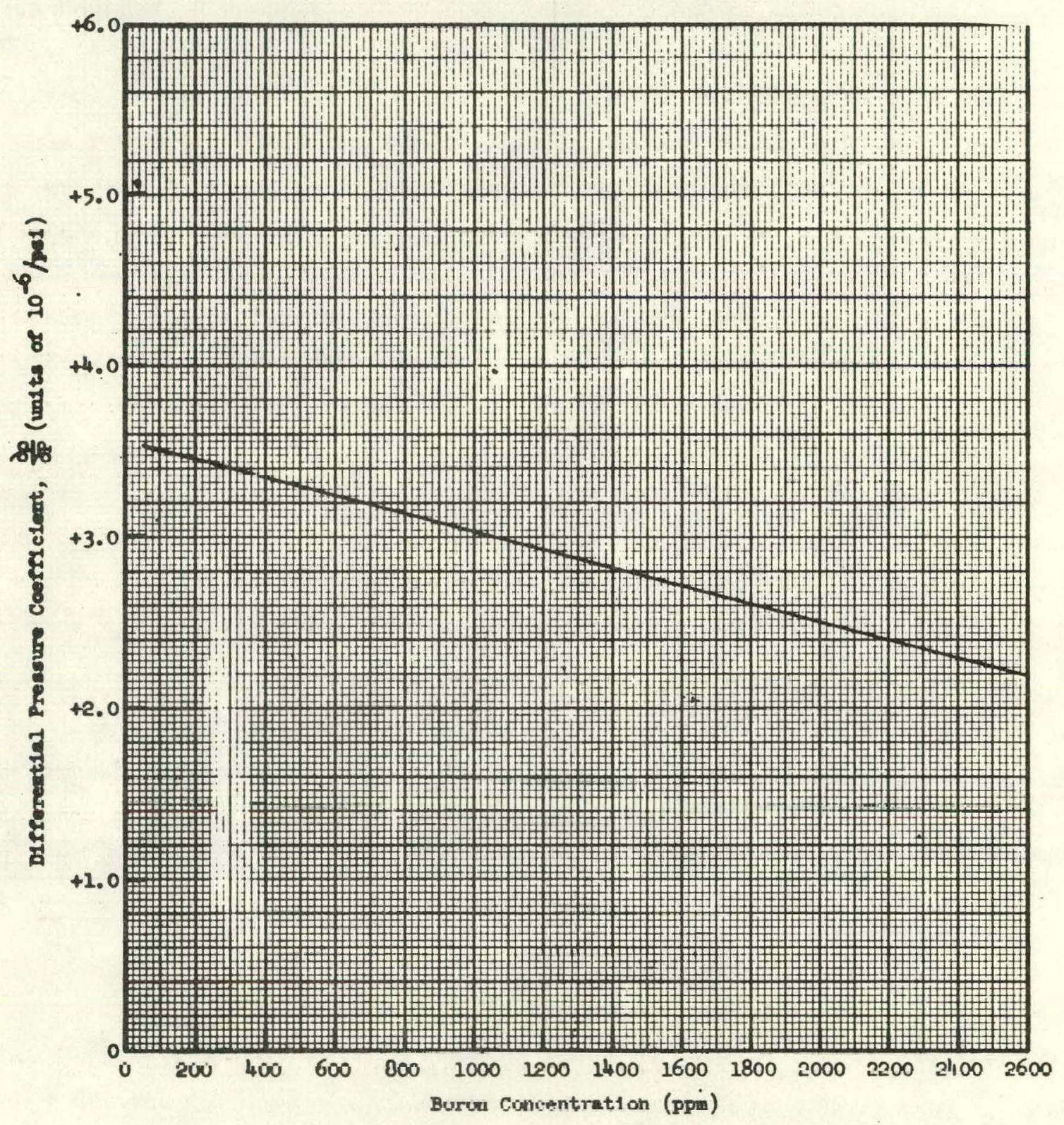

Figure 3.17. Recommended Differential Pressure Coefficient For Saxton Core II Beginning of Life 


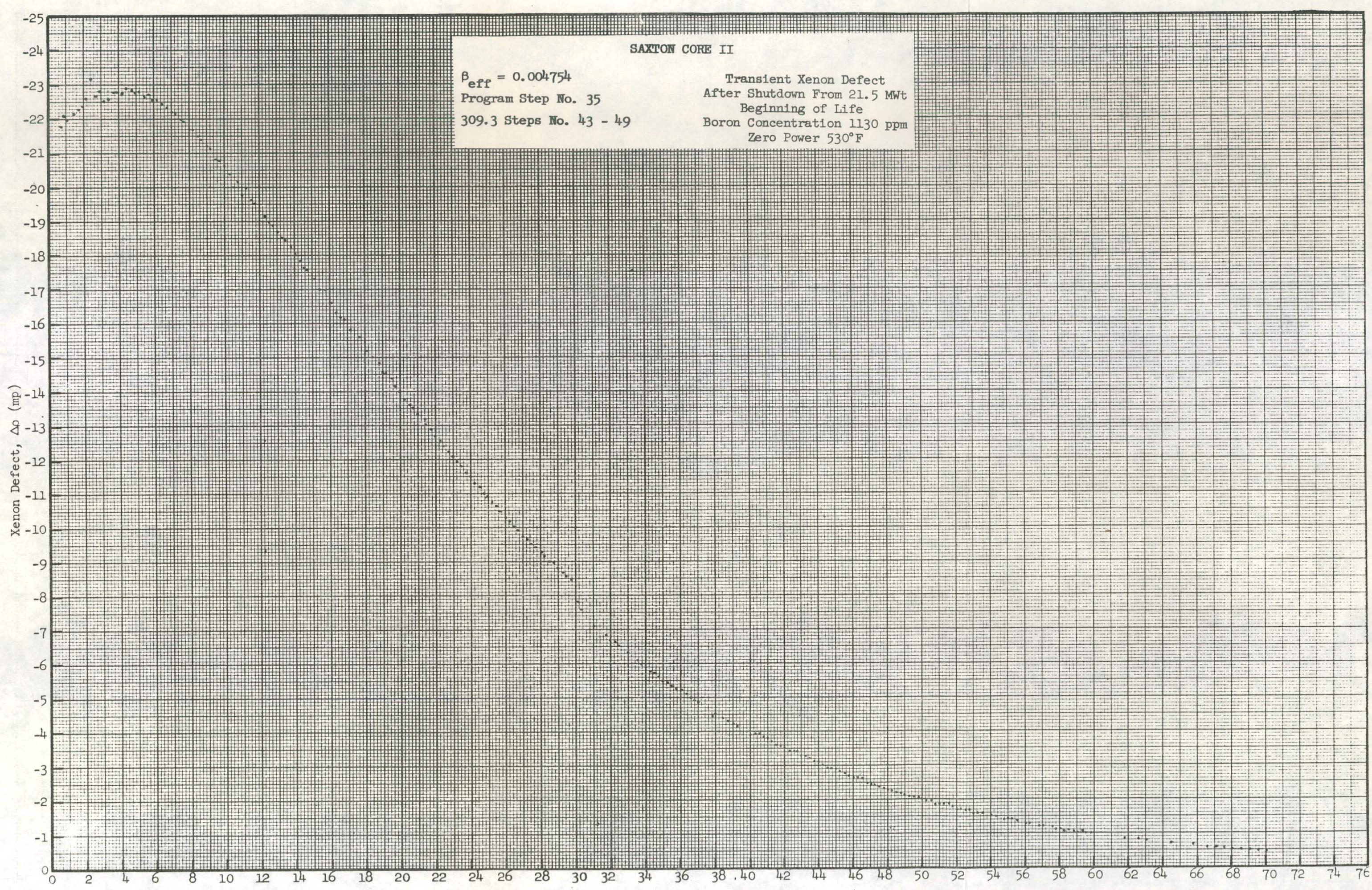
Hours After Shutdown

Figure 3.18. Saxton Core II Transient Xenon Defect After Shutdown From 21.5 MWt, Beginning of Life (Boron Concentration $1130 \mathrm{ppm}$, Zero Power, $530^{\circ} \mathrm{F}$ ) 


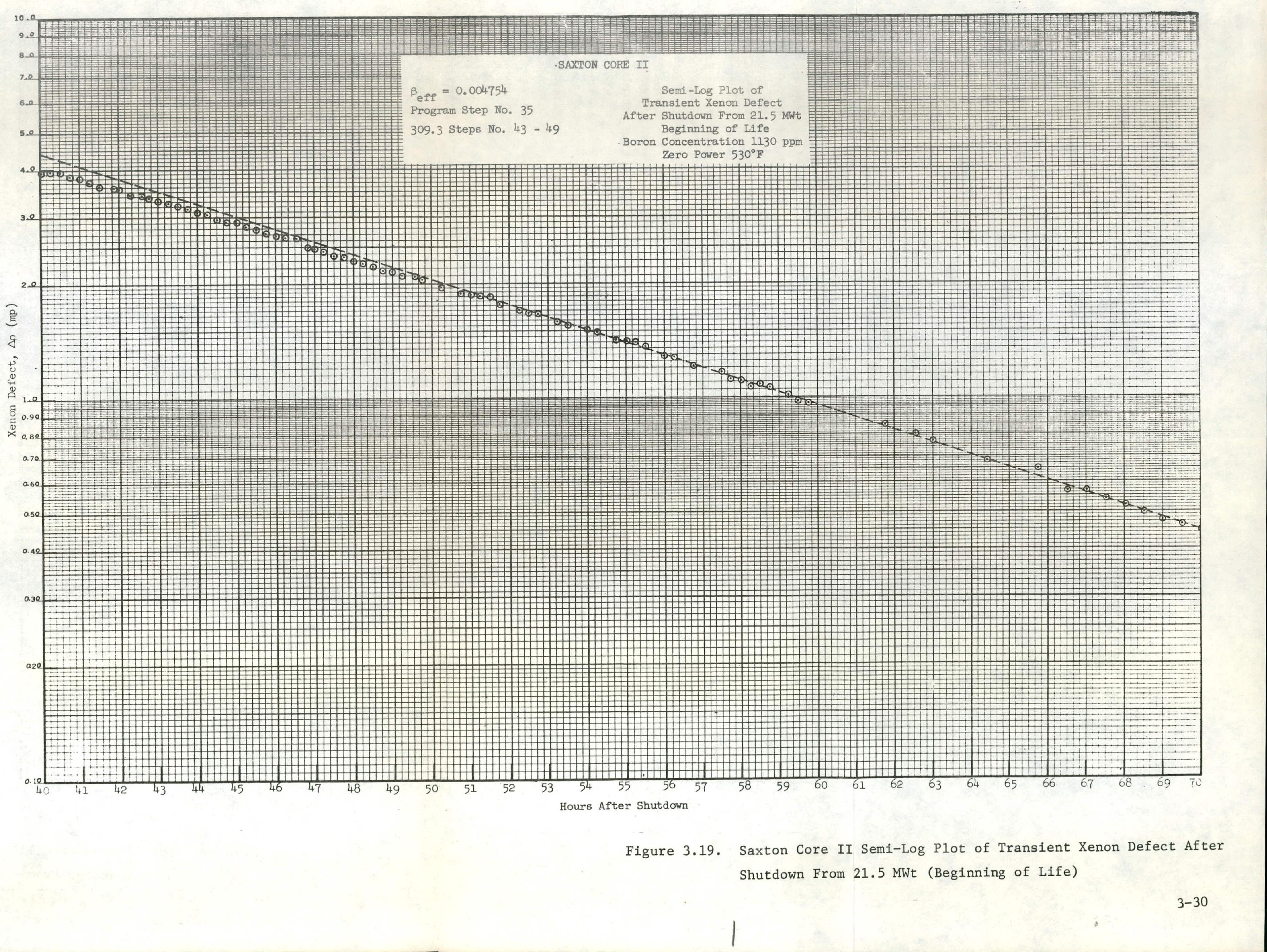




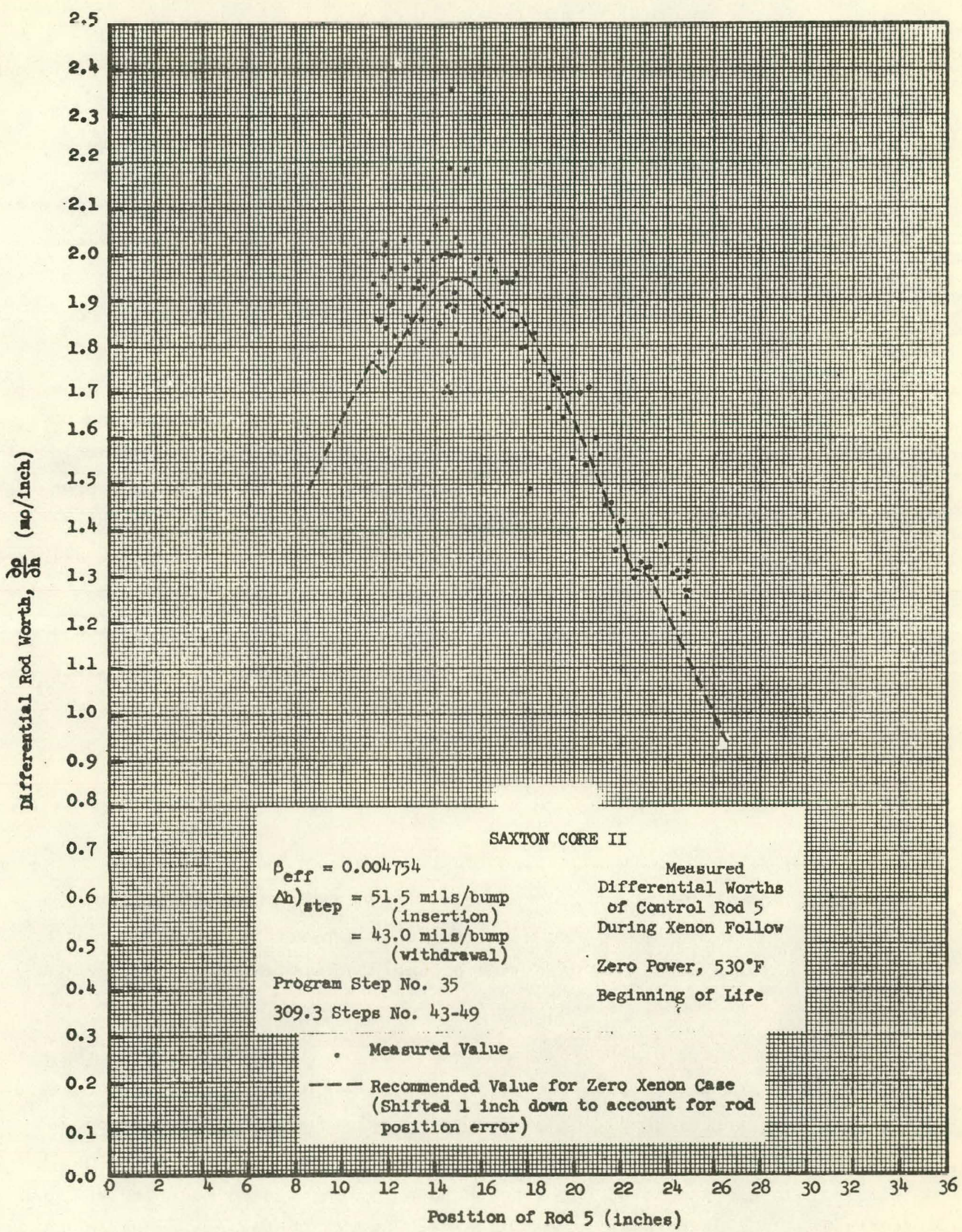

Figure 3.20. Saxton Core II Measured Differential Worths of Control Rod 5 During Xenon Follow 3-31 
At 5715 MWD/MTM, a measurement of the reactivity defect associated with xenon build-in was made using a substitution technique. A baseline was established immediately after startup, and all the measurements were calculated from this temperature and rod position. The poison build-in with the control rods fixed and power level constant was necessarily compensated for by a decrease in moderator average temperature $(\Delta T)$. When the predetermined minimum temperature was reached, the rod was withdrawn $(\Delta \mathrm{H})$ quickly and temperature was restored to the initial value. The resultant poison magnitude was calculated from summing the $\Delta T^{\prime} s$ and multiplying the sum by the average temperature coefficient to obtain its reactivity equivalent. A second calculation involving the $\Delta \mathrm{H}$ measurement also involved two boron dilutions. The $\Delta \mathrm{H}$ from each rod movement was multiplied by the appropriate average differential rod worth measured at zero power, and each boron dilution $(\triangle \mathrm{B})$ was multiplied by the average boron worth coefficient. These two reactivity values were then added to obtain their reactivity equivalent. The temperature/xenon exchange and the control rod and boron/xenon exchange data is compiled in Table 3.7 and shown in Figure 3.21. The increase in xenon worth from the BOL measurement can be directly attributed to the increased power level to which the measurement was made.

\subsubsection{Minimum Shutdown Reactivity Measurements}

Determinations of minimum shutdown boron concentrations and control rod contigurations adequate to give 2 percent shutdown with the maximum worth control rod fully withdrawn were made by means of control rod drops in both the cold and hot condition.

The measurements are described in Table 3.8. The first column gives the initial critical conditions; the second column gives the boron concentration for initial critical conditions. The third column gives the amount of shutdown reactivity after dropping the partially inserted rod. The fourth column gives the amount of boron to be added or removed to make the shutdown reactivity 2 percent. The fifth column is then the boron concentration for 
TABLE 3.7

RESULTS OF THE XENON BUILD-IN MEASUREMENT AT 23.2 MWT AFTER 5715 MWD/MTM BURNUP IN SAXTON CORE II

\begin{tabular}{|c|c|c|c|}
\hline $\begin{array}{l}\text { Temperature/Xenon } \\
\text { Time From } \\
\text { Startup } \\
\text { (hrs) }\end{array}$ & $\begin{array}{l}\text { Exchanges } \\
\text { Accumulated } \\
\text { Reactivity } \\
\quad(\mathrm{mo})\end{array}$ & $\begin{array}{l}\text { Rod and Bo } \\
\text { Time From } \\
\text { Startup } \\
\text { (hrs) }\end{array}$ & $\begin{array}{c}\text { Xenon Exchanges } \\
\text { Accumulated } \\
\text { Reactivity } \\
(\mathrm{m} \rho)\end{array}$ \\
\hline 0 & 0 & 0 & 0 \\
\hline 2.60 & 3.01 & 1.00 & 3.54 \\
\hline 5.50 & 3.28 & 4.00 & 3.38 \\
\hline 9.40 & 3.75 & 7.00 & 3.60 \\
\hline 12.43 & 2.60 & 10.50 & 2.26 \\
\hline 16.40 & 2.93 & 14.00 & 2.46 \\
\hline 22.70 & 3.02 & 18.00 & 3.54 \\
\hline 39.00 & 3.01 & 28.00 & 2.91 \\
\hline 49.00 & 0.45 & 49.00 & 1.30 \\
\hline \multicolumn{2}{|c|}{ Total $=$} & \multicolumn{2}{|r|}{ Total $=22.99$} \\
\hline
\end{tabular}




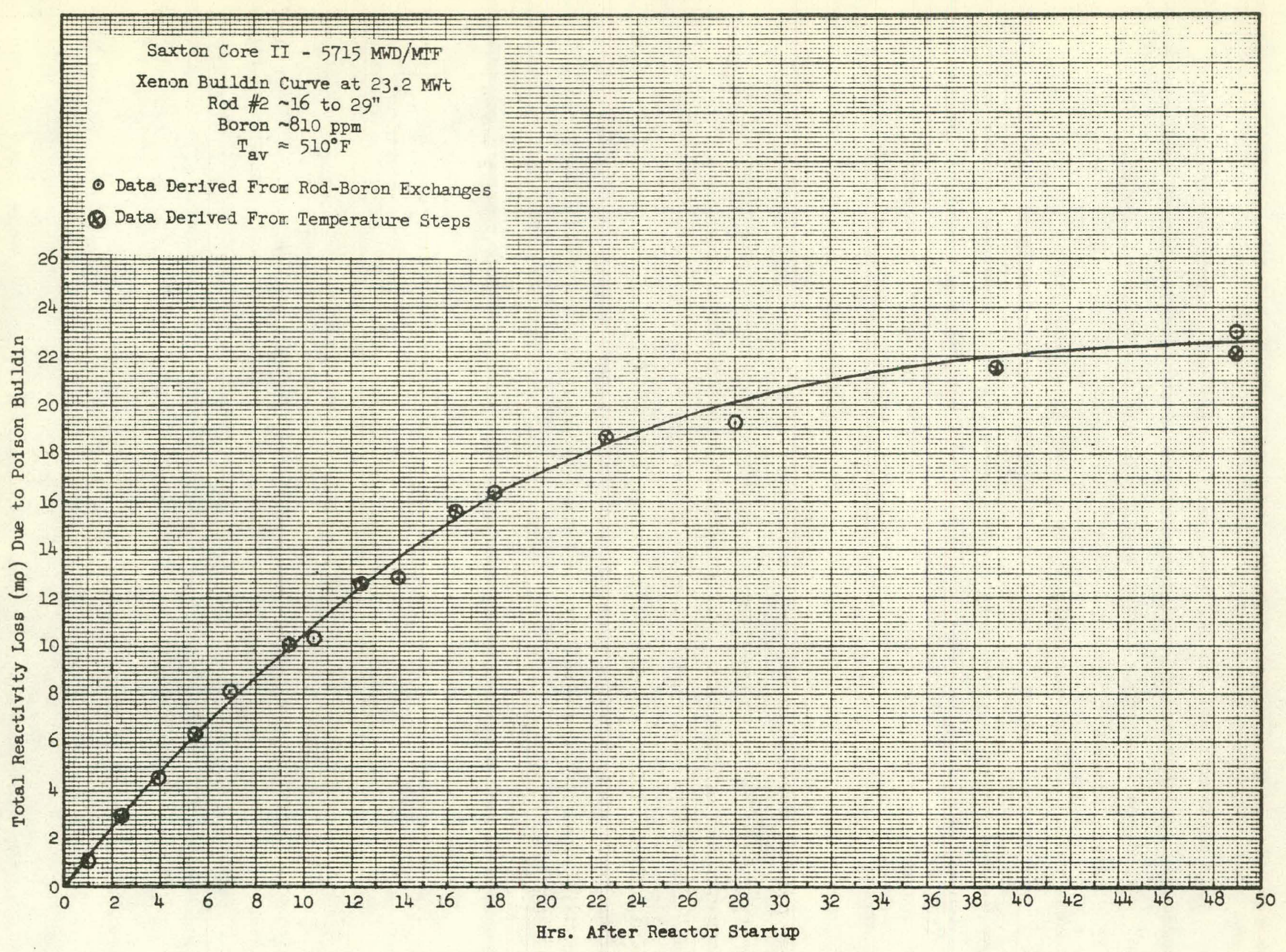

Figure 3.21. Saxton Core II $5715 \mathrm{MWD} / \mathrm{MTF}$ Xenon Buildin Curve at 23.2 MWt, $510^{\circ} \mathrm{F}$ 
TABLE 3.8

MINIMIM SHUTDOWN REACTIVITY MEASUREMENTS

\begin{tabular}{|c|c|c|c|c|c|}
\hline $\begin{array}{l}\text { Rod Configuration } \\
\text { Before Rod Drop }\end{array}$ & $\begin{array}{l}\text { Critical } \\
\text { Boron Concentration } \\
(\mathrm{ppm})\end{array}$ & $\begin{array}{c}\text { Shutdown } \rho \\
\text { After Rod Drop } \\
(m \rho)\end{array}$ & $\begin{array}{c}\text { Boron Equivalent } \\
\text { of Surplus Shutdown } \\
(\mathrm{ppm})\end{array}$ & $\begin{array}{l}\text { Minimum Shutdown } \\
\text { Boron Concentration } \\
(\mathrm{ppm})\end{array}$ & $\begin{array}{l}\text { Minimum Shutdown } \\
\text { Rod Configuration }\end{array}$ \\
\hline $\begin{array}{l}\text { Colc Measurement } \\
\text { Rod } 2 \text { at } 40^{\prime \prime} \\
\text { Rod } 4 \text { at } 26.14^{\prime \prime} \\
\text { Rods } 1,3,5 \text { and } 6 \\
\text { at } 0^{\prime \prime}\end{array}$ & 1516 & -9.8 & +163 & 1679 & $27.3^{\prime \prime}$ on 1 and 6 \\
\hline $\begin{array}{l}\text { Hot Measurement } \\
\text { Rod } 2 \text { at } 40 " \\
\text { Rod } 5 \text { at } 38.46^{\prime \prime} \\
\text { Rod } 1,3,4 \text { and } 6 \\
\text { at } 0 " \text { " }\end{array}$ & 1040 & $\begin{array}{c}-29.8 \text { on } \\
\text { xy Plotter } \\
-26.5 \text { on } L \\
\text { and } N \text { Recorder }\end{array}$ & -157 & 883 & $\begin{array}{l}19.5^{\prime \prime} \text { on } 1 \text { and } 6 \\
22.7^{\prime \prime} \text { on } 1 \text { and } 6\end{array}$ \\
\hline
\end{tabular}


2 percent shutdown. The last column gives the rod configuration that insures 2 percent shutdown at beginning-of-life if the rods are withdrawn from the all inserted configuration in a normal withdrawal sequence. For example, in the cold configuration, the reactor is 2 percent shutdown if it does not go critical with rods 1 and 6 withdrawn to $27.3^{\prime \prime}$ after rods 3 and 4 are completely removed (rods 2 and 5 in.). Normal control rod withdrawal sequence is: (1) rods 3 and 4 as a bank, (2) rods 1 and 6 as a bank, (3) rod 5 and (4) rod 2.

\subsection{Reactivity Measurements at Power}

\subsubsection{Rod Worth Measurements}

Upon completion of the BOL zero power testing, elevated power testing began. Rod worths were measured at 17 MWt in the same manner as the zero power rod worth measurements described in Section 3.2.2. Differential and integral rod worth curves are given for rod 2 (with all other rods withdrawn) and rod 5 (with rod 2 inserted) in Figures 3.22 and 3.23, respectively. Both worth curves are the result of a single measurement with data taken during rod 2 withdrawal (boron addition) and for rod 5 insertion (boron dilution). Delayed neutron characteristics used in the reactivity computer are listed below (Table 3.9).

TABLE 3.9

$B_{\text {eff }}$ FOR SEVERAL CONTROL ROD CONFIGURATIONS
A $\perp$ rods out
0.0045212
Rod 2 moving
0.0046072
Rod 2 in
0.0046932
Rod 5 moving
0.0047791
Rod 2 and 5 in
0.0048650 


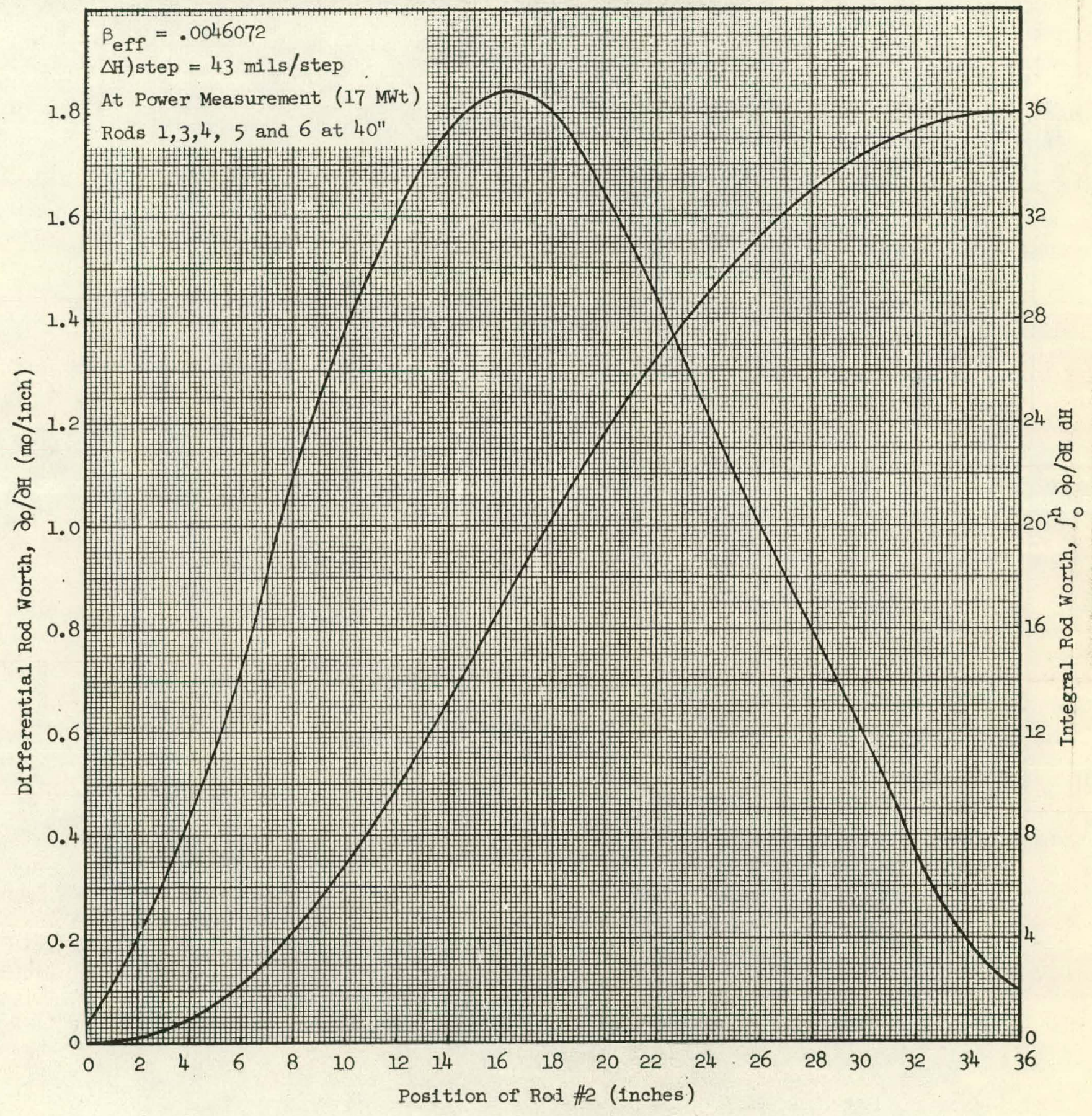

Figure 3.22. Saxton Core II Control Rod 2 - Differential and Integral Worths (Hot, at Power) 


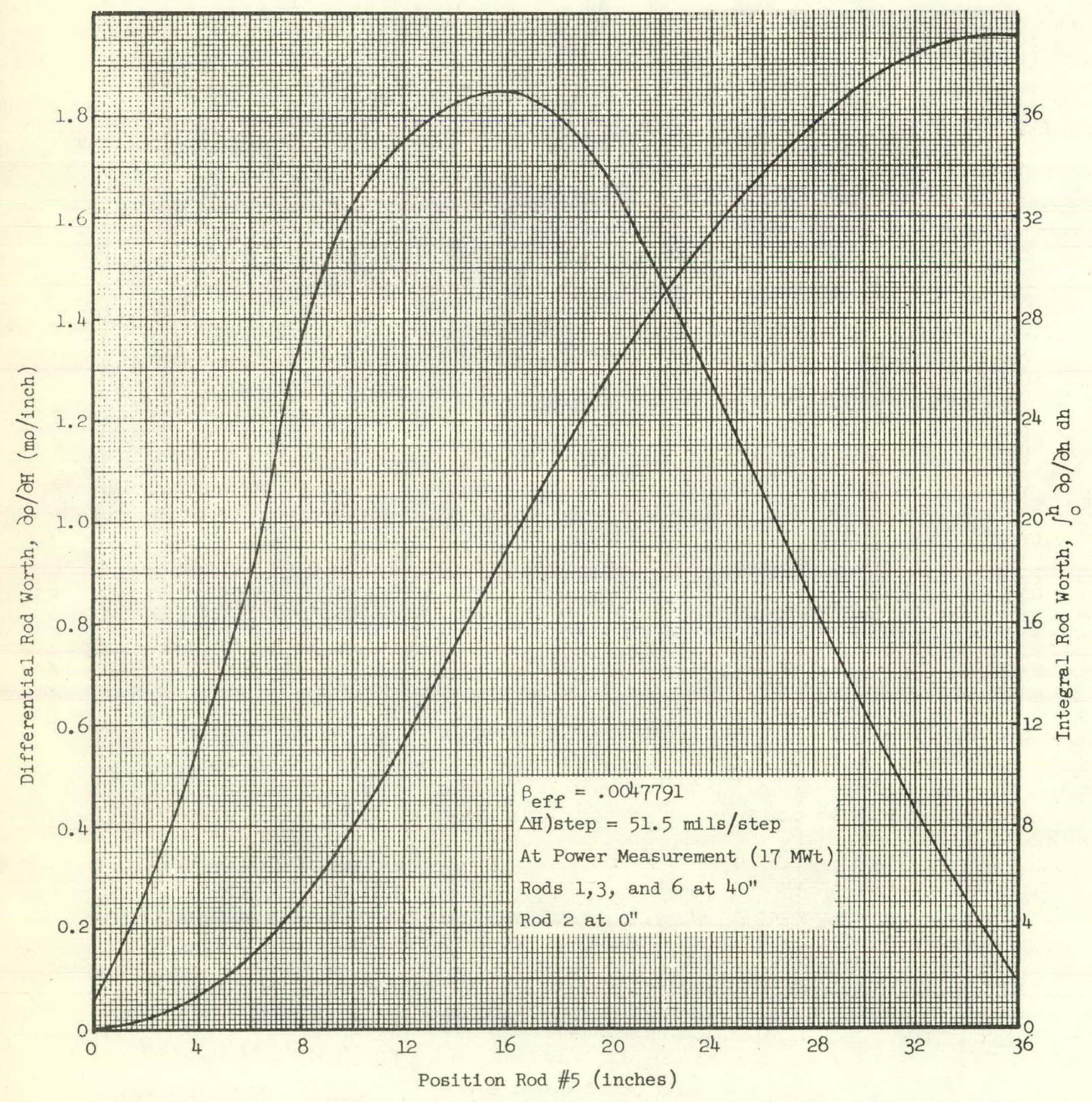

Figure 3.23. Saxton Core II Control Rod 5 - Differential and

Integral Worths (Rod 2 at $0^{\prime \prime}$ - Hot at Power) 


\subsubsection{Differential Boron Worth Measurements}

Boron worth data were accumulated while gathering rod worth measurements by concurrently taking boron samples. The resulting differential boron worths are plotted versus boron concentrations in Figure 3.24. There is a great deal of scatter in the data, but some trend toward higher worth while decreasing boron is shown. In addition to the above measurements at beginning-of-life, (BOL) a series of substitution measurements were made at $3716 \mathrm{MWD} / \mathrm{MTM}$ in which boron worths were determined from rod/boron and boron/temperature interchanger. Though these are in a different boron range, they agree well with the assumed best line extrapolated from the BOL data.

\subsubsection{Power Coefficient Measurements}

During power operations, numerous measurements of the power coefficient were made at different power levels. Measurements relating the power defect to computer measured reactivity were carried out over the entire power range up to $\sim 20 \mathrm{MW}$. The results of these measurements are shown in Figure 3.25 . The only power coefficient measurement made subsequent to this was at end-of-life (10,490 MWD/MIM). On the figure, this measurement is shown to be less negative than the equivalent BOL measurement. This is thought to be because of the higher fuel temperatures predicted by thermal models for higher burnup.

\subsubsection{Moderator Temperature Coefficient Measurements}

The most extensive set of moderator temperature coefficient measurements were made during the substitution measurements at $5200 \mathrm{MWD} / \mathrm{MTM}$. These values were inferred from temperature/rod and temperature/boron exchanges and previously measured rod worths. The extrapolation of the measurement agrees well with other temperature coefficient measurements done with the reactivity computer at higher and lower boron. The data for the above measurements is given in Figure 3.26, with a proposed straight line through the data points. The results of the substitutional tests using small boron dilutions have shown that reliable data, consistent jnternally over a range of interrelated measurements and extcrnally in terms of best valnes derived from other sources, can be obtained. The reactivity data necessary for operation of the plant 


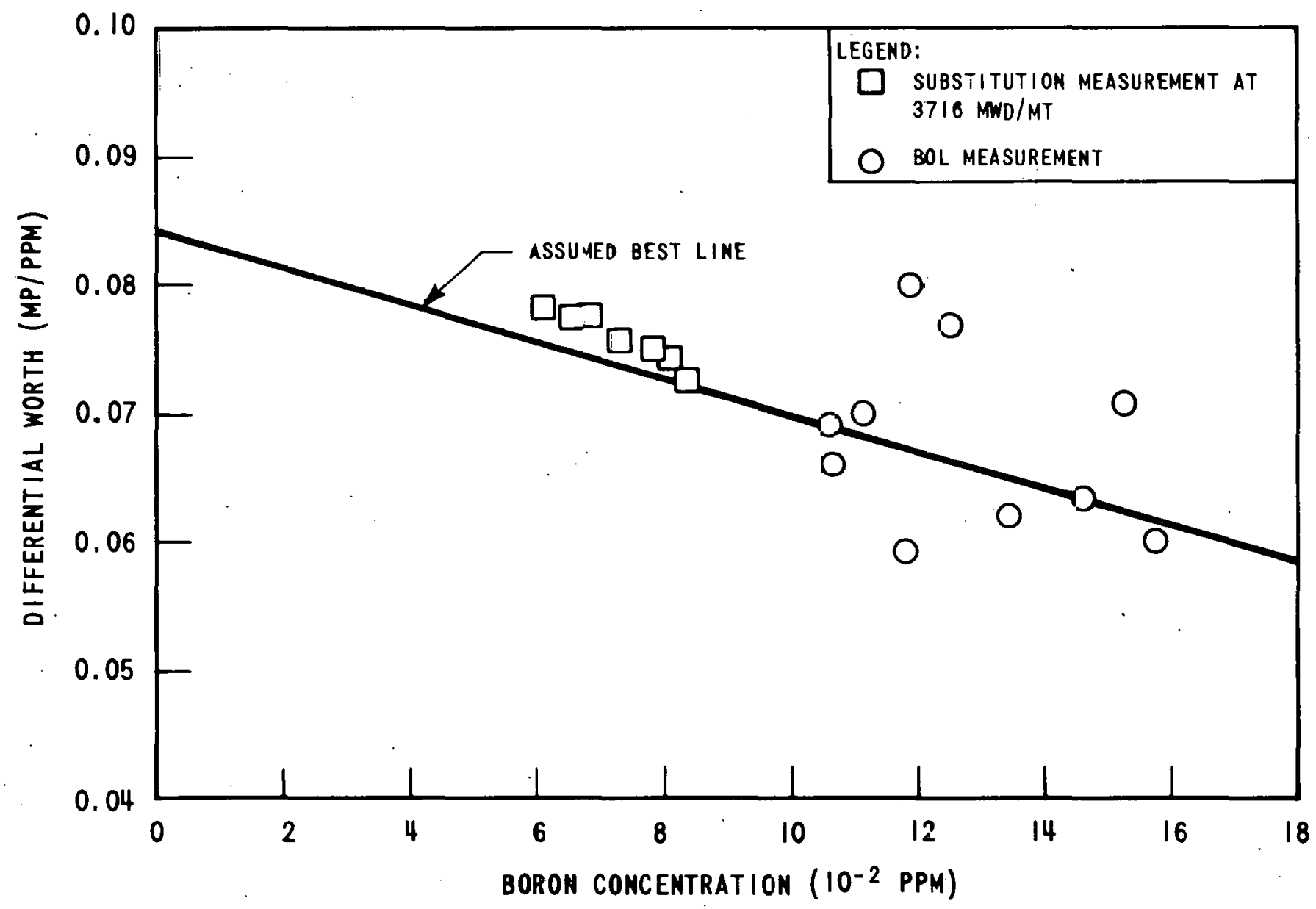

Figure 3. 24. Sax Core II Differential Boron Worth versus Boron Concentratior 


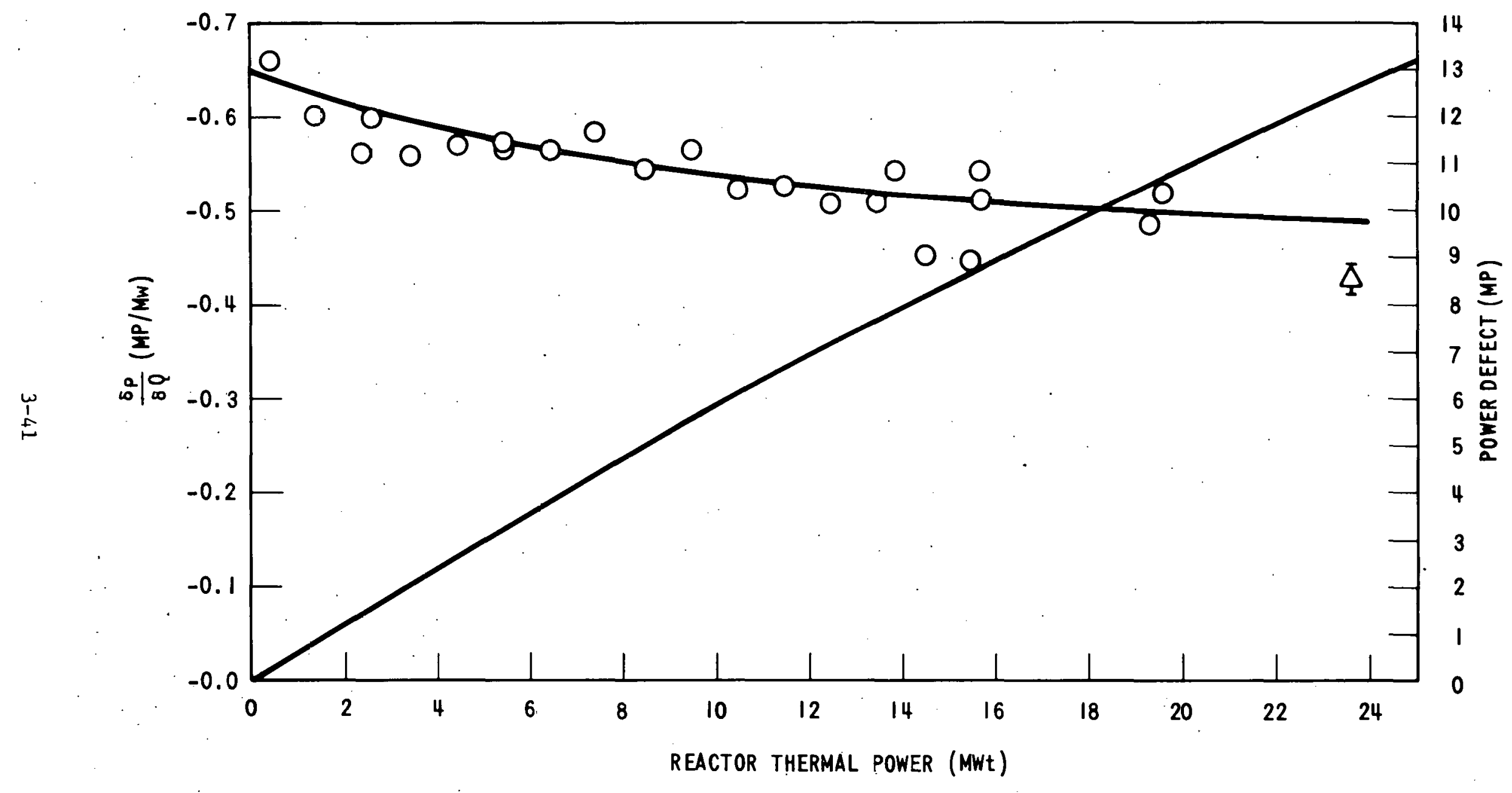

Figure 3.25. Saxton Core II Power Coefficient 


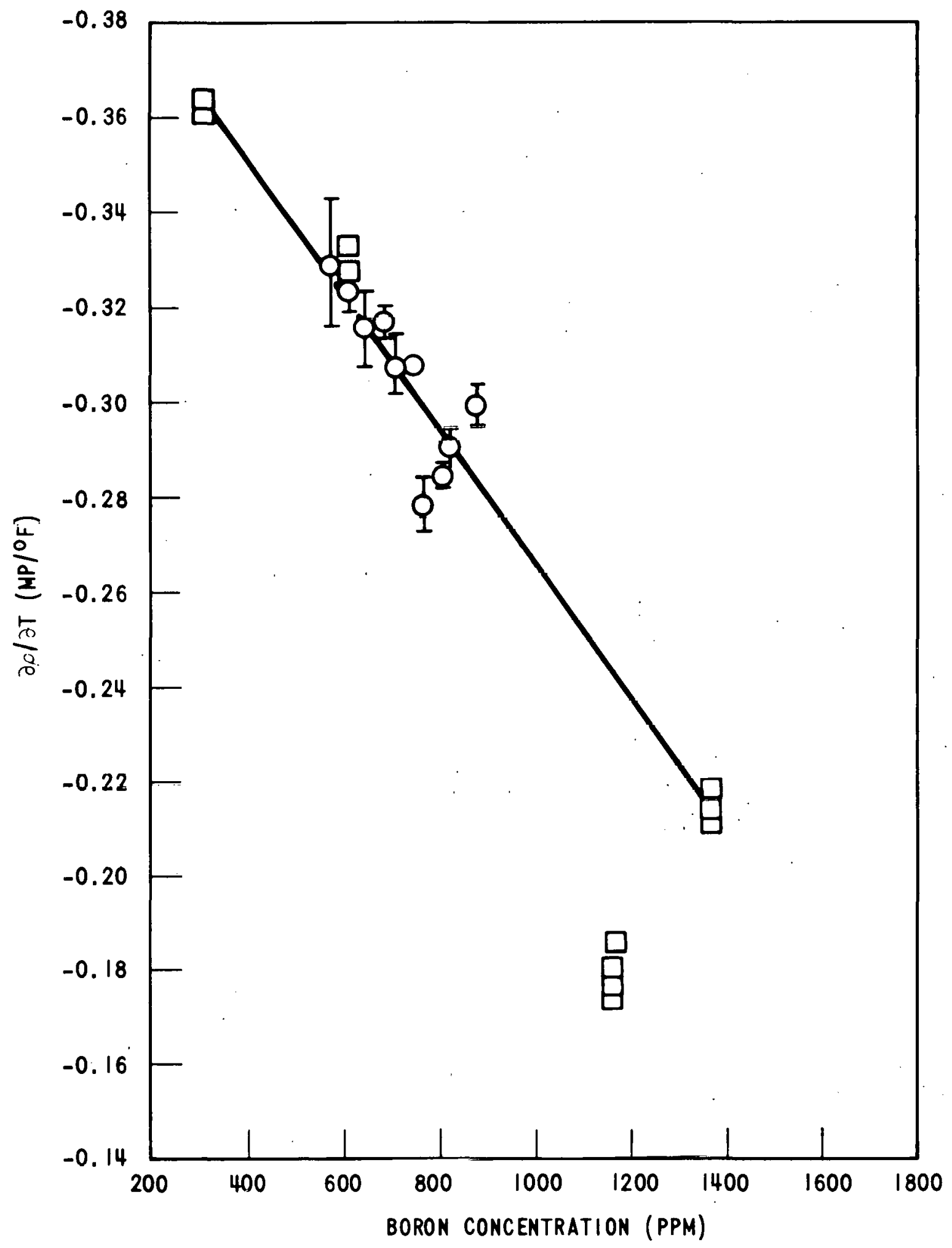

Figure 3.26. Moderator Temperature Coefficient versus Boron (Rod 2 Muving 30-18 Inches) 
can be secured with relatively little effort and virtually no interference with normal reactor operation at full power. These measurements have proven to be some of the most reliable and informative measurements made during Core II.

\subsection{5 pH Reactivity Effect}

On numerous occasions during Core II life, the reactivity effect associated with a change in the main coolant $\mathrm{pH}$ was measured. This was done at power by compensating any reactivity change with moderator temperature and converting it to a reactivity by use of the appropriate temperature coefficient. The data from the $\mathrm{pH}$ measurements is tabulated in Table 3.10 and the $\mathrm{pH}$ reactivity coefficient versus hot $\mathrm{pH}$ is given in Figure 3.27 . A measurement in which the main coolant $\mathrm{pH}$ was changed at zero power showed no measureable change in reactivity. 
TABLE 3.10

SAXTON CORE II PH COEFFICIENTS

\begin{tabular}{|l|l|l|l|l|l|l|}
\hline Date & $\begin{array}{l}\mathrm{pH} \\
\text { Start }\end{array}$ & $\begin{array}{l}\mathrm{pH} \\
\text { Finish }\end{array}$ & $\begin{array}{l}\Delta \mathrm{pH} \\
\text { Units }\end{array}$ & $\begin{array}{l}\Delta \rho \\
(\mathrm{m} \rho)\end{array}$ & $\begin{array}{l}\Delta \mu / \Delta \mathrm{pH} \\
\text { (mo/pH } \\
\text { Unit) }\end{array}$ & $\begin{array}{l}\mathrm{pH} \\
\text { Average }\end{array}$ \\
\hline U5-U4-66 & 7.07 & 5.48 & 1.59 & 2.50 & 1.57 & 6.27 \\
$06-16-66$ & 7.12 & 5.48 & 1.64 & 1.94 & 1.18 & 6.30 \\
$09-08-66$ & 6.16 & 5.16 & .70 & 1.23 & 1.76 & 5.81 \\
$11-29-67$ & 5.61 & 7.32 & 1.71 & 1.31 & 0.77 & 6.47 \\
$12-08-67$ & 7.32 & 5.61 & 1.71 & 1.13 & 0.66 & 6.47 \\
$12-14-67$ & 5.60 & 7.40 & 1.80 & 1.16 & 0.64 & 6.50 \\
$02-05-68$ & 5.57 & 7.38 & 1.81 & 1.83 & 1.01 & 6.48 \\
$02-09-68$ & 7.40 & 5.60 & 1.80 & 1.55 & 0.86 & 6.50 \\
\hline
\end{tabular}




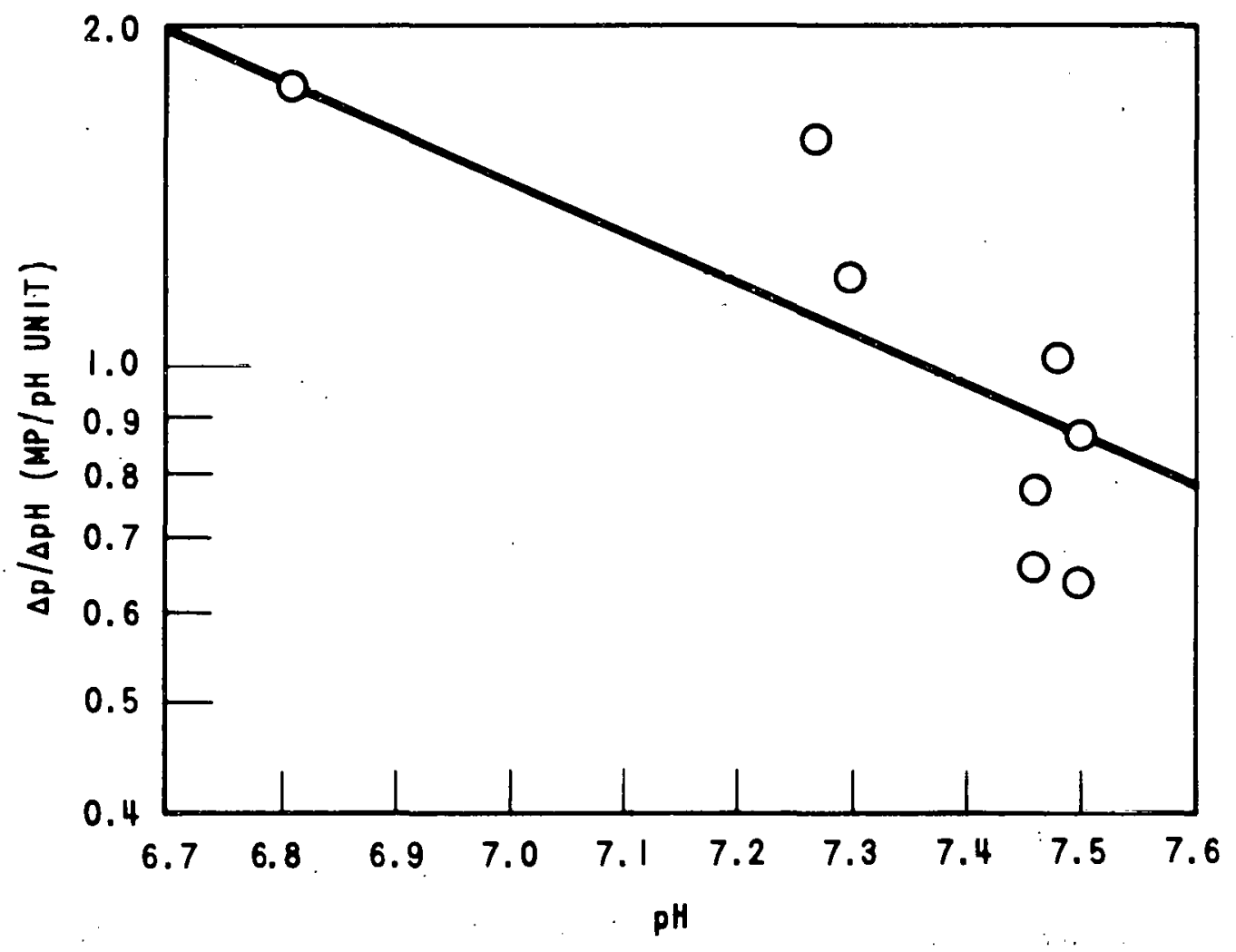

Figure 3.27. Sexton Core II pH Coefficient 
SECTION 4

CORE DEPLETION ANALYSIS

A significant portion of Saxton plutonium follow effort was devoted to continuous evaluation of the depletion characteristics of Core II. The effort entailed both an experimental evaluation of depletion and burnup and a continuous review and evaluation of the analytical methods used in predicting power and crịtical boron.

\subsection{Experimental Core Burnup Follow}

Core depletion is conveniently expressed in terms of the all rods out critical boron concentration as a function of operation. A running plot of the main coolant boron concentration versus burnup was maintained during Saxton Core II. This plot of boron concentration at reference conditions of $23.5 \mathrm{MWt}, 510^{\circ} \mathrm{F}$, and all control rods withdrawn is given in Figure 4.1. The assembly average burnup for the core at $4188 \mathrm{MWD} / \mathrm{MTM}$ and end-of-1ife (10,590 MWD/MTM) determined from PDQ- 3 nuclear constants and measurements are presented Tables 4.1 and 4. 2 .

\subsection{Analytic Core Burnup Fulluw}

Throughout Core II life, the analytical nuclear parameters necessary in making incore power distribution measurements were generated using the LEOPARD-BUBBLEPDQ-3 sequence. These calculations were made periodically to take into account the effect of burnup nn power distribution. The calculations were made after experimental results were available from power operation and the power history of each fuel assembly was known from flux wire measurements. The measured irradiation history was used to determine group constants in the BUBBLE code by interpolation from a previously established boron concentration-irradiation matrix. These constants were then used in PDQ calculations in $x-y$ geometry. 


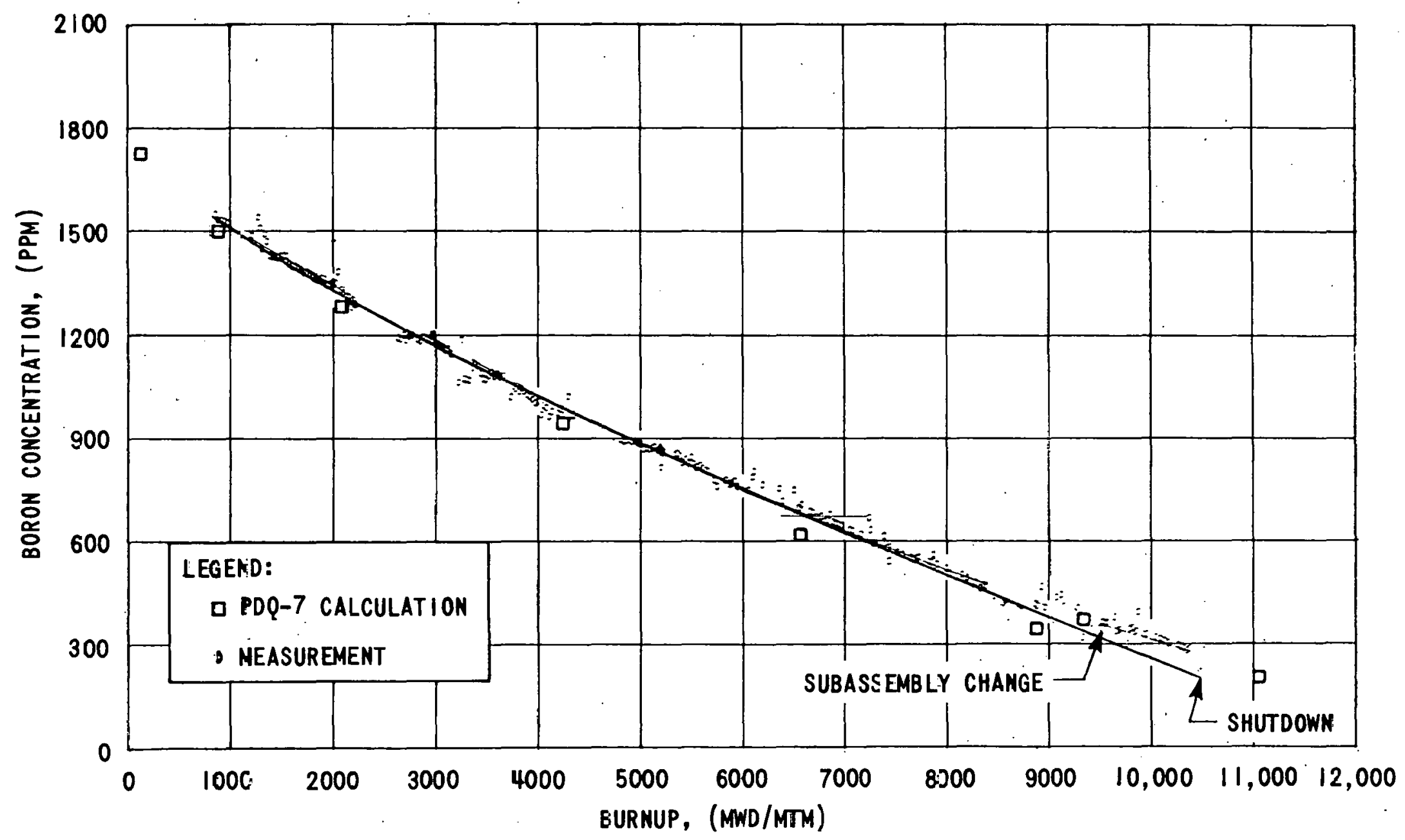

Figure 4.1. Comparison of Calculated and Measured Critical Boron Concentration as a Function of Burncp (Saxton Core II.) 
TABLE 4.1

DEPLETION AFTER 4188 MWD/MTM CORE OPERATION

\begin{tabular}{|c|c|c|c|c|}
\hline $\begin{array}{c}\text { Core } \\
\text { Location }\end{array}$ & Assembly & $\begin{array}{l}\text { Number } \\
\text { of Rods }\end{array}$ & $\begin{array}{l}\text { Initial } \\
\text { MTM }\end{array}$ & MWD/MTM \\
\hline $\begin{array}{l}1 C \\
1 D \\
1 E^{*}\end{array}$ & $\begin{array}{l}503-10-6 \\
503-1-7 \\
503-7-1\end{array}$ & $\begin{array}{l}80 \\
71 \\
58\end{array}$ & $\begin{array}{l}.0426 \\
.03781 \\
.03089\end{array}$ & $\begin{array}{l}2504 \\
3059 \\
2606\end{array}$ \\
\hline $\begin{array}{l}2 B \\
2 C \\
2 D \\
2 E \\
2 F\end{array}$ & $\begin{array}{l}503-10-2 \\
503-12-2 \\
503-12-5 \\
503-12-4 \\
503-10-3\end{array}$ & $\begin{array}{l}72 \\
72 \\
72 \\
80 \\
81\end{array}$ & $\begin{array}{r}.03834 \\
.03469 \\
.03396 \\
.03854 \\
.04313\end{array}$ & $\begin{array}{l}2439 \\
5113 \\
6631 \\
5572 \\
2486\end{array}$ \\
\hline $\begin{array}{l}3 B \\
3 C \\
3 D \\
3 E \\
3 F\end{array}$ & $\begin{array}{l}503-2-3 \\
503-12-3 \\
503-13-1 \\
503-12-6 \\
503-1-19\end{array}$ & $\begin{array}{l}70 \\
70 \\
61 \\
71 \\
71 .\end{array}$ & $\begin{array}{l}.03728 \\
.03471 \\
.02948 \\
.03421 \\
.03781\end{array}$ & $\begin{array}{l}3212 \\
6758 \\
7929 \\
6766 \\
3074\end{array}$ \\
\hline $\begin{array}{l}4 B \\
4 C \\
4 D \\
4 E \\
4 F\end{array}$ & $\begin{array}{l}503-10-4 \\
503-12-7 \\
503-12-1 \\
503-12-8 \\
503-1-11\end{array}$ & $\begin{array}{l}80 \\
71 \\
70 \\
72 \\
70\end{array}$ & $\begin{array}{l}.04260 \\
.03421 \\
.03353 \\
.03469 \\
.03728\end{array}$ & $\begin{array}{l}2731 \\
5464 \\
6840 \\
5307 \\
2739\end{array}$ \\
\hline $\begin{array}{l}5 C \\
5 D \\
5 E\end{array}$ & $\begin{array}{l}503-11-2 \\
503-1-10 \\
503-10-5\end{array}$ & $\begin{array}{l}70 \\
80 \\
72\end{array}$ & $\begin{array}{l}.03728 \\
.0426 \\
.03834\end{array}$ & $\begin{array}{l}2846 \\
3366 \\
2437\end{array}$ \\
\hline Followers & & & & \\
\hline $\begin{array}{l}1^{*} \\
2^{*} \\
3^{*} \\
4^{*} \\
5^{*} \\
6^{*}\end{array}$ & $\begin{array}{l}505-2 \\
505-3 \\
505-4 \\
505-5\end{array}$ & $\begin{array}{l}18 \\
18 \\
18 \\
18 \\
18 \\
18\end{array}$ & $\begin{array}{l}.009216 \\
.009216 \\
.009216 \\
.009216 \\
.009216 \\
.009216\end{array}$ & $\begin{array}{l}4074 \\
4835 \\
4297 \\
4244 \\
5428 \\
4540\end{array}$ \\
\hline
\end{tabular}

*Burnup not including Saxton Core I Burnup 
TABLE 4.2

DEPLETION AFTER 10590 MWD/MTM CORE OPERATION

\begin{tabular}{|c|c|c|c|c|}
\hline $\begin{array}{c}\text { Core } \\
\text { Location }\end{array}$ & Assembly & $\begin{array}{l}\text { Number } \\
\text { of Rods }\end{array}$ & $\begin{array}{l}\text { Initial } \\
\text { MTM }\end{array}$ & MWD/MTM \\
\hline $\begin{array}{l}1 C \\
1 D \\
1 E^{*}\end{array}$ & $\begin{array}{l}503-10-6 \\
503-1-7 \\
503-7-1\end{array}$ & $\begin{array}{l}80 \\
71 \\
58\end{array}$ & $\begin{array}{l}.0426 \\
.03781 \\
.03089\end{array}$ & $\begin{array}{l}6666 \\
7710 \\
6767\end{array}$ \\
\hline $\begin{array}{l}2 B \\
2 C \\
2 D \\
2 E \\
2 F\end{array}$ & $\begin{array}{l}503-10-2 \\
503-12-2 \\
503-12 \quad 5 \\
503-12-4 \\
503-10-3\end{array}$ & $\begin{array}{l}72 \\
72 \\
72 \\
80 \\
81\end{array}$ & $\begin{array}{r}.03834 \\
.03469 \\
.03396 \\
.03854 \\
.04313\end{array}$ & $\begin{array}{r}6470 \\
12911 \\
16052 \\
13492 \\
6592\end{array}$ \\
\hline $\begin{array}{l}3 B \\
3 C \\
3 D \\
3 E \\
3 F\end{array}$ & $\begin{array}{l}503-2-3 \\
503-12-3 \\
503-13-1 \\
503-12-6 \\
503-1-19\end{array}$ & $\begin{array}{l}70 \\
70 \\
61 \\
71 \\
71\end{array}$ & $\begin{array}{l}.03728 \\
.03471 \\
.02948 \\
.03421 \\
.03781\end{array}$ & $\begin{array}{r}8247 \\
15909 \\
19704 \\
16242 \\
8165\end{array}$ \\
\hline $\begin{array}{l}4 B \\
4 C \\
4 D \\
4 E \\
4 F\end{array}$ & $\begin{array}{l}503-10-4 \\
503-12-7 \\
503-12-1 \\
503 \cdots 12-8 \\
503-1-11\end{array}$ & $\begin{array}{l}80 \\
71 \\
70 \\
72 \\
70\end{array}$ & $\begin{array}{l}.04260 \\
.03421 \\
.03353 \\
.03469 \\
.03728\end{array}$ & $\begin{array}{r}7037 \\
14259 \\
16792 \\
13631 \\
7289\end{array}$ \\
\hline $\begin{array}{l}5 \mathrm{C} \\
5 \mathrm{D} \\
5 \mathrm{E}\end{array}$ & $\begin{array}{l}503-11-2 \\
503-1-10 \\
503-10-5\end{array}$ & $\begin{array}{l}70 \\
80 \\
72\end{array}$ & $\begin{array}{l}.03728 \\
.0426 \\
.03834\end{array}$ & $\begin{array}{l}7934 \\
9342 \\
6901\end{array}$ \\
\hline Followers & & & & \\
\hline $\begin{array}{l}1 * \\
2 * \\
3 * \\
4 * \\
5 * \\
6 *\end{array}$ & $\begin{array}{l}50.5-2 \\
505-3 \\
505-4 \\
505-5\end{array}$ & $\begin{array}{l}18 \\
18 \\
18 \\
18 \\
18 \\
18\end{array}$ & $\begin{array}{l}.009327 \\
.009327 \\
.009327 \\
.009327 \\
.009327 \\
.009327\end{array}$ & $\begin{array}{r}10115 \\
7998 \\
10798 \\
10220 \\
13790 \\
11268\end{array}$ \\
\hline
\end{tabular}

*Burnup not including Saxton Core I Burnup 
The agreement between measured and calculation in general, was good (see Section 5.0). However, as shown in Figure 4.2, at approximately $5000 \mathrm{EFPH}$, just critical boron predictions using this method start to deviate from measurements. Because of this, a study was made to determine possible discrepancies in the analysis. Those identified were: failure to include the effects of nonunfform axial depletion in PDQ-xy calculations; and differences in plutonium fission product cross sections from those included in LEOPARD and, thus, inherently incorporated in the BUBBLE-PDQ03 analysis sequence. :loreover, due "to the average assembly representation in the BUBBLE-PDQ03, it is impossible to determine local burnup and power effects correctly. In LEOPARD, all fission products except Xe-135 and $\mathrm{Sm}-149$ are lumped together and treated as a single nuclide whose number density equals the integrated fission density. The cross sections $\sigma_{a 3}$ and $\sigma_{a 4}$ (which are for the resonance and thermal spectrum, respectively); used for lumped fission products, vary with burnup and are represented in LEOPARD by polynominals which are fitted to the results of a CINDER calculation for a $3 \mathrm{w} / \mathrm{o}$ U-235 enrichment and a water/U ratio of 3.0 . This treatment is inadequate for plutonium-fueled cores because of the difference in fission product yields between uranium and plutonium fissions and the different neutron flux levels.

To investigate the effect of the LEOPARD representation on the analyses, CINDER calculations were carried out for the $6.6 \mathrm{w} / \mathrm{o} \mathrm{PuO}_{2}-\mathrm{UO}_{2}$ and the $5.7 \mathrm{w} / \mathrm{o} \mathrm{UO}_{2}$ fuels at the Saxton pitch. The lumped fission product cross sections for the uranium fuel are shuwl in Figures 4.3 and 1.4 . As show in these figures, the change in enrichment and $W / U$ compensate, so that there is little difference from the LEOPARD-calculated cross sections for the uranium region. The lumped fission products cross sections for the plutonium fuel as calculated in CINDER are shown in Figures 4.5. and 4.6. Use of the CINDER fission products cross sections in place of the LEOPARD fission products cross section would reduce the PDQ-3 calculated life by approximately 250 hours. Sinre the effects of non-uniform axial depletion are not considered in the two dimensional calculations, a correction for the reactivity difference between uniform and non-uniform axial depletion of the core is applied. 


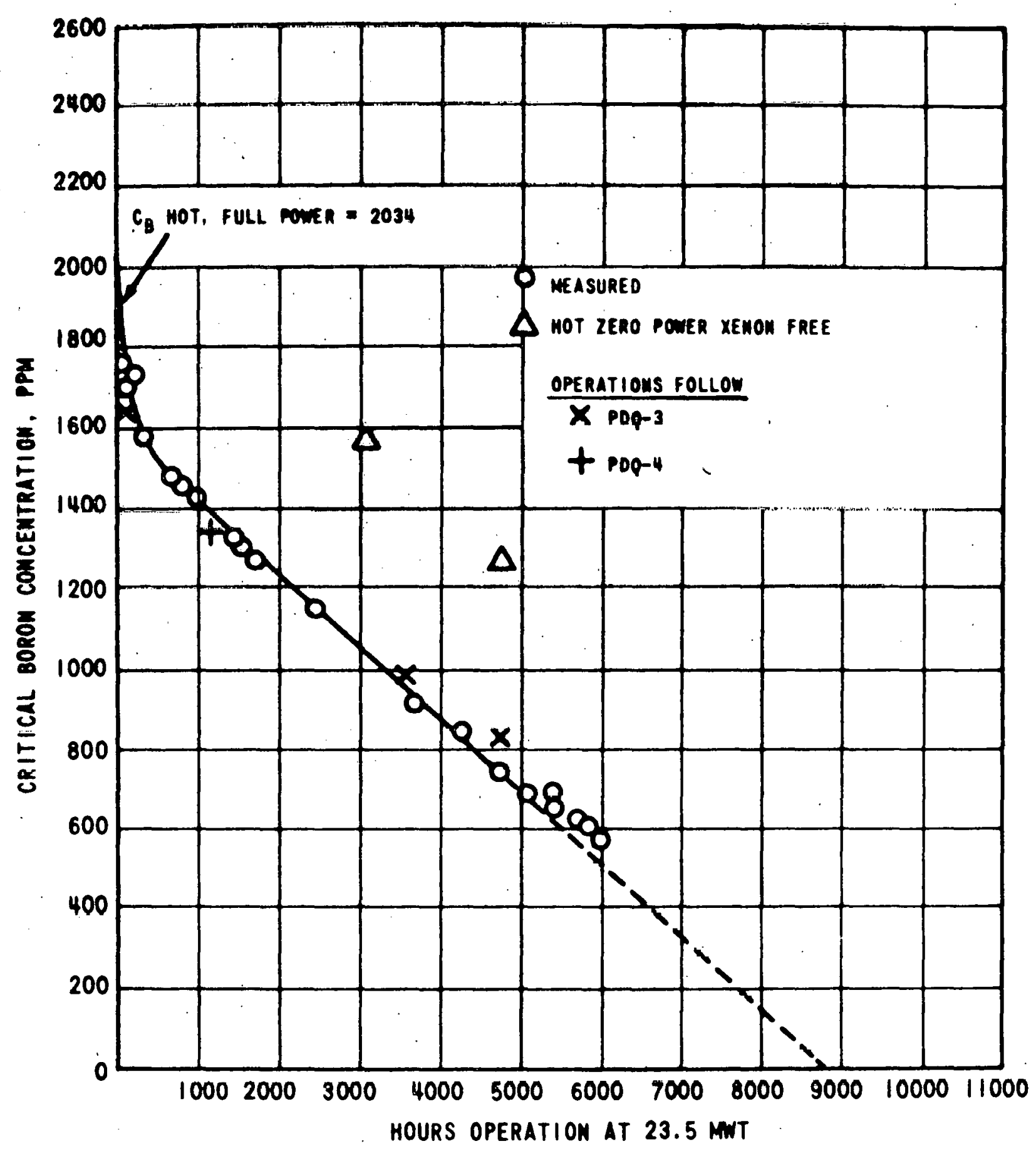

Figure 4.2. A Comparison of the Calculated and Measured Critical Boron Concentration as a Function of Hours Operation for Saxton Core II 


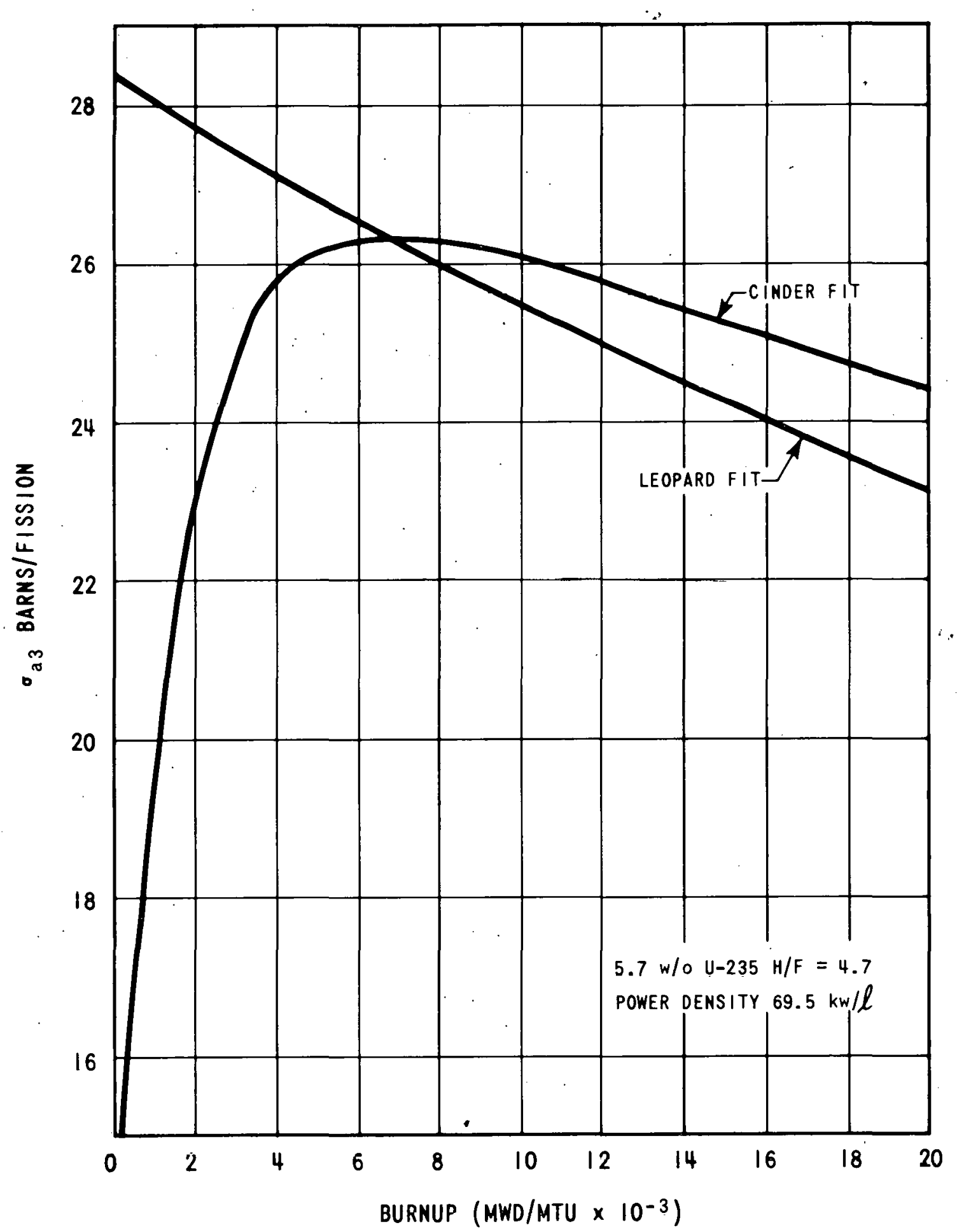

Figure 4-3. Comparison of 5.7\% Enriched $\mathrm{UO}_{2}$ Resonance Fission Product Cross Section from CINDER with Fit from LEOPARD 


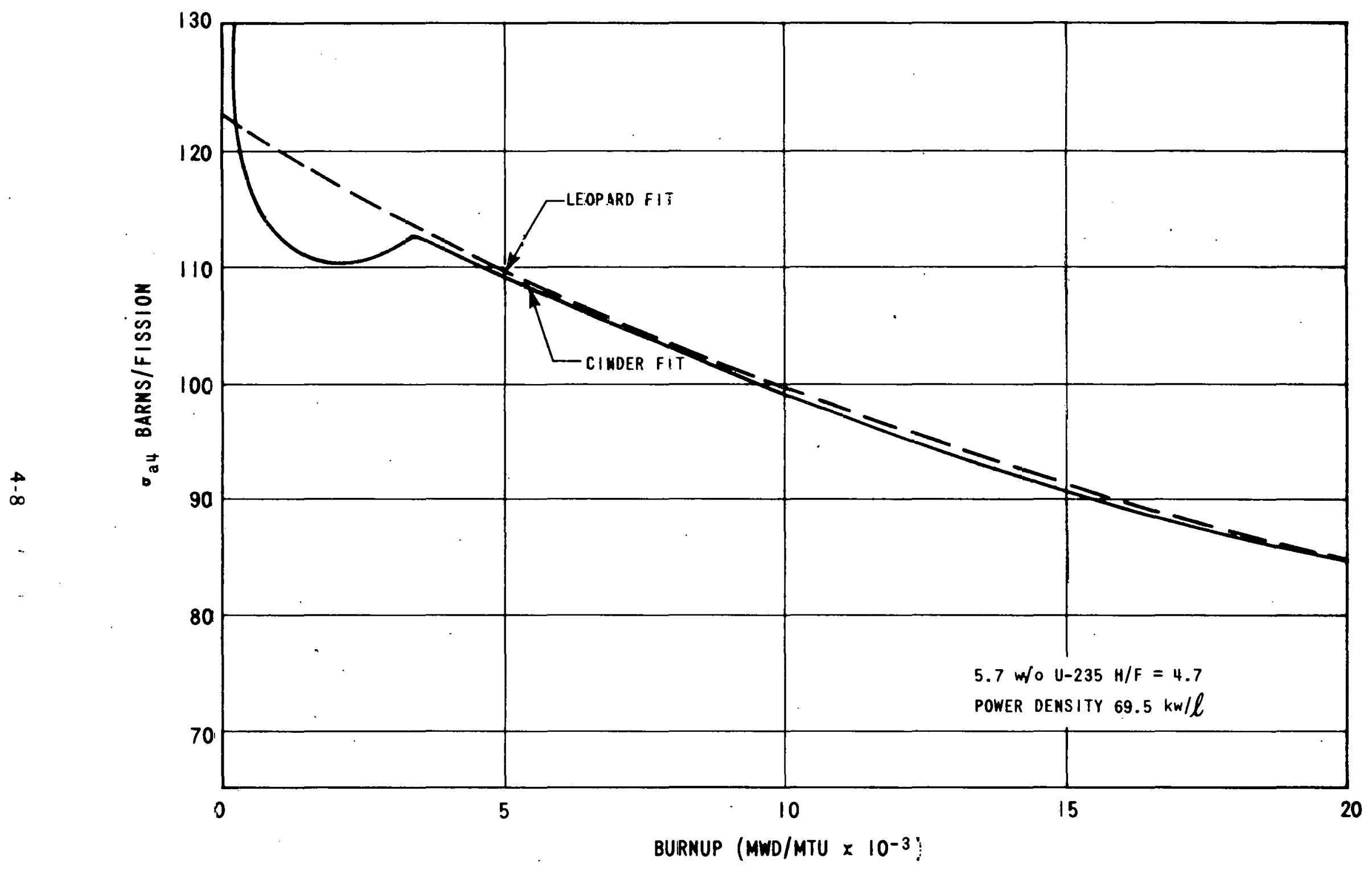

Fi zure 4-4. Comparisan of 5.7\% Enriched UO, Thernal Fission Product Cross Section from CINDER wi th ${ }^{2}$ Fit from LEOPARD 


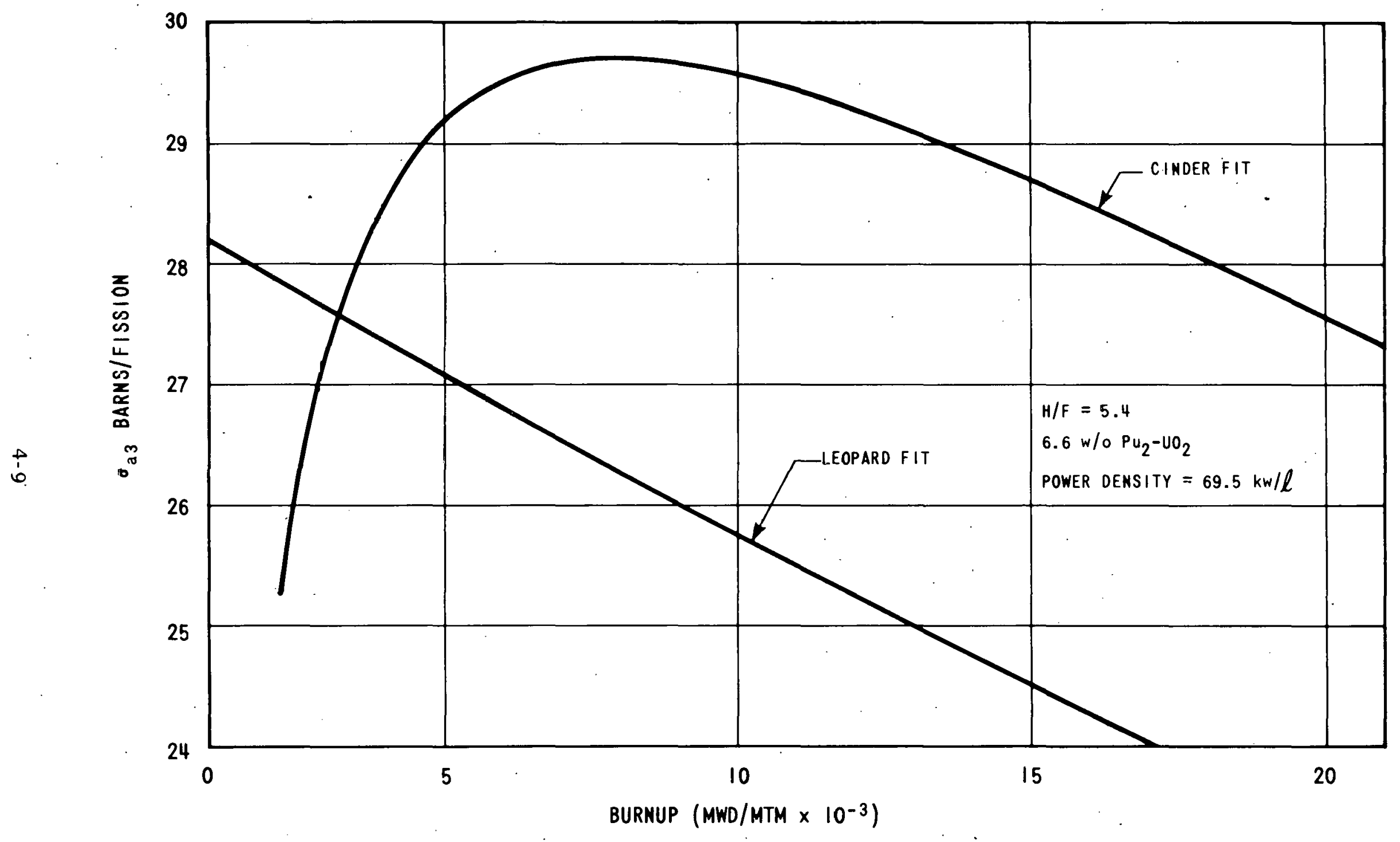

Figure 4-5. Comparison of $\mathrm{PuO}_{2}$ Resonance Fission Product Cross Section from CINDER with Fit from LEOPARD 


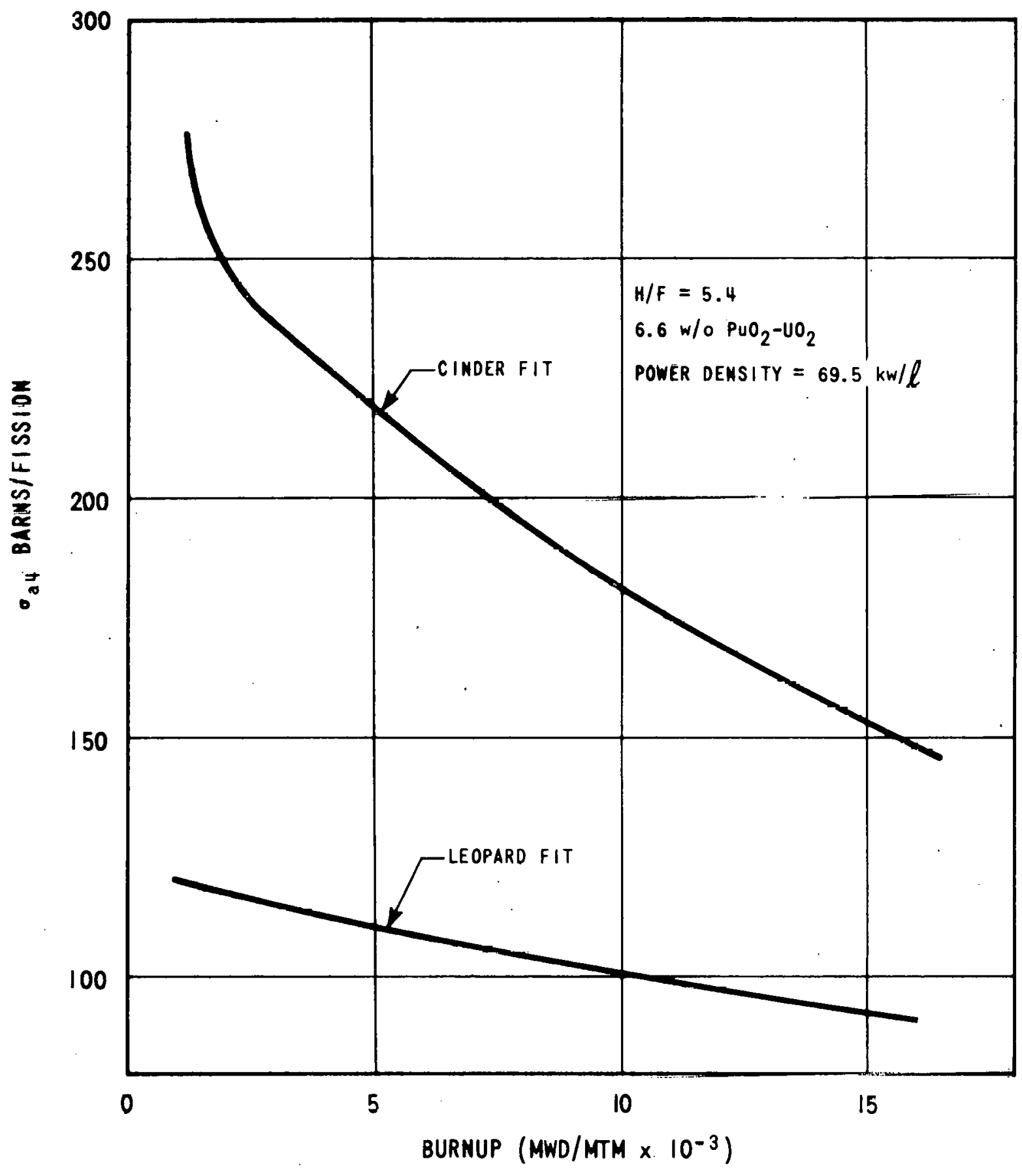

Figure 4-6. Comparison of $\mathrm{PuO}_{2}$ Thermal Fission Product Cross Section from CINDER with Fit from LEOPARD 
The axial depletion was determined with the aid of a one-dimensional calculation which considers pointwise effects of burnup, water density, and xenon. The reactivity difference determined for the $\mathrm{PuO}_{2}-\mathrm{UO}_{2}$ and the $\mathrm{UO}_{2}$ fuels is shown in Figure.4.7.

In addition to the above items, a revised diffusion theory depletion analysis that would follow local burnup and power effects more accurately was performed. The revised analysis was carried out with a LEOPARD-PDQ-7-HARMONY sequence. In this sequence, the diffusion theory group constants were generated using improved plutonium yields for iodine, xenon, samarium and promethium. The required LEOPARD calculations were made using the actual operating conditions of the core which included a slightly lower moderator temperature than that specified in the original design operating conditions. New fuel temperatures for the $\mathrm{PuO}_{2}-\mathrm{UO}_{2}$ were generated with the latest thermal calculation models. A new homogenization method to represent the control rod followers was adopted. A bias of $0.9 \% \Delta \mathrm{K}_{\text {eff }}$, determined from the Saxton plutonium criticals, was used in the $6.6 \mathrm{w} / \circ \mathrm{PuO}_{2}-\mathrm{UO}_{2}$. fuel. No bias was used for the $5.7 \mathrm{w} / \mathrm{O} \mathrm{UO}_{2}$ fuel..

In the PDQ-7-HARMONY sequence, burnup-dependent macroscopic diffusion theory group constants were input in the form of a burnup matrix. Power and accumulated burnup is computed at each point. The burnup at each point is then used to find new group constants from the burnup matrix. The boron concentration was changed separately.

Table 4.3 shows the time step sequences used in the depletion calculation. At the end of each time step, certain subassembly changes were made in the removable positions in locations $\mathrm{P}-3, \mathrm{~F}-4$, and $\mathrm{C}-5$. These were included explicitly in the calculations.

The calculated just-critical boron values are compared with measured values in Table 4.4. Subassembly changes made after the original calculations made it necessary to recompute. the final two time steps. Step VII. (a) represents a calculation corresponding to the core condition before the subassembly changes with Step VII (b) corresponding to the core condition after the change. The calculated effect on the critical boron requirement for the change was $+56 \mathrm{ppm}$, 


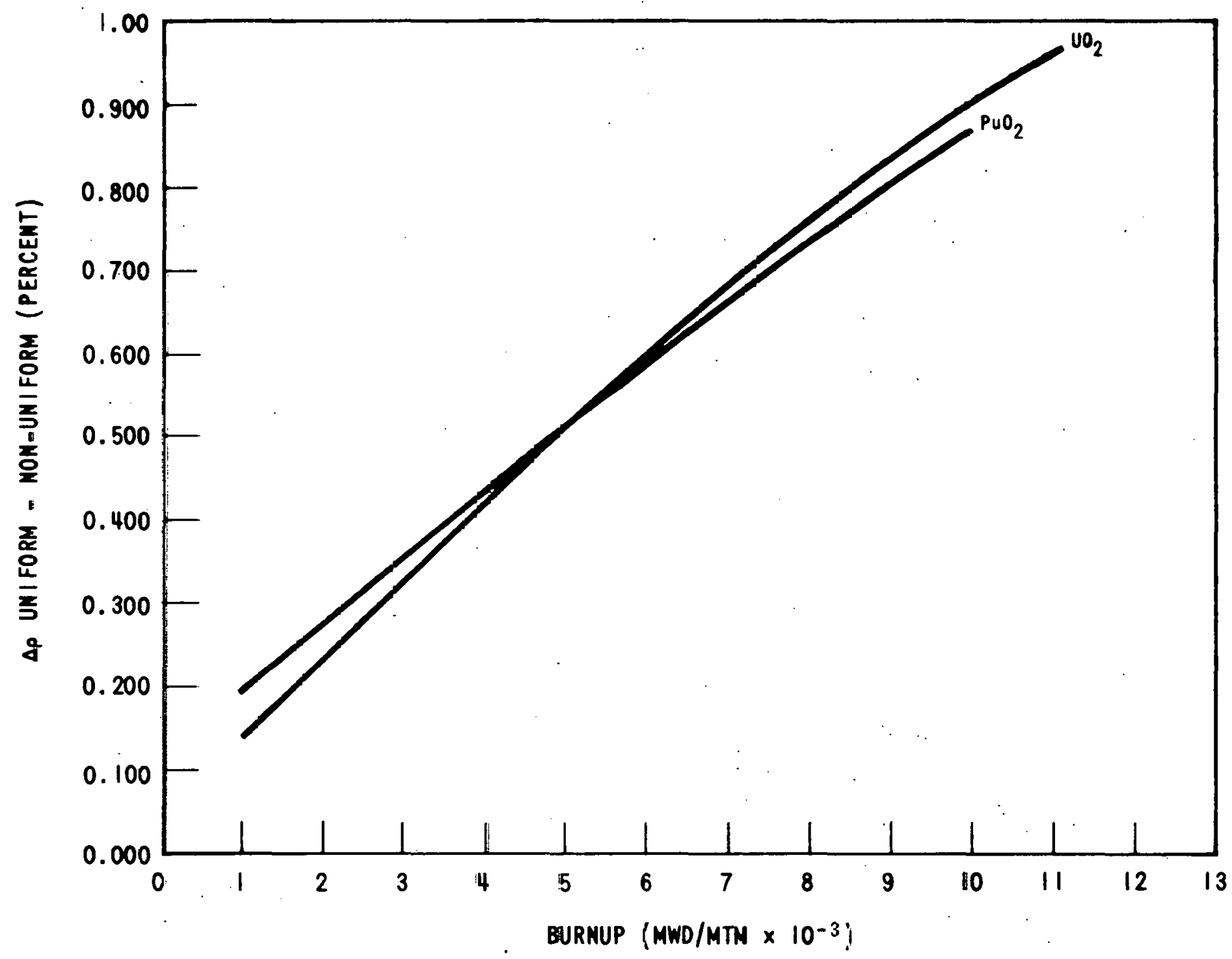

Figure 4-7. Reactivity Difference Between Uniform and Non-Uniform Depleticn - $6.6 \mathrm{w} / \mathrm{o} \mathrm{PuO}_{2}$ and $5.7 \mathrm{w} / \mathrm{o} \mathrm{WO}_{2}$ Fuel 
TABLE 4.3 .

PDQ-7 ANALYSIS SEQUENCE AND CORE CHANGES USED IN SAXTON CORE II DEPLETION STUDY

\begin{tabular}{|c|c|c|c|}
\hline $\begin{array}{c}\text { Time } \\
\text { Step }\end{array}$ & $\begin{array}{l}\text { Beginning } \\
\text { Time (hrs) }\end{array}$ & $\begin{array}{l}\text { Boron* } \\
(\mathrm{ppm})\end{array}$ & $\begin{array}{l}\text { Control Rod } \\
\text { Position }\end{array}$ \\
\hline I & 125.0 & 1550 & Al1 Rods Out \\
II & 125.0 & 1550 & Rod \#2 In \\
III & 800.0 & 1350 & All Rods Out \\
IV & 1810.0 & 1125 & All Rods Out \\
V & 3640.0 & 750 & All Rods Out \\
VI & 5640.0 & 400 & Al1 Rods Out \\
VII (a) & 7640.0 & 200 & All Rods Out \\
VII (b) & 7640.0 & 200 & All Rods Out \\
VIII & 9500.0 & 200 & All Rods Out \\
\hline
\end{tabular}

*Used in calculation. Not necessarily equal to critical boron shown in Table 4.4 . 
TABLE 4.4

COMPARISON OF CALCULATED AND MEASURED CRITICAL BORON CONCENTRATIONS AS A FUNCTION OF SAXTON CORE II OPERATION

\begin{tabular}{|c|c|c|c|c|}
\hline Time & EFPH @ & & & \\
Step & $23.5 \mathrm{MWt}$ & MWD/MTM & Analysis & Measurement \\
\hline I & 125.0 & 146.0 & 1724 & 1743 \\
III & 800.0 & 937.0 & 1507 & 1530 \\
IV & 1810.0 & 2120.0 & 1294 & 1319 \\
V & 3640.0 & 4265.0 & 960 & 997 \\
VI & 5640.0 & 6607.0 & 624 & 692 \\
VII (a) & 7640.0 & 8950.0 & 356 & 414 \\
VII (b) & 7640.0 & 8950.0 & 412 & - \\
VIII & 9500.0 & 11060.0 & 202 & 414 \\
\hline
\end{tabular}

(a) prior to subassembly change

(b) after subassembly change 
which is equivalent to an increase in system reactivity of $\simeq 0.4 \% \Delta$. The data is shown on the boron versus burnup curve (Figure 4.1); the good agreement is clearly evident. 


\section{SECTION 5}

POWER DISTRIBUTION MEASUREMENTS

At the beginning-of-life (BOL) and throughout the core life, numerous measurements were made of the power distribution in the reactor using the incore instrumentation. The flux maps were made at many different control rod positions and power levels with both flux wire and direct reading fission chambers.

The most extensive set of measurements were made at BOL. The maps at different rod positions were necessary to determine the adequacy of design calculations and to establish safe operating limits for the reactor. Hot channel factors and peak power levels, in kw/ft were obtained from an analysis of the flux map data and are given in Table 5.1. An engineering factor of 1.045 is included in values of $\mathrm{F}_{\mathrm{Q}}$ and peak $\mathrm{kw} / \mathrm{ft}$. No uncertainty factors have been applied to any of the numbers in the table. The locations of the peak rods are shown in Figure 5.1.

Additional Flux maps, along with the previous measurements, were used to determine the trend of hot channel factor with control rod position. Three curves from those measurements are reported here. Figure 5.2 illustrates the variation of the axial hot channel factor $\left(F_{Z}\right)$ as a function of control rod configuration for the three peak fuel rods. Figure 5.3 shows how the radial hot channel factor $\left(\mathrm{F}_{\Delta \mathrm{H}}^{\mathrm{N}}\right)$ varies with control rod position for the same three peak rods of Figure 5.2. The last figure, 5.4, shows how the total hot channel factor $\left(F_{q}^{N}=F_{Z} \times F_{\Delta H}^{N}\right)$ varies with control rod position for various peak rods. None of the figures has engineering factors included in the hot channel numbers. The rod identifications in these figures correspond to the hot channel locations shown in Figure 5.1 . 
TABLE 5.1

HOT CHANNEL FACTORS (ROD 2 INSERTED)

\begin{tabular}{|c|c|c|c|c|c|c|c|}
\hline $\begin{array}{l}\text { Control Rod } 5 \\
\text { Position } \\
\text { (inches withdrawn) }\end{array}$ & $\begin{array}{l}\text { Method of } \\
\text { Measurement }\end{array}$ & $\begin{array}{l}\text { Power Level } \\
\text { During } \\
\text { Measurement } \\
\text { (MW) }\end{array}$ & $F_{Z}$ & $\mathrm{~F}_{\Delta \mathrm{H}}^{\mathrm{N}}$ & $\mathrm{F}_{\mathrm{Q}^{*}}$ & $\begin{array}{l}\text { Peak } \\
\text { Power + } \\
\text { (KW/FT) }\end{array}$ & $\begin{array}{l}\text { Peak Rod } \\
\text { Position }\end{array}$ \\
\hline 15.65 & Wir $=S$ & 10 & $1.665^{\prime} \dot{4}$ & 1.8251 & 3.1770 & 15.153 & 103 \\
\hline 15.65 & DET & 10 & 1.7568 & $1.95 i 36$ & 3.5811 & 17.080 & 103 \\
\hline 18.48 & DET & 10.63 & 1.8130 & 1.5950 & 3.0238 & 14.408 & 90 \\
\hline 21.55 & Wires & 17 & 1.6658 & $1.71+7$ & 2.9848 & 14.209 & 90 \\
\hline 21.55 & DET & 16.9 & 1.6034 & 1.8529 & 3.1214 & 14.859 & 88 \\
\hline OUT & Wire & 17.5 & 1.3108 & 2.2239 & 3.0463 & 14.435 & 82 \\
\hline OUT & $\mathrm{DET}$ & 17.5 & 1.3566 & 2.0305 & 2.9494 & 13.973 & 85 \\
\hline 28.55 & Wires & 17 & 1.4864 & 1.9553 & 3.0371 & 14.429 & 90 \\
\hline 28.55 & IET & 16.6 & 1.5030 & $1.89^{\circ} 6$ & 2.9711 & 14.115 & 90 \\
\hline 29.02 & Wires & 19.5 & 1.4411 & 1.9802 & 2.9 .320 & 14.163 & 90 \\
\hline 29.02 & IET & 19.54 & 1.4776 & 1.9037 & 2.9395 & 13.961 & 90 \\
\hline 30.00 & IET & $21 . .58$ & 1.4505 & 1.9316 & 2.9279 & 13.901 & 90 \\
\hline
\end{tabular}


TABLE 5.1 (Cont)

HOT CHANNEL FACTORS (ROD 2 INSERTED)

\begin{tabular}{|c|c|c|c|c|c|c|c|}
\hline 33.65 & DET & 21.2 & 1.3548 & 1.9465 & 2.7559 & 13.072 & 85 \\
\hline OUT & Wire & 21.5 & 1.3088 & 2.0962 & 2.8670 & 13.586 & 82 \\
\hline IN & Wire & 16.6 & 1.3110 & 1.9444 & 2.6638 & 12.764 & 37 \\
\hline 17.2 & Wires & 1.7 & 1.6266 & 1.8507 & 3.1458 & 14.995 & 113 \\
\hline Rod $2 @ 26$ & Wires & 16.67 & 1.3868 & 2.0546 & 2.9777 & 14.234 & 86 \\
\hline
\end{tabular}

$* \mathrm{~F}_{\mathrm{Q}}=\mathrm{F}_{\mathrm{Z}} \times \mathrm{F}_{\Delta \mathrm{H}}^{\mathrm{N}} \times 1.045$

+ Includes engineering इactor $=1.045$, peak referenced to $23.5 \mathrm{MWt}$ 


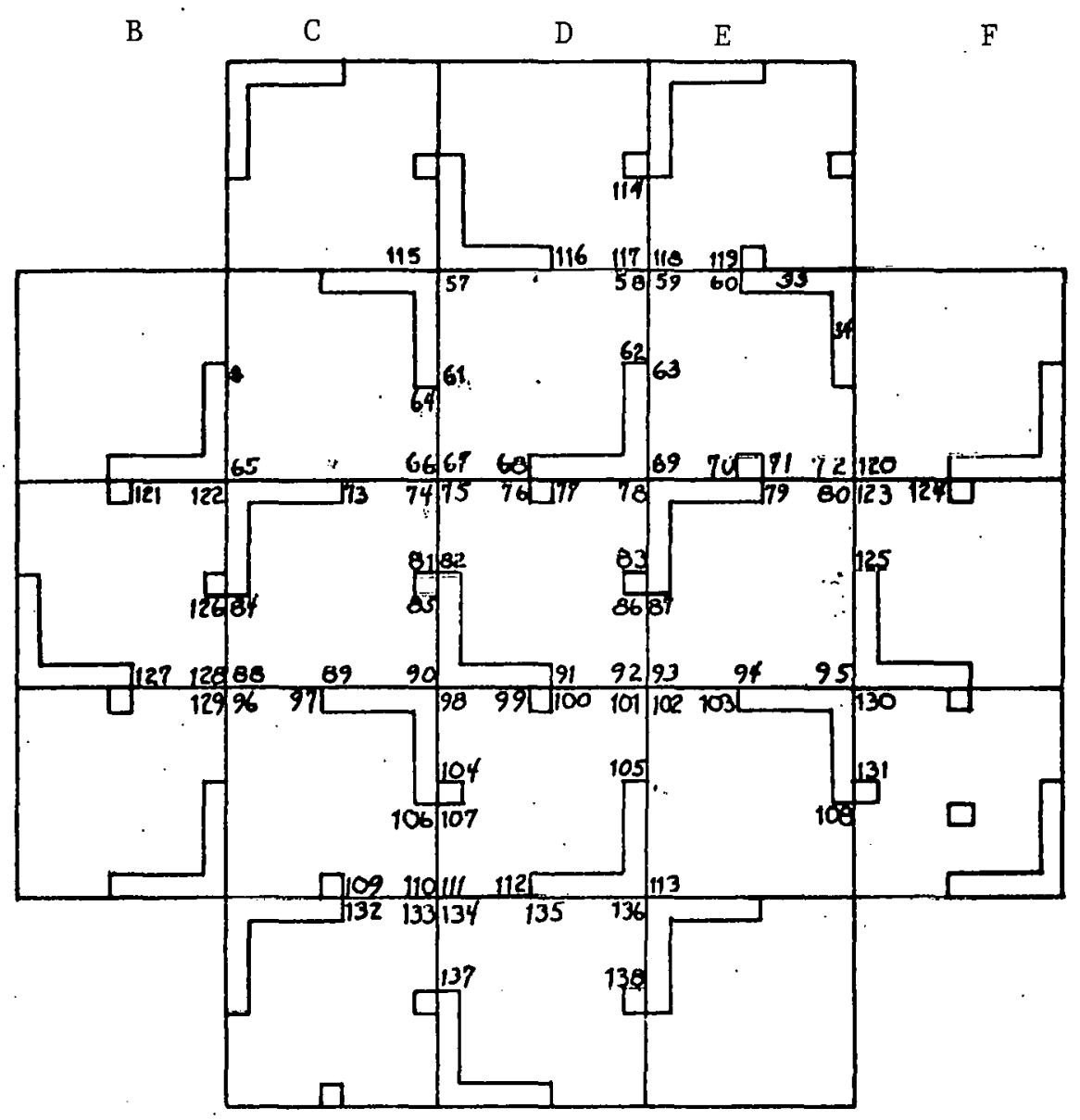

1

2

Individul Fuel Rod Source Nimhers for Saxton Gore 2 Inoorco

$$
\begin{array}{rl}
57-113 & \mathrm{Pu} \\
114-138 \mathrm{U}
\end{array}
$$

Other Sources:

$$
\begin{aligned}
& 1-21 \text { Assemblies } \\
& 22-26 \text { Subassemblies } \\
& 27-32 \text { Followers } \\
& 33-34 \text { L-Section in } \mathrm{Pu} \\
& 35-56 \text { Be low } \mathrm{T} / \mathrm{C}
\end{aligned}
$$

Figure 5.1. Saxton Core II Hot Channel Locations 


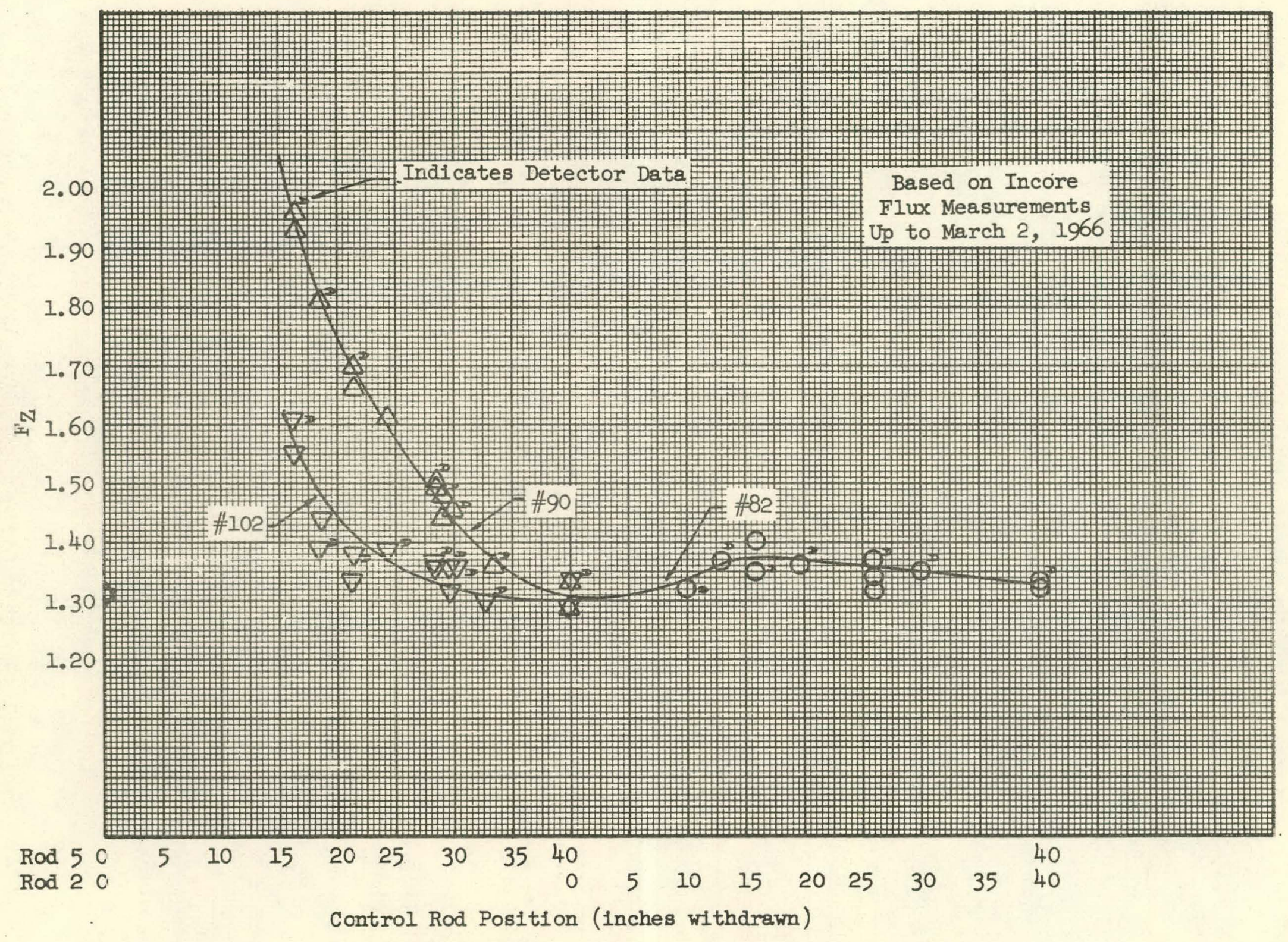

Figure 5.2. Saxton Axial Peaking Factor 
2.3

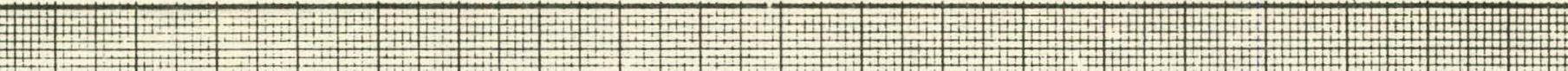
_ W W W W W W

.2 W

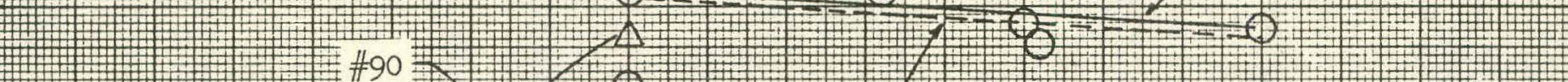

2.1

. 0 (1) W \# \# W W W W W

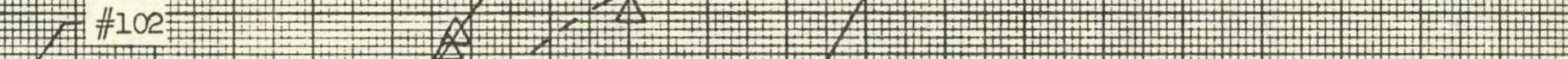

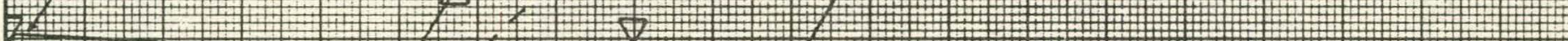

1.9

.8 W

1.7 W Expected W W W W W W W W W W W W W W W W W W W

.4 W W W

1.3 W $\begin{array}{lll} & \end{array}$

1.2

1.1

1.0 \# W W W 饻

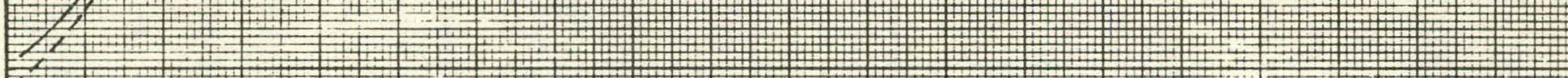

0.9

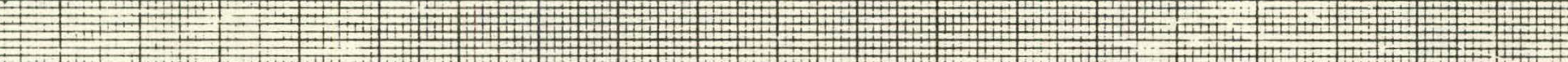

$\operatorname{mad} 5$ ?

(1)

$\operatorname{Rod} 20$

10
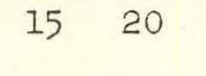

2530
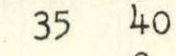

Control Rod Position (inches withdrawn)

40

Figure 5.3. Saxton Nuclear Enthalpy Rise Peaking Factor 


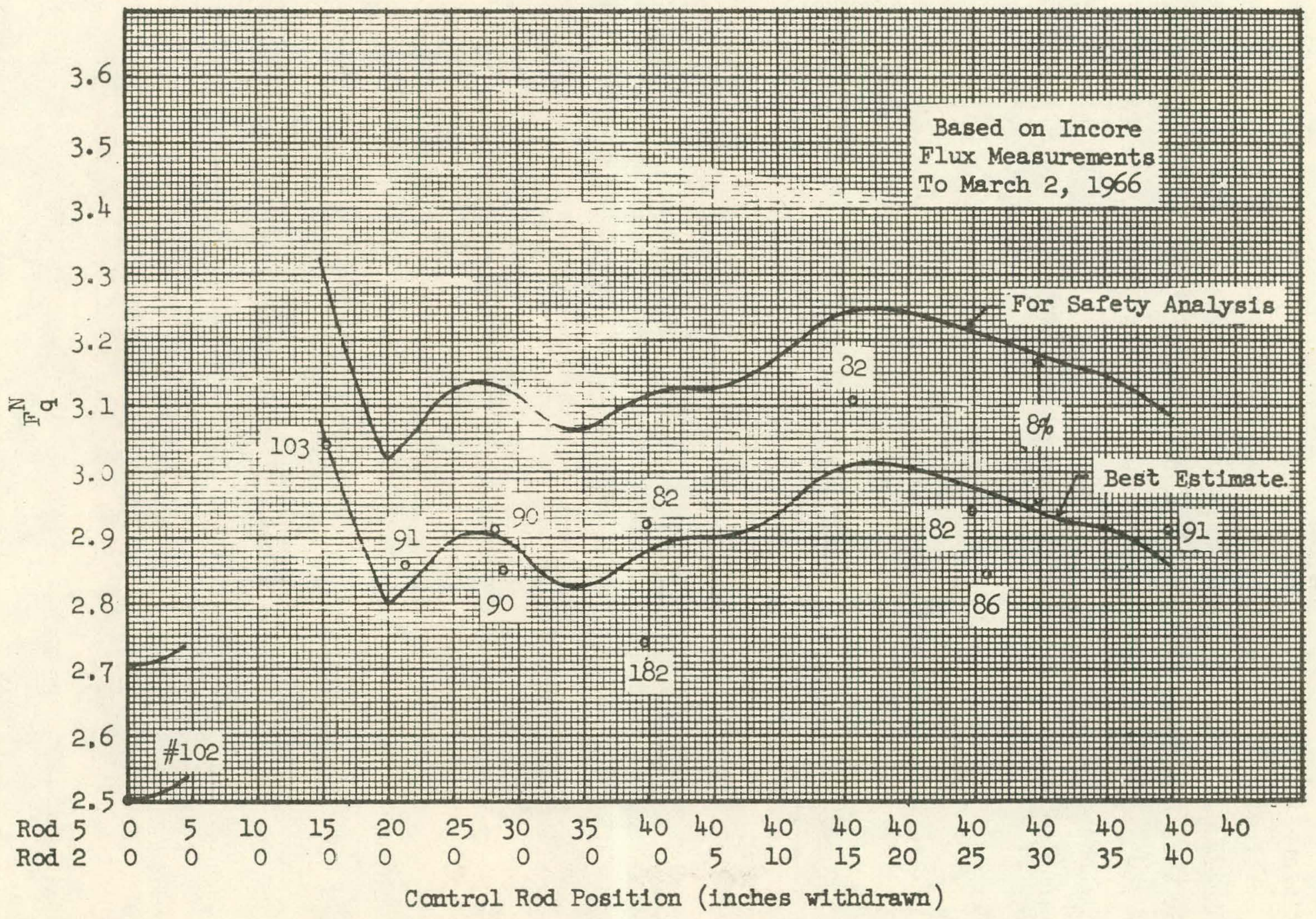

Figure 5.4. Saxton Nuclear Heat Flux Peaking Factor 
After approximately 5700 MWD/MTM ( 5000 hours), additional flux map data were obtained. These measurements showed that the radial peaking factors, $\mathrm{F}_{\Delta \mathrm{H}}^{\mathrm{N}}$, decreased about 6 percent from those at beginning of life. Figure 5.5 illustrates the change in axial hot channel factor, $F_{z}$, for several high power fuel rods as a function of control rod 2 position. Figure 5.6 shows the highest total hot channel factor, $\left(\mathrm{F}_{\mathrm{q}}^{\mathrm{N}}=\mathrm{F}_{\Delta \mathrm{H}}^{\mathrm{N}} \times \mathrm{F}_{\mathrm{z}}\right)$ for various control rod positions as determined from measurements at 1000 hours and 5000 hours. 


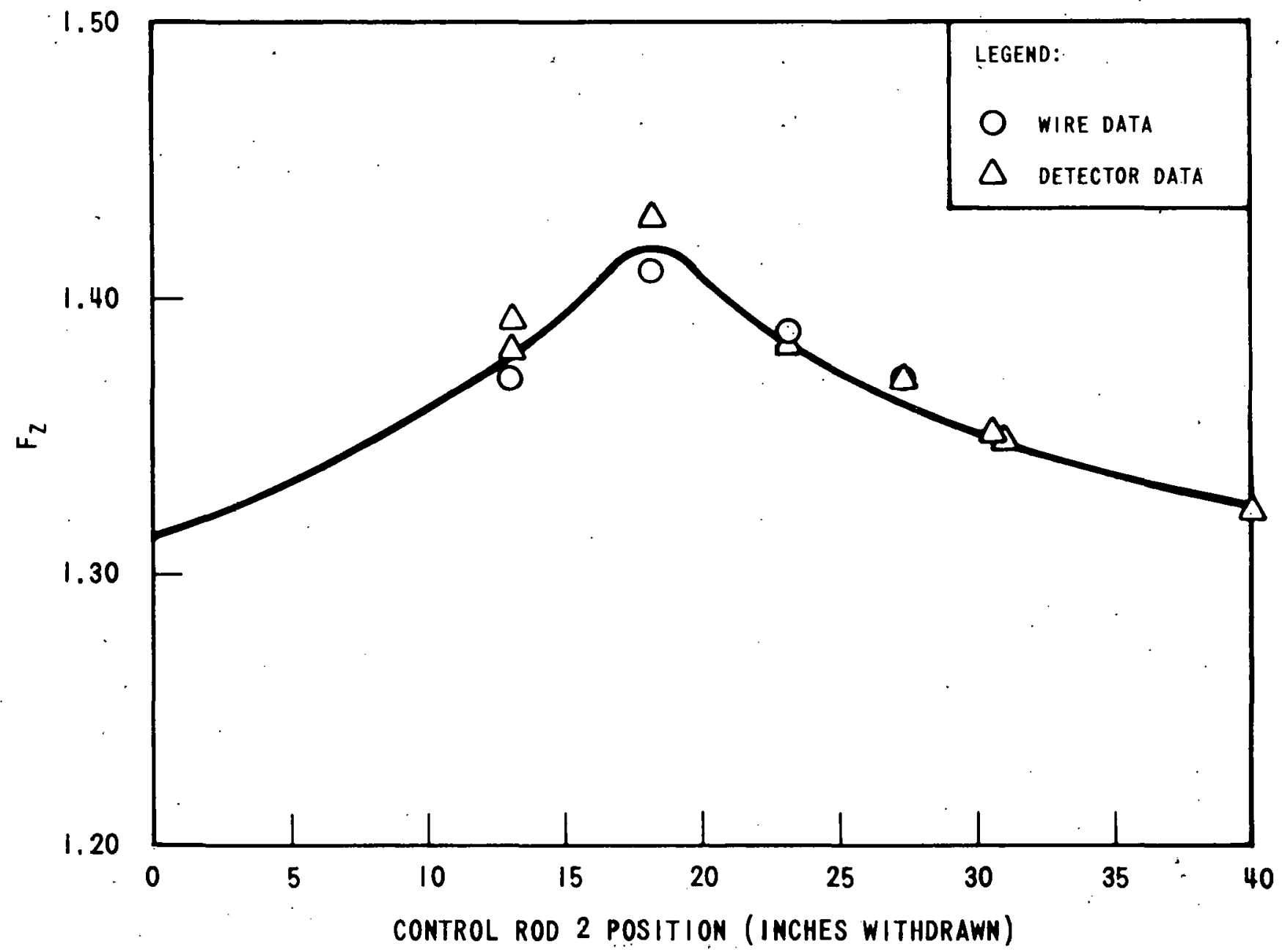

Figure 5.5. Saxton Axial Peaking Factors 


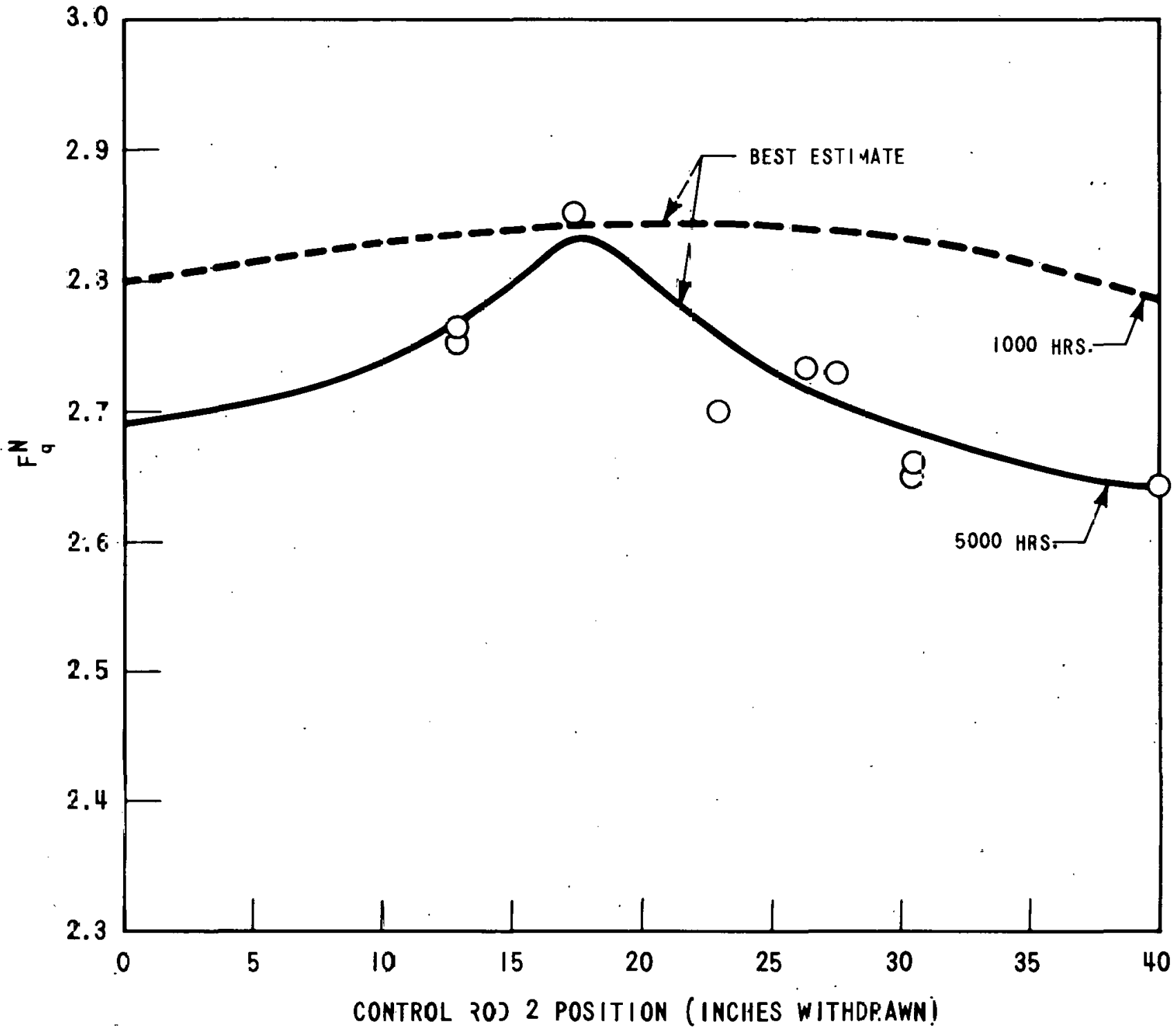

Figure 5:6. Saxton Nuclear Heat Flux Peakir.g Factor 